\title{
Inhibition of Hox Function by the Cell Cycle Regulator Geminin
}

\author{
PhD Thesis \\ in partial fulfillment of the requirements \\ for the degree "Doctor of Philosophy (PhD)" \\ in the Molecular Biology Program \\ at the Georg August University Göttingen, \\ Faculty of Biology
}

submitted by

\section{Lingfei Luo}

born in

Chongqing, P.R.China

Göttingen 2004 


\section{Affidavit}

Here I declare that my Ph.D. thesis entitled "Inhibition of Hox function by the cell cycle regulator Geminin" has been written independently and with no other sources and aids than quoted.

Lingfei Luo

August $4^{\text {th }}, 2004$

Göttingen 


\section{Publications:}

Lingfei Luo, Xiaoping Yang, Yoshihiro Takihara, Hendrik Knoetgen and Michael Kessel. The cell-cycle regulator geminin inhibits Hox function through direct and polycomb-mediated interactions. Nature, 427(6976): 749-753 (2004).

Lingfei Luo and Michael Kessel. Geminin coordinates cell cycle and developmental control. Cell Cycle, 3(6): 711-714 (2004).

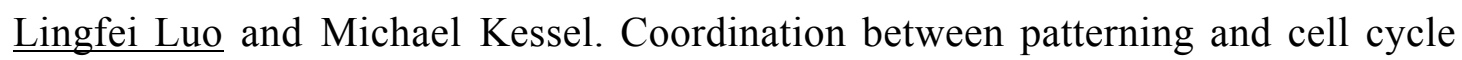
control by Geminin. MPIbpc News, 10(5): 1-4 (2004). 


\section{Acknowledgements}

This work was done from October 2001 to July 2004 in the Research Group Developmental Biology, Department of Molecular Cell Biology in the Max-PlanckInstitute for Biophysical Chemistry, under the direction of Prof. Dr. Michael Kessel.

Upon the accomplishment of my Ph.D. career, I would first like to sincerely acknowledge my supervisor, Prof. Dr. Michael Kessel, for his patient supervision as well as extensive support both in science and in everyday life. In the period of these three years, what I have learned from him are not only knowledges and techniques. More important, from his serious and strict scientific attitude, I have learned how to be a good scientist. I cannot be more grateful to him.

I would also like to cordially appreciate the members of my thesis committee, Prof. Dr. Herbert Jäckle and Prof. Dr. Tomas Pieler, as my co-supervisors. They have put great efforts into my Ph.D. project and provided me many valuable suggestions.

When I was a neophyte in the lab and knew almost nothing about developmental biology, it was Dr. Hendrik Knoetgen who first led me into this area. I would like to express my cordial appreciation to him.

Many thanks to the members in our department, especially Priv. Doz. Dr. Ahmed Mansouri, Dr. Lars Wittler, Dr. Ulrike Teichmann, Dr. Nicole Bäumer, Dr. Mara Pitulescu, Sven Pilarski (M.Sc.), and Yvonne Uerlings for suggestions and discussions. Thank Wiebke Behrens for her technical assistance and Sharif Mahsur for his help in cell culture.

I have benefited a lot from the Chinese community in the institute, Dr. Xiaoping Yang, Dr. Chaoshe Guo, Dr. Xunlei Zhou and other friends. I am very grateful to them.

I appreciate Prof. Dr. Peter Gruss and Prof. Dr. Dieter Gallwitz for their continuous support on my Ph.D. project. 
I also acknowledge the coordination office and all the faculty members of our International M.Sc./Ph.D. Program "Molecular Biology”, especially Dr. Steffen Burkhardt, for their kind help and hard work.

For providing experimental materials, I would like to acknowledge D. Duboule, Y. Takihara, A. Dutta, C. J. Tabin, S. Potter, R. Mass, and H. Koseki for their generosities.

Finally, and importantly, I sincerely say thanks to my parents and my wife for their persistent warm support. When I was almost punched down by experiments or referees, it is them who gave me most of the consolations and encouragements. Without their support, I would not have finished my Ph.D. career successfully. Thank you. 


\section{Introductions}

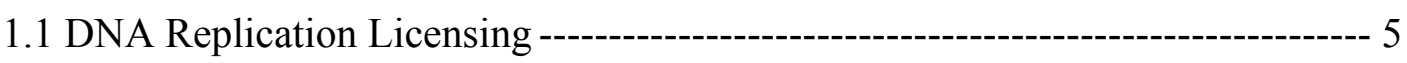

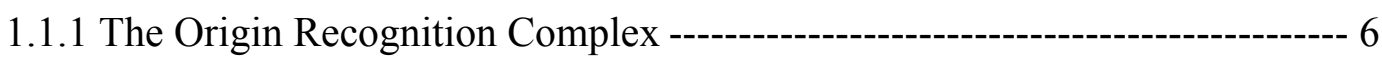

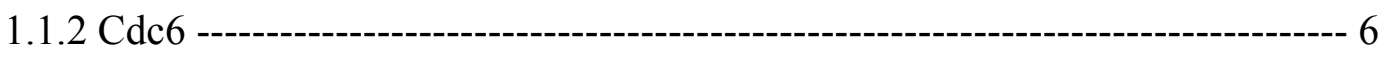

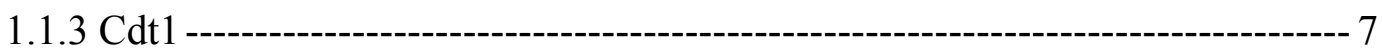

1.1.4 MCM Complex and the pre-RC Assembly -------------------------------------- 7

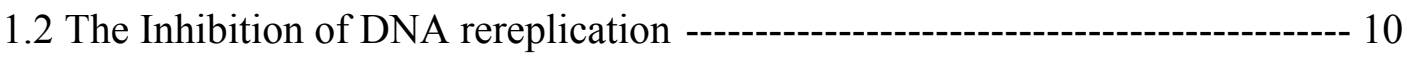

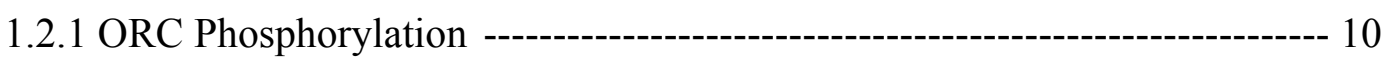

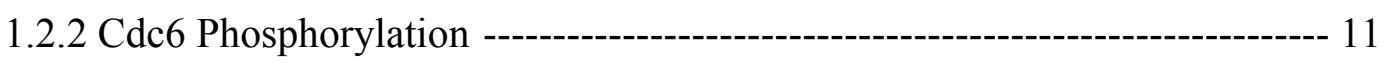

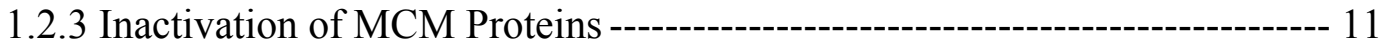

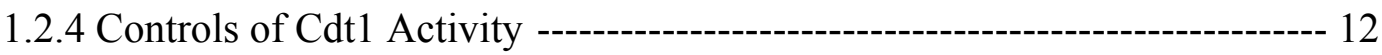

1.3 The Involvement of Geminin in Preventing Rereplication ---------------------- 14

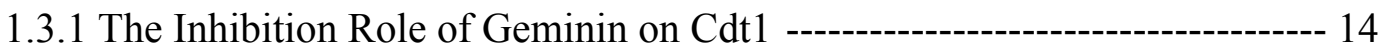

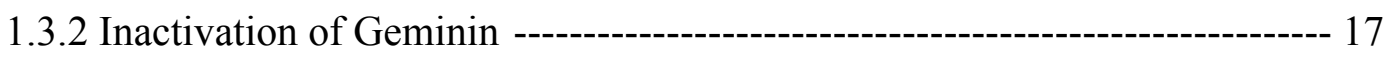

1.4 The Roles of Geminin in Embryonic Development ------------------------------ 21

1.5 Homeosis and Hox Genes ------------------------------------------------------------ 22

1.5.1 Homeodomain and Homeobox ----------------------------------------------- 23

1.5.2 Drosophila Homeotic Genes ---------------------------------------------------- 24

1.5.3 Vertebrate Hox Genes: Clustering and Colinearity ---------------------------- 27

1.5.4 Patterning the Anteroposterior Axis: The Hox Code -------------------- 31

1.5.5 Maintenance of Hox Gene Transcription or Inhibition ---------------------- 34

1.6 Aims of the Work ---------------------------------------------------------------------- 38

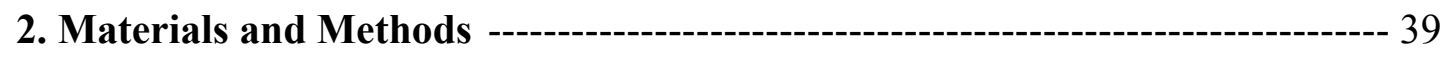

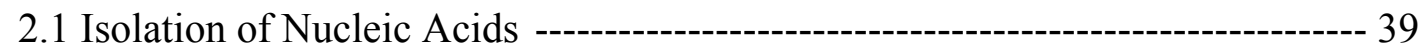

2.1.1 Plasmid DNA Isolation from $E$. coli

2.1.2 Genomic DNA Extraction from Mammalian Cells or Mouse Tissue ------- 39

2.1.3 DNA Electrophoresis and Purification from Agarose Gel ------------------- 40

2.1.4 Total RNA Isolation from Eukaryotic Cells or Embryos --------------------- 40

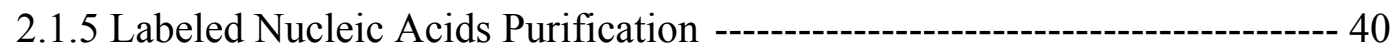

2.2 Modifications and Manipulations of Nucleic Acids ------------------------------- 41

2.2.1 DNA Digestion with Restriction Enzymes ------------------------------------- 41 
2.2.2 Dephosphorylating or Blunting the Ends of DNA Fragment ----------------- 41

2.2.3 Annealing of Complementary Single-Stranded DNAs ----------------------- 41

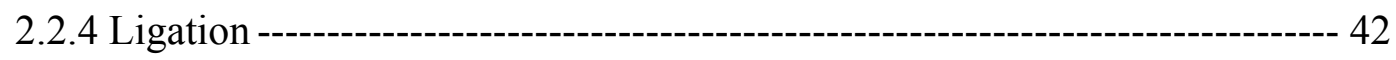

2.3 Polymerase Chain Reaction (PCR) ----------------------------------------------- 42

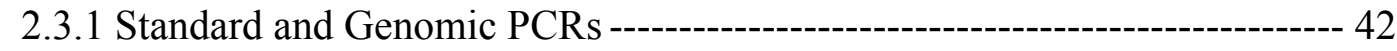

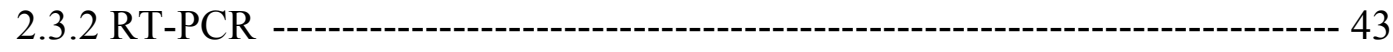

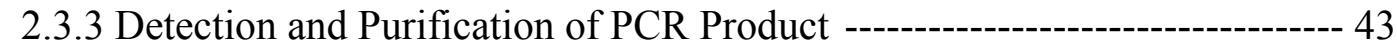

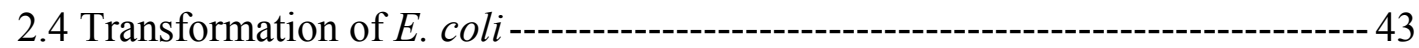

2.4.1 Preparation of Electrocompetent Cells ------------------------------------------ 43

2.4.2 Preparation of Competent Cells for Heat Shock Transformation ------------ 44

2.4.3 Transformation of $E$. coli by Electroporation ---------------------------------- 45

2.4.4 Transformation of E. coli by Heat Shock -------------------------------------- 45

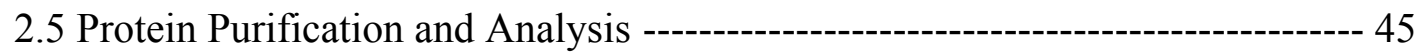

2.5.1 GST-Fused Recombinant Protein Expression and Purification --------------- 45

2.5.2 His-Tagged Recombinant Protein Expression and Purification--------------- 47

2.5.3 Total Protein Extraction from Mouse Embryos -------------------------------- 49

2.5.4 In Vitro Transcription/Translation ----------------------------------------------- 49

2.5.5 Protein Gel Electrophoresis -------------------------------------------------------- 49

2.5.6 Western Blotting--------------------------------------------------------- 51

2.5.7 N-Terminal Coupling of Protein ------------------------------------------------- 52

2.5.8 Antibody Purification from Crude Serum ---------------------------------- 53

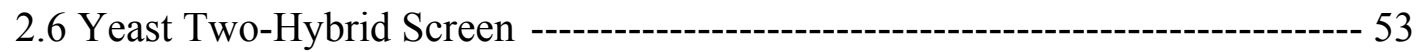

2.6.1 Constructs for the Two-Hybrid Screen -------------------------------------- 54

2.6.2 Cotransformation Efficiency Evaluation of MaV203 Competent Cells ---- 54

2.6.3 Determination of the 3AT Concentration ------------------------------------ 55

2.6.4 Total Protein Extraction from Yeast ---------------------------------------------- 55

2.6.5 cDNA Library Screen on Histidine Minus Medium------------------------- 56

2.6.6 cDNA Library Screen by X-gal assay -------------------------------------------- 57

2.6.7 DNA Extraction from Yeast Cells ------------------------------------------------ 58

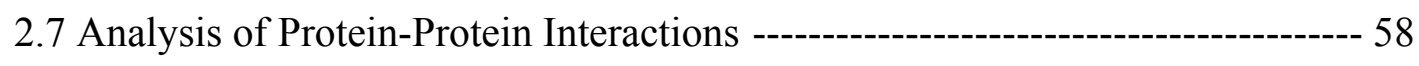

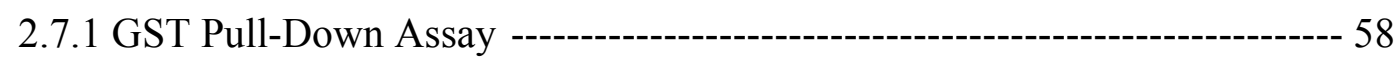

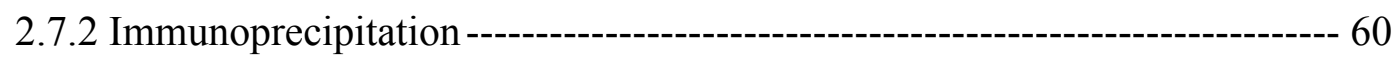

2.7.3 Peptide Array Analysis -------------------------------------------------------------- 60

2.8 Analysis of Protein-Nuclei Acids Associations ------------------------------------ 61 


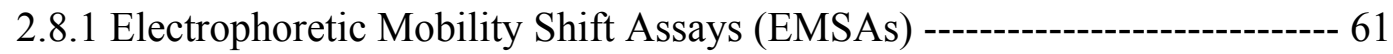

2.8.2 Chromatin Immunoprecipitation (ChIP) Assay ------------------------------ 62

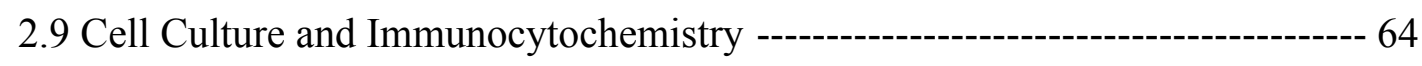

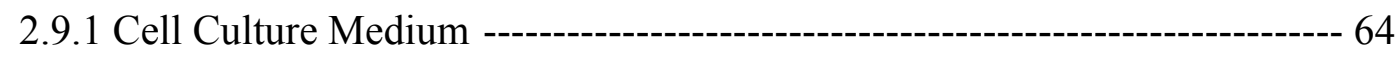

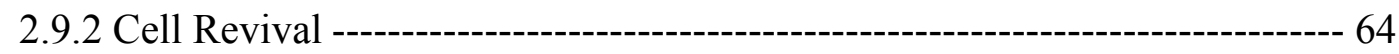

2.9.3 Cell Passage and Freeze ----------------------------------------------------------- 65

2.9.4 Immunocytochemistry ------------------------------------------------------------ 65

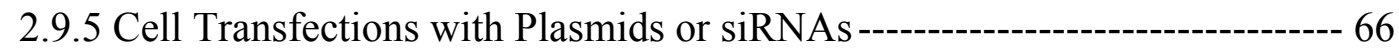

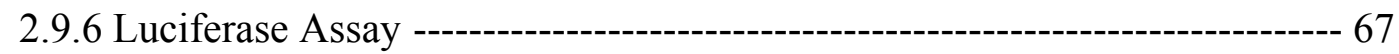

2.10 Competition Assays ------------------------------------------------------------------ 68

2.10.1 In Vitro Competition Assay ----------------------------------------------------- 68

2.10.2 In Vivo Competition Assay ---------------------------------------------------- 68

2.11 Manipulation and Analysis of Chick Embryos --------------------------------- 68

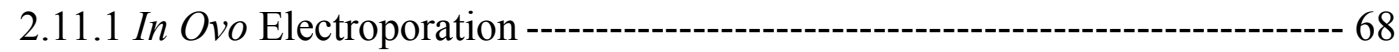

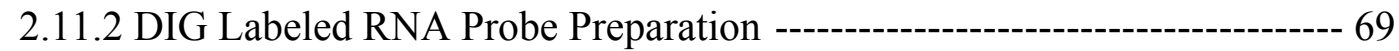

2.11.3 Whole-Mount In Situ Hybridization ------------------------------------------ 70

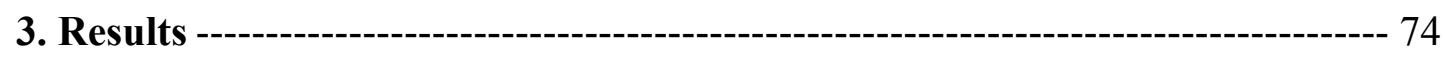

3.1 Geminin Directly Interacts with Hox Proteins and a Polycomb Group

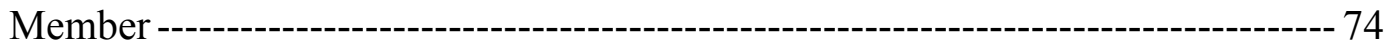

3.2 Geminin Associates with the Polycomb Complex ----------------------------- 76

3.3 Geminin Associates with Hox Regulatory DNA Elements In Vivo ------------- 77

3.4 Overexpression of Geminin Represses Hox Gene Transcription ---------------- 78

3.5 Loss of Geminin Function Derepresses Hox Gene Transcription --------------- 80

3.6 Geminin Directly Interacts with the Homeodomain of Hox Proteins ----------- 82

3.7 The Interaction with Geminin Inhibits the DNA Binding of Hox Proteins ---- 84

3.8 Geminin Inhibits Hox Dependent Transcriptional Activations of Reporter

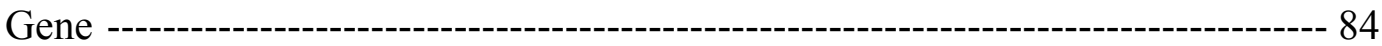

3.9 Geminin Inhibits Hox Dependent Transcriptional Activation of Endogenous

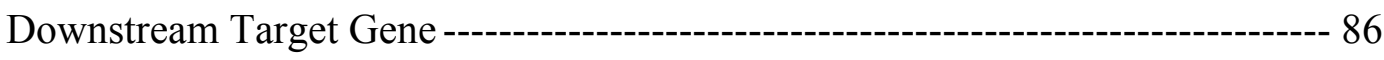

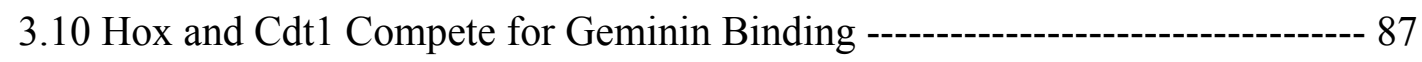

\section{Discussion}

4.1 The Roles of Hox and Polycomb Proteins in Cell Cycle Regulation and the 
Involvment of Geminin ------------------------------------------------------------------ 89

4.2 The Association between Geminin and the Polycomb Complex ---------------- 90

4.3 The Direct Interaction between Geminin and Hox Proteins ---------------------- 91

4.4 The Coordination of Cell Cycle and Developmental Control by Geminin ----- 92

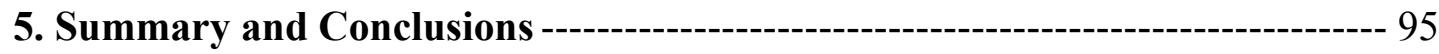

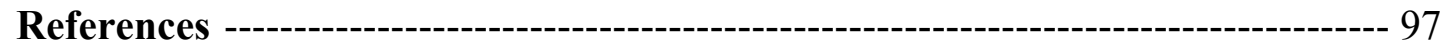

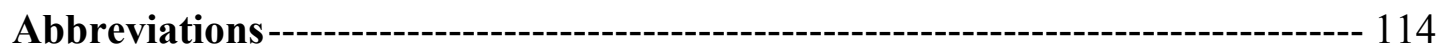

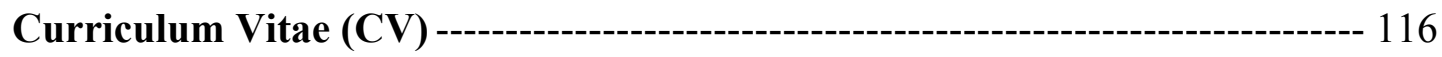




\section{Introduction}

From fertilization to maturity, a unicellular zygote undergoes numerous cell divisions to form a multicellular organism. During each cell cycle, a single set of genetic information must be accurately passed on to each daughter cell. At the same time, in order to form complex and different functional structures, cells are specialized by activating different combinations of genes during embryonic development. The timing of the cellular fate acquisitions and structure allocations has to be strictly coordinated with the schedule of embryonic growth, ensuring the correct size, location, as well as function of structures. Therefore, there is a strict coordination between embryonic patterning and the cell cycle. From this point of view, dual roles or mutual interactions of typical proliferation and developmental control genes are likely. The aim of my work is to understand the roles of a typical cell cycle regulator, Geminin, in embryonic development, and to provide further insights into the molecular links between the cell cycle regulation and embryonic patterning.

\subsection{DNA Replication Licensing}

For the maintenance of the genetic integrity of all organisms, cells must receive a complete copy of their genome every time they divide. This purpose is achieved during two phases of cell cycle: the S phase, during which the genomic DNA is replicated, and the $\mathrm{M}$ phase or mitosis, during which the replicated DNA equally segregates into the two newly divided daughter cells. Complete and accurate DNA replication is critical to guarantee the genomic stability from mother to daughter cells. Therefore, replication of the chromosomes is tightly controlled, so that DNA duplicates only once in each cell cycle. This goal is enabled by a process called licensing, which ensures that chromatin becomes competent for the next round of DNA replication only after passage through mitosis (Blow and Laskey, 1988). Licensing involves the ordered assembly of a number of replication initiation factors including the origin recognition complex (ORC), Cdc6, Cdt1, and minichromosome maintenance (MCM) complex, at replication origins, thus resulting in the assembly of pre-replicative complex (pre-RC). The regulation of licensing and the consequent pre$\mathrm{RC}$ formation is a key element of the mechanisms coordinating DNA replication with the cell cycle. 


\subsubsection{The Origin Recognition Complex}

DNA replication licensing is initiated from the binding of ORC to chromatin and achieved after the loading of MCM onto DNA (Fig. 1-1). ORC is a six-subunit complex that acts as the initiator selecting the sites for subsequent replication initiation at eukaryotic origins of replication (Bell and Dutta, 2002). Although identified in S. cerevisiae as binding to origins of replication in the chromatin in an ATP-dependent manner (Bell and Stillman, 1992), ORC have been demonstrated in subsequent studies as a conserved key factor for chromosomal replication in all eukaryotes. In Xenopus egg extracts, immunodepletion of several ORC subunits individually blocks MCM loading and pre-RC formation, indicating the essential role of the ORC in licensing and the initiation of DNA replication (Rowles et al., 1996; Carpenter et al., 1996; Romanowski et al., 1996). Similarly, recessive lethal mutations in multiple Drosophila ORC subunits each show dramatic reductions of BrdU incorporation in third instar larva (Pflumm and Botchan, 2001). The bestunderstood activity of ORC is its ability to bind DNA at replication origins (Chesnokov et al., 2001). Although this chromatin binding of ORC itself does not accomplish the licensing process, it is necessary for the recruitments of other initiation factors.

\subsubsection{Cdc6}

Cdc6, one of the members recruited by ORC, was first identified in the original screen of $S$. cerevisiae mutants with changes in the cell division cycle (Hartwell, 1973). It plays a crucial role in the assembly of the pre-RC, since immunodepletion of $X l \mathrm{Cdc} 6$ abolishes chromosomal replication, but not elongation, on single-stranded DNA templates. The direct association of Cdc6 with chromatin at the replication origins requires $\mathrm{ORC}$ and is in turn required for $\mathrm{MCM}$ chromatin association (Coleman et al., 1996; Tanaka et al., 1997), indicating that Cdc6 is involved in the licensing process at a step after ORC and before MCM complex loading. Binding of Cdc6 increases the DNA binding specificity of ORC by inhibiting its non-specific DNA binding (Mizushima et al., 2000). In addition, Cdc6 is an ATPase, and ATP binding and hydrolysis by Cdc6 is strictly required for MCM loading and DNA replication (Perkins and Diffley, 1998; Weinreich et al., 1999). 


\subsubsection{Cdt1}

Cdt1, another initiation factor recruited by ORC, was originally identified in $S$. pombe and implicated as a key factor in chromosomal duplication, since its mutation results in an abolition of DNA replication and defects in the S-phase checkpoint (Hofmann and Beach, 1994). Furthermore, SpCdt1 was demonstrated to associate with $S p C d c 6$ to cooperatively promote the loading of MCM onto chromatin (Nishitani et al., 2000). Like other licensing factors, Cdt1 is conserved in other eukaryotes including Xenopus, humen and Drosophila. In Xenopus egg extracts, the chromatin association of Cdt1 requires ORC but not Cdc6. And as in $S$. pombe, $X l \mathrm{Cdt} 1$ and $X l \mathrm{Cdc} 6$ are also found to be collaboratively required for MCM loading (Maiorano et al., 2000). In Drosophila, mutations of Cdt1 show a failure to undergo S phase during the postblastoderm divisions, and defects in DNA replication and amplification in the adult ovary. In common with a role in the pre-RC, $\mathrm{DmCdt} 1$ colocalized with $D m$ ORC at sites of DNA replication and requires $D m$ ORC for this localization (Whittaker et al., 2000). In mammalian cells, Cdt1 and Cdc6 are also mutually dependent on one another for the loading of MCM onto chromatin. The recruitment of MCM by Cdt1 is carried out through direct binding of the C-terminal region of Cdt1 to MCM subunits. Interestingly, the association of Cdt1 with MCM is regulated by cell growth. MCM prepared from quiescent cells associates very weakly with Cdt1, whereas MCM from serum-stimulated cells associates with Cdt1 much more efficiently, correlating with the normal accumulation of Cdc6 as cells progress from quiescence into the G1 phase. Corroboratively, Cdc6 is capable of inducing the binding of MCM to Cdt1, when ectopically expressed in quiescent cells. Further studies have demonstrated that the MCM-Cdt1 association is facilitated by Cdc6 through a direct physical interaction between Cdc6 and Cdt1, which is essential for Cdc6 function as well. Mechanistically, this sheds lights on how Cdt1 and Cdc6 cooperate to promote the MCM loading (Cook et al., 2004). In contrast to Cdc6, there is no enzymatic activity suggested for Cdt1. However, besides the interactions with ORC, Cdc6 and MCM, Cdt1 can also direct bind DNA in a sequence-, strand-, and conformation-independent manner. This DNA binding activity of Cdt1 may contribute to anchoring the MCM complex at the origins of replication (Yanagi et al., 2002).

\subsubsection{Complex and the pre-RC Assembly}


The genes that encode the MCM2-7 complex were originally identified in genetic screens for proteins involved in plasmid maintenance, cell cycle progression, and chromosome missegregation and were primarily group together based on their sequence similarity (Dutta and Bell, 1997). Each MCM protein is highly related to all others, but unique sequences distinguishing each of the subunit types are conserved across eukaryotes. And all eukaryotes appear to have strictly six MCM proteins that each fall into one of the existing classes (MCM2-7), which together suggest that each MCM member has a unique and critical function. This hypothesis was proved by the lethality that results from deleting any individual MCM gene in yeast (Kelly and Brown, 2000). Subsequently, the functional significance of MCM2-7 multiprotein complex in replication licensing system was confirmed in Xenopus egg extracts (Chong et al., 1995; Madine et al., 1995; Kubota et al., 1997). Both biochemical and genetic studies strongly demonstrate that these MCM proteins function together as a complex in the cell. As described above, the assembly of the MCM complex onto chromatin requires the coordinated functions of ORC, Cdc6 and Cdt1. Consistent with these requirements, reexpression of MCM proteins in S phase fails to rescue the replication arrest in MCM mutant (Labib et al., 2000). Once the MCM proteins are loaded on chromatin, ORC and Cdc6 can be removed from the chromatin without interfering subsequent DNA replication (Hua and Newport, 1998), indicating that the successful loading of MCM complex manifests the accomplishment of the licensing process and the pre-RC assembly.

One more point needs to be addressed on the path to replication licensing. There is ample evidence to support an important role of nucleotide binding in controlling the pre-RC assembly. Of the known members of the pre-RC, ten of fourteen proteins have consensus motifs for nucleotide binding (MCM2-7, Orc1, Orc4, Orc5, and Cdc6). Mutations in eight of these ten nucleotide binding motifs result in nonfunctional proteins, with only mutants in the Orc4 and Orc5 ATP binding sites still viable (Bell and Dutta, 2002). Recent studies have begun to elucidate the role of nucleotides in the pre-RC assembly. At least two ATP dependent steps are required on the way to the pre-RC formation. The first step is the association of ORC with the origin, which strictly requires ATP binding but not hydrolysis (Bell and Stillman, 1992; Klemm et al., 1997; Chesnokov et al., 2001). A second ATP dependent step is required for the recruitment of Cdc6 and MCM complex (Seki and Diffley, 2000). Especially during the recruitment of Cdc6, it is very well defined that the ATP binding configurations of 
both ORC and Cdc6 are simultaneously required for their mutual interaction (Klemm and Bell, 2001; Mizushima et al., 2000).

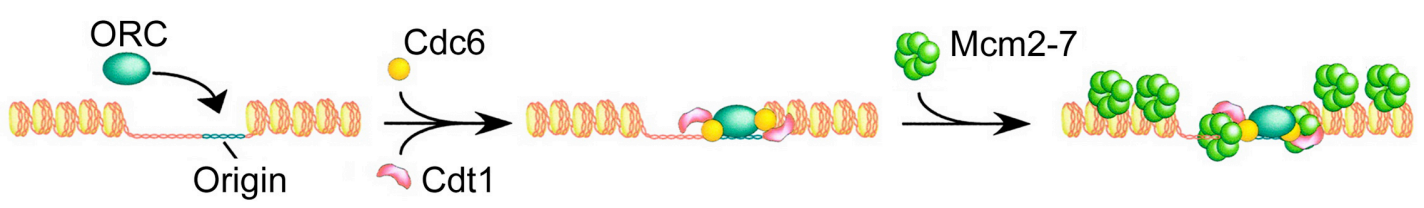

Figure 1-1: The process of DNA replication licensing. DNA replication licensing is initiated by the binding of ORC to chromatin, followed by Cdc6 and Cdt1 recruitment, and finally achieved after the loading of the MCM complex onto DNA (For further discussion, see body text 1.1) (Bell and Dutta, 2002).

In summary, the individual factors depicted above function together to direct the pre-RC formation, a key intermediate in the replication initiation process, and license subsequent DNA replication (Fig. 1-1). Association of ORC with the origin, which is required to recruit both Cdc6 and Cdt1, initiates the assembly of this structure. Cdc6 and Cdt1 associate with ORC-bound chromatin independent of one another (Nishitani et al., 2000; Maiorano et al., 2000). ORC, Cdc6, and Cdt1 together are required for the stable association of the MCM complex with the origin during G1 phase. Although the studies in several different organisms support the basic outline of these events, the molecular details of the recruitments of these different factors to the origin remain unclear.

The formation of pre-RC marks potential sites for the initiation of DNA replication, but multiple other proteins or protein complexes are further required to associate with the origins to initiate DNA synthesis. MCM complex is essential not only for the initiation but also for the elongation stages of DNA replication, since the MCM mutant alleles result in no replication if inactivated prior to $\mathrm{S}$ phase, and rapidly arrest the progression of the replication fork if inactivated during $\mathrm{S}$ phase (Labib et al., 2000). Mechanistically, roles of the MCM complex are believed to play through either recruitment of further protein factors, or help to unwind DNA helix with its weak, nonprocessive, and intrinsic DNA helicase activity (Ishimi, 1997; You et al., 1999), or interaction with histone and regulation of the local chromatin structures (Labib and Diffley, 2001). The transition from the pre-RC to the replication machinery will not be further discussed here. But, in general, the events occurring 
during this transition can be divided into two main stages: the first leading to unwound DNA at origins and the second leading to the loading of DNA polymerase at the primer-template junctions, which together bring about a successful DNA duplication during S phase.

\subsection{The Inhibition of DNA rereplication}

After DNA replication initiation, it is very critical to ensure that the origins do not refire in the same cell cycle in order to maintain the genetic stability of the organism. Thus, eukaryotic cells have developed a number of redundant mechanisms to prevent DNA replication reinitiation by inhibiting new pre-RC formation, in which cyclindependent kinases (CDKs) play pivotal roles.

CDKs have a bipartite role in the regulation of eukaryotic DNA replication. On the one hand, increased CDK activity activates origins of replication when cell enters into $\mathrm{S}$ phase. On the other hand, the same elevated CDK activity is also required to prevent reinitiation from origins during S, G2, and M phases of the same cell cycle. The important role of CDKs in preventing rereplication was originally identified by genetic studies in yeast, in which inactivation of CDK activity in G2/M cells resulted in full rereplication of the genome. That the rereplication inhibition activity of CDKs is mediated by the inhibition of pre-RC formation is supported by findings in yeast as well as Xenopus, indicating that the elevation of CDK activity in G1 phase prevents the pre-RC formation (Dahmann et al., 1995; Hua et al., 1997; Detweiler and Li, 1998). All the four components of the pre-RC depicted above (ORC, Cdc6, Cdt1, and MCM) have been defined to be phosphorylated by CDKs to prevent rereplication and the pre-RC assembly.

\subsubsection{ORC Phosphorylation}

Although ORC appears to associate constitutively with origins throughout the cell cycle in yeast and Drosophila (Ogawa et al., 1999; Pak et al., 1997), several subunits start to be phosphorylated in a CDK-dependent manner, when cells progress into $\mathrm{S}$ phase. This phosphorylation is required for preventing rereplication, since mutations of the phosphorylation sites on ORC lead to a rereplication of the genome (Nguyen et al., 2001; Vas et al., 2001). In contrast, XlORC is released from the chromatin and exported to the cytoplasm during $\mathrm{M}$ phase, which is a consequence of increased CDK activities (Romanowski et al., 1996; Rowles et al., 1999). In mammalian cells, 
$H_{s} \mathrm{Orcl}$ is dissociated from chromatin dependent on CDK activities and rapidly degraded after dissociation (Kreitz et al., 2001). Together, CDK dependent ORC phosphorylation serves as one of the multiple, redundant mechanisms to prevent rereplication during the cell cycle.

\subsubsection{Cdc6 Phosphorylation}

The phosphorylation of Cdc6 by CDK activity is well documented both in vitro and in vivo, and this phosphorylation turns out to control either degradation or nuclear export of Cdc6 protein at the G1/S transition. In yeast, Cdc6 is targeted for ubiquitinmediated proteolysis by the E3 ubiquitin ligase SCF (CDC4) from the end of G1 phase until mitosis, following a CDK-dependent phosphorylation. Mutations in several consensus CDK phosphorylation sites at the N-terminus of Cdc6 inhibit the degradation, suggesting that the elevated CDK activity promotes this proteolysis (Drury et al., 1997; Elsasser et al., 1999; Calzada et al., 2000). In contrast, Cdc6 activity is controlled by a different mechnism in mammalian cells, but in a CDKdependent manner as well. As cell enters S phase, phosphorylation of the HsCdc6 by CDK triggers the export of the protein from the nucleus. In subsequent mitosis, it is degraded by anaphase promoting complex (APC) mediated ubiquitination and proteolysis (Saha et al., 1998; Jiang et al., 1999; Petersen et al., 2000). However, although mutations of all consensus CDK phosphorylation sites on Cde6 result in either stabilization (yeast) or nuclear retention (mammals) of Cdc6, they are not sufficient to induce rereplication (Drury et al., 1997; Delmolino et al., 2001; Petersen et al., 1999).

\subsubsection{Inactivation of MCM Proteins}

To prevent rereplication, CDK dependent phosphorylation also controls the function of the MCM proteins. It can phosphorylate at least Mcm2 and Mcm4 both in vitro and in vivo (Fujita et al., 1998). Current scrutiny has proposed four possible mechanisms, not mutually exclusive, underlying the functional inhibition of MCM complex by CDK phosphorylation. One mode of regulation, especially in yeast, is likely to be through the regulation of the nuclear localization of the MCM proteins. ScMCM proteins are localized in the nucleus in G1 and S phase, but are exported from the nucleus in $\mathrm{G} 2$ and $\mathrm{M}$ phase. Inactivation of CDK activity results in the stable maintenance of MCM proteins in the nucleus (Labib et al., 1999; Nguyen et al., 
2000). Another possible mechanism is the direct inhibition of MCM complex activities. Phosphorylation of mouse Mcm4 at specific sites by CDK leads to a loss of Mcm4/6/7 helicase activity. In addition, Mcm4/6/7 purified from G1 and G1/S cells, but not from $\mathrm{M}$ phase cells, is active as a helicase (Ishimi et al., 2000; Ishimi and Komamura-Kohno, 2001). A third proposed mechanism is that CDK phosphorylation induces release from chromatin and prevents MCM reassociation. In Xenopus, Mcm4 is one of the substrates for mitotic CDKs. Mcm4 is underphosphorylated in interphase, and its hyperphosphorylation is correlated with the release of MCM complex from chromatin. Furthermore, hyperphosphorylated MCM complex cannot be assembled onto chromatin any more (Hendrickson et al., 1996; Findeisen et al., 1999; Pereverzeva et al., 2000). Recently, a novel metazoan-specific regulatory system, which serves as the fourth MCM inhibition mechnism during S phase of the cell cycle, was identified in Xenopus. In this system, MCM is removed from chromatin and sequestered by direct association with exportin-1/Crm1. This MCMCrm1 complex formation is required for preventing rereplication, dependent on both Cdk2 activity and high Ran-GTP level. Lowering Ran-GTP within nuclei or nuclear extracts breaks the MCM-Crm1 complex, allows MCM to reassociate with chromatin during S or G2 phase and induces rereplication. Cdk2 kinase activity is a prerequisite and absolutely required for the Ran-GTP dependent MCM-Crm1 complex formation, since the association of MCM to chromatin is no longer inhibited by the addition of Cdk2 specific inhibitor p27/Kip, even in the presence of Ran-GTP. Importantly and intriguingly here, beyond the classic exportin function of $\mathrm{Crm} 1$, prevention of rereplication requires $\mathrm{MCM}-\mathrm{Crm} 1$ association, but does not require export of $\mathrm{MCM}$ from the nucleus (Yamaguchi and Newport, 2003).

\subsubsection{Controls of Cdt1 Activity}

Controls of Cdt1 activity after the pre-RC assembly are also crucial for preventing rereplication. Human Cdt1 accumulates only during G1 phase. The level of the protein decreases after $\mathrm{S}$ phase onset, and becomes undetectable in later $\mathrm{S}$ phase and G2 (Nishitani et al., 2001). At the G1/S transition, along with the expression of Cyclin A, human Cdt1 is phosphorylated by cyclin A-dependent kinases dependent on its cyclin-binding motif. This CDK phosphorylation results in a physical interaction between Cdt1 and SCF (Skp2) ubiquitin ligase, followed by an SCF (Skp2) mediated ubiquitination and proteolysis of Cdt1. Inhibition of CDK activity by overexpressed 
p21 or p27 and the consequent Cdt1 dephosphorylation lead to a disruption of the Cdt1-Skp2 interaction, thus the Cdt1 stabilization and chromatin reassociation. A downregulation of Skp2 by siRNA also brings about a similar Cdt1 accumulation effect in S phase (Li et al., 2003; Sugimoto et al., 2004; Liu et al., 2004). In addition, the DNA binding activity of Cdt1 is also inhibited by CDK phosphorylation, which may contribute to the Cdt1 functional inactivation (Sugimoto et al., 2004). In $C$. elegans, Cdt-1 is present in G1 phase nuclei, but degraded through Cul-4 ubiquitin ligase mediated ubiquitination and proteolysis as cells enter $\mathrm{S}$ phase to prevent aberrant DNA replication reinitiation. Inactivation of Cul-4 causes massive DNA rereplication, and Cdt-1 levels fail to decrease during $\mathrm{S}$ phase and instead remain constant in the rereplicating cells. Removal of one genomic copy of $C d t 1$ suppresses the Cul-4 mutant rereplication phenotype (Zhong et al., 2003). All these studies have suggested that functional inactivation of Cdt1 appears to be one of the redundant mechanisms to prevent rereplication. Interestingly, in metazoans such as fly, fish, frog, mouse and human, but not in yeast, one more significant protein has been discovered to sequestrate $\mathrm{Cdt} 1$ and ensure a complete inhibition of rereplication Geminin.

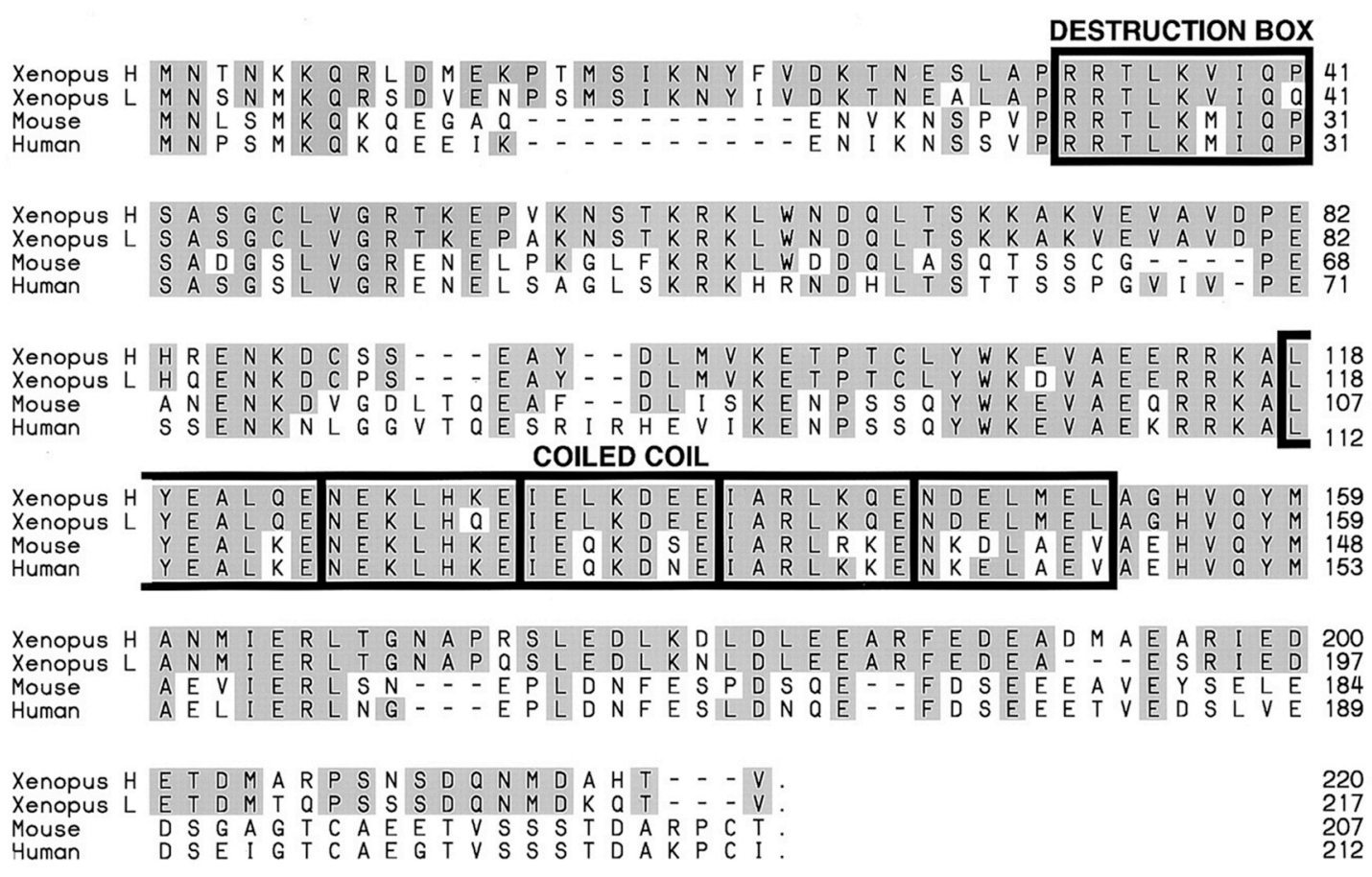

Figure 1-2: The amino acid sequence and conserved structural motifs of Geminin protein. Note that the N-terminal portion contains a consensus destruction box sequence and the central portion contains a conserved coiled-coil domain (McGarry and Kirschner, 1998). 


\subsection{The Involvement of Geminin in Preventing Rereplication}

Geminin was first discovered in a screen for proteins that are degraded by mitotic Xenopus egg extracts but not by interphase egg extracts. Except for B-type cyclins, the cDNA encoding Geminin was most abundant in the screen. Several structural motifs have been identified by inspection of the amino acid sequence of Geminin (Fig. 1-2). The N-terminal portion contains a short sequence that has homology to the consensus destruction box of mitotic cyclins and appears to be an ubiquitination signal. The central portion of Geminin contains five heptad amino acid repeats predicted to form a coiled-coil domain that is commonly used in protein dimerization (amino acids 118-152 of $X l$ Geminin). There are clusters of basic amino acids between the destruction box and the coiled-coil domain. They may serve as a nuclear localization signal of the Geminin protein.

\subsubsection{The Inhibition Role of Geminin on Cdt1}

As discussed above, during G1 phase, Cdc6 and Cdt1 are recruited by ORC to the replication origins and in turn required for the loading of MCM complex onto DNA to form the pre-RC. The formation of pre-RC is essential for the assembly of replication machinery and subsequent DNA replication initiation at $\mathrm{S}$ phase onset. Geminin starts to accumulate in the nucleus at this point of the cell cycle after DNA replication is initiated, and maintains its nuclear presence until the end of mitosis. Geminin physically interacts with Cdt1, and sequesters Cdt1 from its role in the pre-RC assembly, thus preventing DNA rereplication. In the cell-free Xenopus egg extracts system, the supply of recombinant Geminin protein disrupts the pre-RC assembly by inhibiting the loading of MCM proteins, without affecting the chromotin association of ORC and Cdc6. Consequently, this unloading of MCM proteins leads to an inhibition of nuclear DNA replication. All these inhibitory effects resulted from recombinant Geminin can be efficiently rescued by the addition of excess Cdt1 (McGarry and Kirschner, 1998; Wohlschlegel et al., 2000). Immunodepletion of endogenous Geminin from metaphase Xenopus egg extracts allows MCM complex to associate with replication origins and promotes DNA replication. This gain of licensing activity in the absence of Geminin is not due to the loss of CDK activity. Conversely, the inhibition of CDKs in metaphase extracts stimulates origin assembly only after the depletion of Geminin, further suggesting that Geminin is the major inhibitor of rereplication in metaphase (Tada et al., 2001). 
The inhibition of rereplication by Geminin through Cdt1 sequestration is conserved in metazoans. The Drosophila Geminin homolog also inhibits DNA replication in vitro by preventing binding of MCMs to chromatin (Quinn et al., 2001). The in vivo overexpression of Geminin in Drosophila embryos results in a general decrease of BrdU-labeling cells in mitotic and endoreplicating tissues, that is, an inhibition of DNA replication. The DNA replication inhibition phenotype is accompanied by a dramatic decrease of $\mathrm{S}$ phase cells, increased numbers of metaphase cells and apoptosis. In addition, Geminin overexpression during the early proliferative phase of the eye-antennal imaginal disc also results in an extraordinary decrease of $\mathrm{S}$ phase cells, thus the size of third instar larvae eye discs and adult eye. In agreement with the overexpression phenotypes and the inhibitory role of Geminin in DNA replication, Drosophila Geminin mutants exhibit overreplication defects late in embryogenesis and in oogenesis. For an instance, in most stage-12 wild type ovaries, DNA amplification is only observed in the anterior region in one focus per cell, whereas $100 \%$ of Geminin mutant stage-12 ovaries show strong BrdU labeling of four amplification loci in all follicle cells. By stage-14, all follicle cells of wild type ovaries have ceased DNA amplification, whereas many follicle cells from Geminin mutant ovaries still continue amplification. Mechanistically, Geminin not only physically associates with Cdt1 like in other species, which is clarified by an immunoprecipitation from Drosophila embryos, but also interacts genetically with Cdt1. A similar phenotype of Geminin overexpression is observed in Cdt1 mutants, suggesting their opposite roles in regulating DNA replication. Halving the dosage of Cdt1 enhances the Geminin overexpression eye phenotype, leading to a smaller and rougher eye. Vice versa, the Cdt1 mutant phenotypes can be suppressed by a Geminin mutant (Quinn et al., 2001). Therefore, it seems that the regulatory role of Geminin in DNA replication and the mechanism are conserved among metazoans.

Direct elimination of Geminin by antisense techniques in developing Xenopus embryos provide further insight into the roles and mechanisms of Geminin in preventing rereplication. The Geminin eliminated embryos have a unique early embryonic lethal phenotype. These embryos arrest in G2 phase immediately after the midblastula transition, the point in development when the cell cycle slows and zygotic gene expression begins. The cells in the deficient embryos show overreplicated DNA content, which confirms the role of Geminin in preventing rereplication. The mechanisms of Geminin loss of function to arrest the embryos in G2 phase partly 
assign to a hyperphosphorylation of Chk1 protein kinase, an effector to implement checkpoint response. The activated Chk1 by increased phosphorylation prevents entry into mitosis in part by inhibiting $\mathrm{Cdc} 25 \mathrm{C}$, the phosphatase that removes the phosphates from T14 and Y15 of the mitotic cyclin-dependent kinase Cdc2 and consequently activates $\mathrm{Cdc} 2$ at the onset of mitosis. Cdc2 is always hyperphosphorylated on Y15 and maintained as an inactive form in the absence of Geminin. Bypassing of Chk1 pathway by injecting either Cdc25C mutant or Chk1 mutant individually rescues G2 arrest phenotype (McGarry, 2002). Similarly, in support to the rereplication inhibition role of Geminin, silencing of Geminin by siRNA in Drosophila Schneider D2 cells leads to a cessation of mitosis and asynchronous overrreplication of the genome, with cells containing single giant nuclei and partial ploidy between $4 \mathrm{~N}$ and $8 \mathrm{~N}$ DNA content (Mihaylov et al., 2002). This phenotype of Geminin deficiency is completely rescued by cosilencing of Cdt1, in agreement with the mechanism discussed above that Geminin prevents rereplication by direct sequestering Cdt1. In addition, the phenotype induced by Geminin knock down is also partially rescued by coablation of Chk1, again indicating the involvement of Chk1 in the checkpoint control in response to DNA overreplication (Mihaylov et al., 2002). Together, loss of function phenotypes in both Xenopus embryos and Drosophila cells reinforce our understandings that Geminin plays a pivotal role in DNA rereplication inhibition through Cdt1 binding and sequestration.

The Cdt1 interaction domain is mapped into the coiled-coil domain of Geminin. A fragment of $X l \mathrm{Geminin}$ consisting only of amino acids $87-168$, which includes the coiled-coil domain, is sufficient to inhibit DNA replication (McGarry and Kirschner, 1998). By contrast, the N-terminal domain, which does not interact with Cdt1 but accounts for the neuralizing activity of Geminin (see below), has no effect on DNA replication or cell cycle progression. In mammals, the Geminin binding region of Cdt1 has also been characterized. The Cdt1 central region (amino acids 177-380) is demonstrated to be the Geminin binding domain, whereas Mcm6 interacts with the Cdt1 C-terminal region (amino acids 407-477). Interestingly, the C-terminal region of Cdt1 is conserved among all eukaryotes including yeast, whereas the central Geminin binding region is only conserved in metazoans, which exactly correlates with that Geminin is a metazoan specific protein.

Recent studies provide further insight into the molecular basis of the GemininCdt1 regulatory mechanisms in mammalian cells. The DNA binding domain of Cdt1 
partly overlaps with its Geminin association domain. Therefore, the tight GemininCdt1 interaction masks the DNA binding region of Cdt1 and inhibits the association of Cdt1 to replication origins in the chromatin. Furthermore, the Geminin-Cdt1 interaction blocks the binding of Cdt1 to $\mathrm{Mcm} 2 / 6$ as well as Cdc6, thus inhibiting the association of Cdt1 into pre-RC and the subsequent MCM complex recruitment. Although the Geminin and MCM interaction domains of Cdt1 are independent and the mechanisms underlying the inhibition of Cdt1-MCM association by Geminin still remain unclear, it is plausible to speculate that the binding of Geminin to the Cdt1 central region leads to a conformational change in the overall structure of Cdt1, which concomitantly results in its C-terminal MCM binding domain to be masked. Together, by means of interacting with and sequestering Cdt1, Geminin blocks the bindings of Cdt1 to DNA, Cdc6 and MCM proteins, thus inhibiting the assembly of pre-RC and preventing DNA rereplication (Yanagi et al., 2002; Cook et al., 2004). In addition, the CDK dependent phosphorylation of Cdt1 during S phase does not interfere with its binding to Geminin, suggesting that the phosphorylation and Geminin binding of Cdt1 are independent but function synergically to ensure a thorough inactivation of Cdt1, thus a complete DNA rereplication inhibition (Sugimoto et al., 2004).

\subsubsection{Inactivation of Geminin}

After being expressed at early S-phase, the nuclear presence of Geminin is maintained in the following S, G2, and M phases of cell cycle until the anaphasetelophase transition, during which the nuclear Geminin protein needs to be inactivated to release Cdt1, hence making the Cdt1 protein available for the pre-RC assembly and licensing the DNA replication in the next round of cell cycle. At the end of mitosis, the nuclear Geminin protein is inactivated in a number of pathways in different organisms. In agreement with the N-terminal consensus destruction box sequence, the mitotic degradation of Geminin was first identified in Xenopus egg extracts and it was suggested to be through the APC mediated ubiquitination and proteolysis (McGarry and Kirschner, 1998). The in vitro transcribed/translated Geminin protein is stable in interphase egg extracts, whereas it is ubiquitinated and disappeared with a half-life of 15 minutes in mitotic egg extracts. This Geminin degradation is dependent on APC activity, since the co-incubation of cyclinB destruction box peptide (D-box peptide) as a dominant-negative APC inhibitor restrains the formation of Geminin-ubiquitin conjugates and stabilizes Geminin in mitotic extracts. If the destruction box is deleted 
from the protein sequence, the resulted mutant Geminin ${ }^{\mathrm{DEL}}$ recombinant protein is then stable in mitotic extracts but retains the wild type DNA replication inhibition activity. This correlates with the characterization of the coiled-coil domain as the DNA replication inhibition domain of Geminin. An injection of the mutant Geminin ${ }^{\mathrm{DEL}}$ protein into one cell of a two-cell Xenopus embryo does not affect the process of cytokinesis and cell cleavage. However, the injected embryos fail to replicate their chromosomal DNA properly, thus the cells produced by cleavage are completely anucleated. Consequently, these embryos do not develop normally with a cessation at the blastula stage and never proceed into gastrulation. In contrast, embryos injected with the same concentration of wild type Geminin have small, misshapen nuclei instead of anucleated cells, indicating much weaker or even no DNA replication inhibition (McGarry and Kirschner, 1998). The APC mediated ubiquitination and degradation also turns out to be a substantial mechanism to inactivate Geminin in mammalian cells. In synchronized Hela cells, the dynamics of endogenous Geminin indicates that Geminin starts to disappear at the end of mitosis and accumulates again during the next early $\mathrm{S}$ phase. Although a transient overexpression of wild type Geminin in U2OS cells, an osteosarcoma cell line, does not result in a cell cycle progression defect, an overexpression of the nondegradable mutant Geminin $^{\mathrm{DEL}}$ arrests cell proliferation (Wohlschlegel et al., 2002; Shreeram et al., 2002). A recent study characterizes the roles of the Geminin destruction box in regulating cell cycle in details by knocking out the N-terminal 27 amino acids of Geminin, including most of the destruction box, through homologous recombination in HCT116 human cancer cell line (Yoshida et al., 2004). The excision of the destruction box stabilizes the endogenous Geminin protein in all phases of cell cycle without elevating the total amount of Geminin, simultaneously eliminating the pleiotropic effects due to the overexpression of an exogenous protein. The G1 stabilization of Geminin diminishes chromatin loading of MCM complex, thus inhibiting the assembly of pre-RC and subsequent DNA replication. The DNA replication inhibition phenotype of mutated cells is accompanied by an activation of DNA damage checkpoint pathway with increased levels of p53 and p21 proteins, but without triggering apoptosis that normally happens in cases of Geminin overexpressions (Quinn et al., 2001; Shreeram et al., 2002). In addition, since the mutated Geminin inhibits cell proliferation, the in vivo tumorigenesis capacity of the HCT116 cell line is suppressed in mutant cells. All these deficits resulted from the 
deletion of Geminin destruction box can be efficiently rescued by overexpression of Cdt1, which further supports the inhibition role of Geminin on Cdt1 (Yoshida et al., 2004). The Drosophila Geminin also contains the destruction box and is degraded at the end of mitosis, although there is no direct evidence showing that this DmGeminin degradation is APC dependent (Quinn et al., 2001; Mihaylov et al., 2002). Therefore, the degradation of Geminin during the anaphase is significant for DNA replication licensing and normal cell cycle progression. Alteration of the cell cycle dependent regulation of Geminin inhibits DNA replication and suppresses tumor growth. However, besides the APC mediated degradation, redundant mechanisms to inactivate Geminin were also discovered.

In Xenopus egg extracts, although some Geminin degradation is clearly observed upon exit from mitosis, 30-60\% of endogenous Geminin resists degradation and maintains its existence after released into interphase. The presence of Geminin protein in the interphase extracts does not prohibit the loading of MCM complex onto chromatin (Hodgson et al., 2002). For the licensing system to be activated, the remaining Geminin has to be inactivated. One of mechanisms involves the CDK dependent transient polyubiquitination without proteolysis, in which the destruction box sequence also serves as the ubiquitination signal. This transiently ubiquitinated Geminin loses its affinity to Cdt1, and cannot form a complex during the interphase. Thus, MCM complex can be successfully loaded onto chromatin to license the DNA replication in S phase. The inhibitors blocking APC mediated ubiquitination such as the D-box peptide result in a recomplex of Geminin and Cdt1, preventing activation of the licensing system. In contrast, inhibitors of the 26S proteasome, in which the APC ubiquitinated proteins are digested, do not interfere with the inactivation of Geminin. The mitotic CDK inhibitors lead to a derepression of Geminin and a consequent loss of licensing activity, suggesting the inactivation of Geminin is CDK dependent. Nevertheless, Geminin is only transiently ubquitinated on exit from mitosis, with deubiquitination leaving Geminin still locked into an inactive form. One possible way is through a second covalent modification that is dependent on earlier ubiquitination of Geminin. Alternatively, ubiquitination may force Geminin into an inactive conformation. Together, although some of the ubiquitinated Geminin is degraded, this is not essential for activation of the licensing system. In order to ensure the activation of the licensing system, the CDK dependent transient ubiquitination is 
essentially required to inactivate the remaining Geminin protein during interphase ( $\mathrm{Li}$ and Blow, 2004).

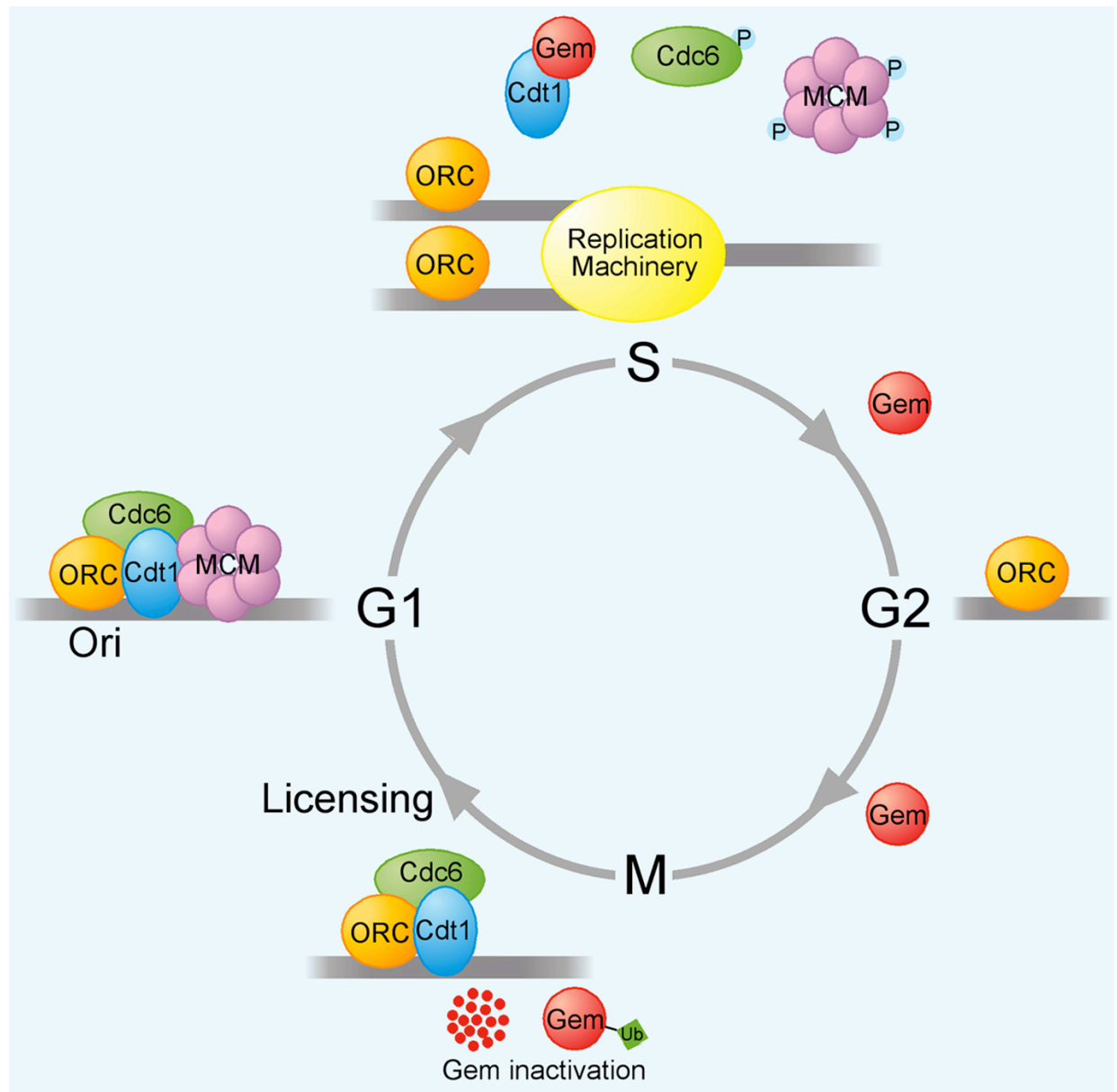

Figure 1-3: The regulatory role of Geminin in DNA replication. Geminin starts to accumulate in nucleus immediately after DNA replication initiation at early S phase, and inhibits DNA rereplication by direct interaction with and sequestration of Cdt1. The presence of active Geminin in the nucleus is maintained throughout S and G2 phases until the end of mitosis, during which Geminin is inactivated through degradation or ubiquitination to license the next round of DNA replication. P: phosphorylation. Ub: ubiquitination (Lygerou and Nurse, 2000; Luo and Kessel, 2004a).

Further inactivation mechanism attributes to the nuclear export of Geminin, since Geminin has been found to be re-activated following a nuclear import process in Xenopus egg extracts. Both nuclear assembly and nuclear transport are required for the generation of the inhibitory activity of Geminin (Hodgson et al., 2002). Like multiple redundant mechanisms have developed to guarantee a complete inhibition of rereplication at early $\mathrm{S}$ phase, a number of Geminin inactivation mechanisms may also be applied to license the next round of DNA replication during late mitosis and 
G1 phase. It is also possible that different organisms use different dominant Geminin inactivation mechanism, since the APC mediated proteolysis of Geminin appears to be essential in mammalian cells to inactivate Geminin comparing to Xenopus eggs.

All together, the role of Geminin in DNA replication regulation is very well characterized (Fig. 1-3). Immediately after DNA replication initiation at early $\mathrm{S}$ phase, Geminin accumulates in nucleus and serves as an important molecule to inhibit DNA rereplication by direct interacting with Cdt1. The Geminin-Cdt1 interaction inhibits the bindings of Cdt1 to DNA, Cdc6 and Mcms, prevents the loading of MCM complex onto chromatin, thus inhibiting rereplication. The presence of active Geminin in the nucleus is maintained throughout $\mathrm{S}$ and G2 phases until the end of mitosis, during which Geminin is inactivated through various pathways including APC mediated degradation, ubiquitination without proteolysis, and nuclear export. The complete inactivation of Geminin ensures the DNA replication licensing for the next round of cell cycle.

\subsection{The Roles of Geminin in Embryonic Development}

The role of Geminin in embryonic development was first discovered as its overexpression expands the neural plate at the expense of adjacent neural crest and epidermis in Xenopus embryos (Kroll et al., 1998). Therefore, in addition to preventing DNA rereplication in cell cycle, Geminin has also been defined as a neuralizing molecule that demarcates the future neural plate at the onset of gastrulation. The injection of Geminin mRNA into one cell of the two-cell stage embryo leads to a hypertrophy of neural tissue at early neurula stage. The injected embryos exhibit an increased primary neuron density, or an expansion of N-tubulin expressing tissue. Downregulation of bone morphogenetic protein 4 (BMP4) levels is the primary means by which Geminin neuralizes ectoderm. Misexpression of Geminin in gastrula ectoderm suppresses BMP4 and epidermal keratin expressions, thus converting prospective epidermis into neural tissue. On the contrary, BMP4 has neither a stimulatory nor inhibitory effect on Geminin transcription. The neuralizing domain of Geminin is mapped to its N-terminal region (amino acids 38-90), which is independent of its cell cycle regulation domain and sufficient to evoke neural hypertrophy and ectopic neurogenesis. Furthermore, two secreted proteins expressed in vivo as BMP inhibitors in gastrula organizer mesoderm, chordin and noggin, can directly bind BMPs to prevent their receptor binding. Both chordin and noggin can 
strongly induce Geminin expression (Kroll et al., 1998). Similarly, in Drosophila, ectopic overexpression of Geminin results in the formation of ectopic neuronal cells, while a percentage of Geminin mutant embryos have a reduction of the dorsal most peripheral neurons (Quinn et al., 2001). Therefore, both in Xenopus and Drosophila, Geminin plays an important role in inducing neural differentiation.

Hence, Geminin is a bifunctional protein that prevents DNA rereplication in the cell cycle, also regulates processes of embryonic development such as neurogenesis. This is how the name "Geminin" comes from, for gemini meaning twins, to denote its functional duality.

The involvement of Geminin in eye development was first suggested from phenotypes of the Drosophila embryos with Geminin overexpressed. In these embryos, overexpression of Geminin leads to a decrease in the size of third instar larvae eye discs as well as the size of adult eyes. Recently, the role of Geminin in eye development has been further investigated in Medaka fish (Del Bene et al., 2004). Different overdoses of Geminin in the embryo by mRNA injection resulted in smaller eyes, cyclopia, or loss of the entire forebrain structure. These eye phenotypes were accompanied by or resulted from a decreased number of proliferative cells and premature neural induction in the optic vesicles, which correlated with the roles of the Geminin in cell cycle regulation and neurogenesis. Furthermore, in support to the overexpression effect of Geminin in cultured cells, the injection of Geminin mRNA also led to apoptosis in Medaka embryos. Vice versa, Geminin knock down by morpholino increased the number of mitotically active cells, thus enlarging the size of the optic vesicles (Del Bene et al., 2004).

\subsection{Homeosis and Hox Genes}

More than one hundred years ago, the term "homeosis", also called homeotic transformation nowadays, was first proposed by William Bateson to qualify morphological variations transforming "something into the likeness of something else" (Fig. 1-4; Bateson, 1894). In the late 1940s, scientists began a study of mutations that produced homeotic transformations in fly, such as flies with four wings instead of two at the expense of balance organs, the halteres. Over the past twenty years, genes involved in such transformations have been isolated from all kinds of metazoans. 

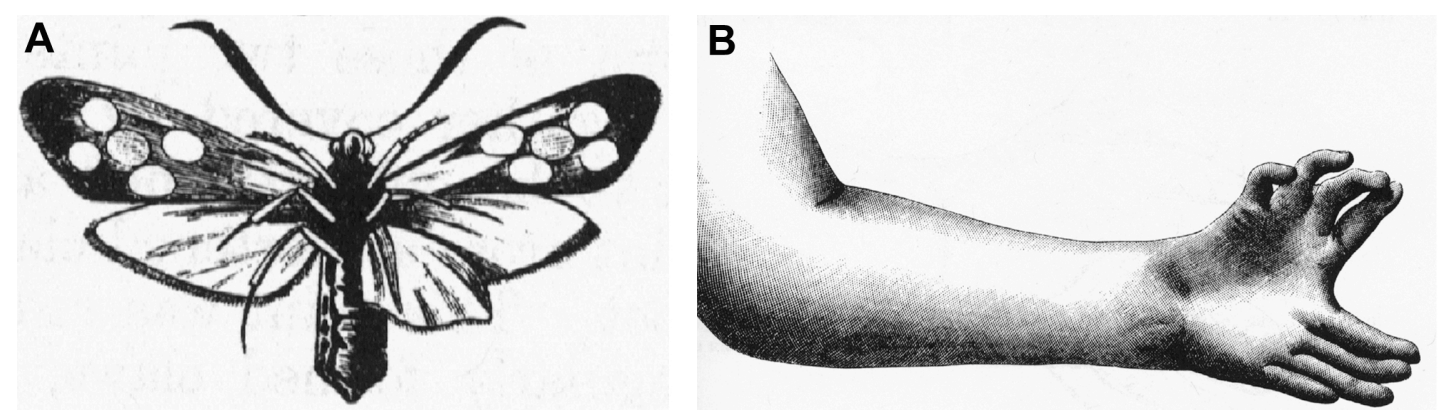

Figure 1-4: Homeosis: transformations of "something to the likeness of something else". (A) One example of homeosis in a moth: the transformation of a leg to a wing. (B) Another example of homeosis on a human autopod: the transformation of a thumb into a set of four fingers (Bateson, 1894).

\subsubsection{Homeodomain and Homeobox}

Homeodomain proteins are a family of transcription factors characterized by a $60-$ amino acid DNA binding domain, the homeodomain, which is encoded by a 180-base pair DNA sequence known as the homeobox. The highly conserved homeobox motif was first discovered in homeotic genes of the Drosophila homeotic complexes (HOM-

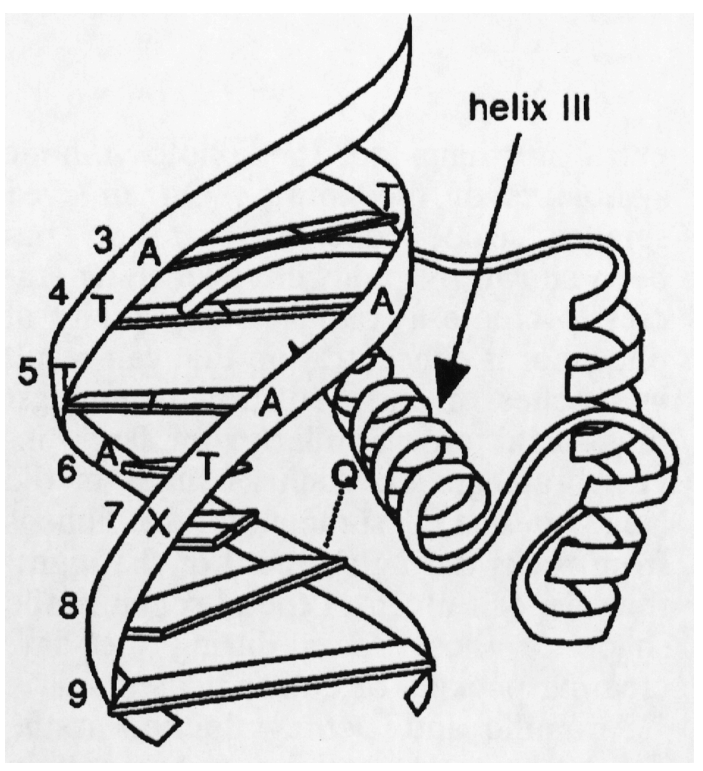

Figure 1-5: Homeodomain-DNA interactions. The helix-turn-helix motif of the homeodomain binds to DNA in the major groove of double helix, in which the four-base motif TAAT serves as the conserved core recognition sequence (Riddihough, 1992).

C) (McGinnis et al., 1984a; McGinnis et al., 1984b; Scott and Weiner, 1984). The homeodomain folds into three $\alpha$-helices, the latter two folding into a helix-turn-helix conformation that is characteristic of transcription factors that bind DNA in the major groove of the double helix. The third helix is the recognition helix, making contact with the bases of the DNA. A four-base motif, TAAT, is conserved in nearly all sites recognized by homeodomains, which probably distinguishes those sites to that 
homeodomain proteins can bind (Fig. 1-5). The 5' terminal $\mathrm{T}$ appears to be critical in this recognition, as mutating it destroys all homeodomain binding. The base pairs following the TAAT motif have been demonstrated to be important in distinguishing between similar recognition sites (Riddihough, 1992).

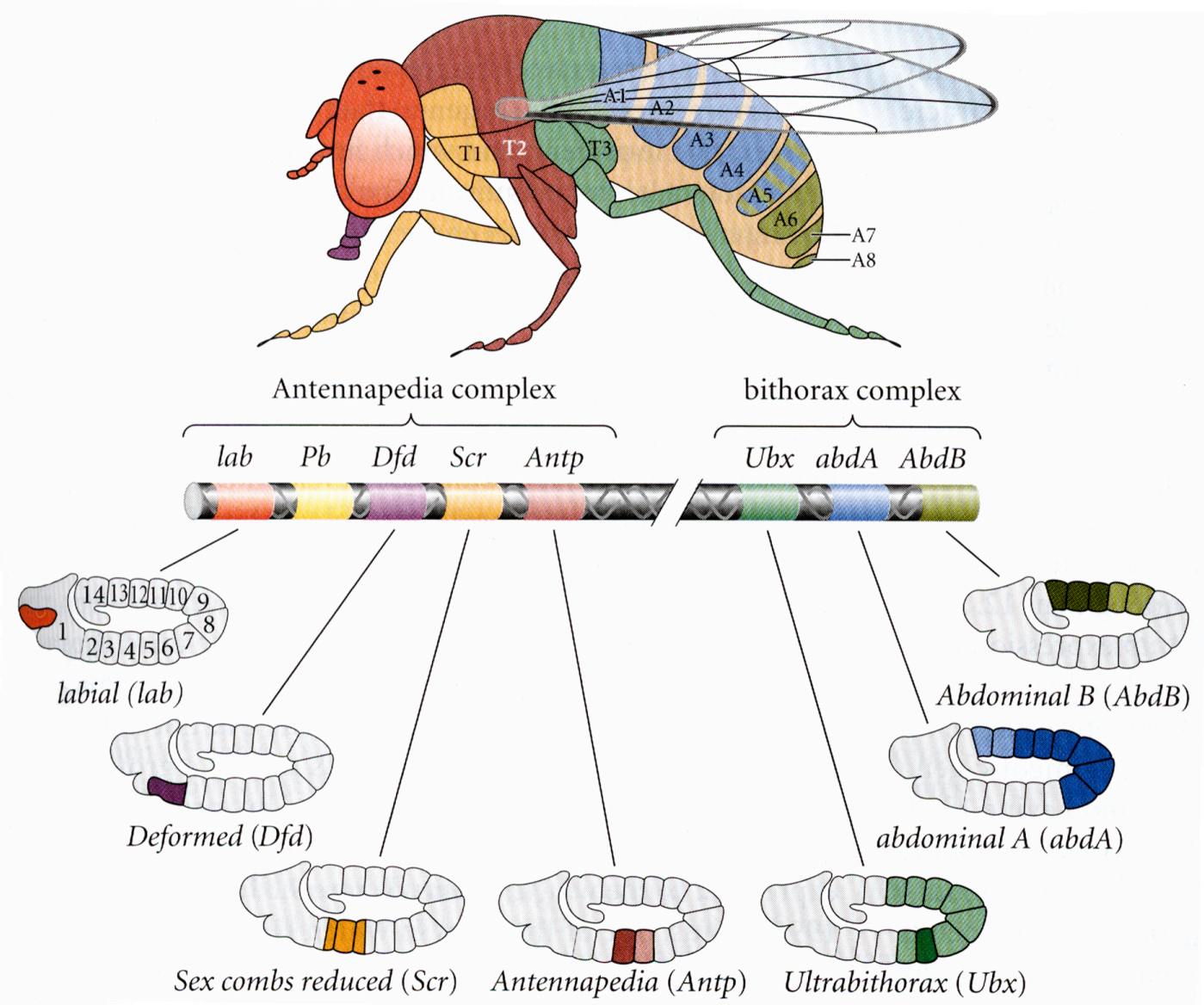

Figure 1-6: Homeotic gene expression in Drosophila. In the center are the genes of the Antennapedia and bithorax complexes and their functional domains. Below and above the gene map, the regions of homeotic gene expression in the blastoderm of the Drosophila embryo and the regions that form from them in the adult fly are shown. The dark shaded areas represent those segments and parasegments with the most product.

\subsubsection{Drosophila Homeotic Genes}

The wild-type functions of homeotic genes are individually restricted to a specific region of the developing insect and specify the segmental identities. Two regions of Drosophila chromosome 3 contain most of these homeotic genes (Fig. 1-6). One of these, the Antennapedia complex, includes the homeotic genes labial (lab), 
proboscipedia $(p b)$, Deformed $(D f d)$, Sex combs reduced $(S c r)$, and Antennapedia (Antp). The second region of homeotic genes is the bithorax complex, in which three genes, Ultrabithorax (Ubx), abdominal $A(a b d A)$, and Abdominal $B(A b d B)$, are found. The chromosome region containing both the Antennapedia complex and the bithorax complex is often referred to as the homeotic complex (HOM-C). In Drosophila, transcripts from each homeotic gene can be detected in specific regions of the embryo, especially prominent in the central nervous system (Harding et al., 1985; Akam, 1987). The current prevalent view is that different homeotic genes in different segments along the body axis can select for different developmental programs, for example by activating or repressing incompletely overlapping sets of target genes, thereby leading to the formation of different structures, such as antenna, leg, haltere, or wing (Lawrence and Morata, 1994). The lab and Dfd genes specify the head segments, while the Scr and Antp contribute to the identities of the first and second thoracic segments. More posterior, $U b x$ is required for the identity of the third thoracic segment, while $a b d A$ and $A b d B$ are responsible for the positional identities of the abdominal segments (Fig. 1-6; Wakimoto et al., 1984; Kaufman et al., 1990; Sánchez-Herrero et al., 1985).
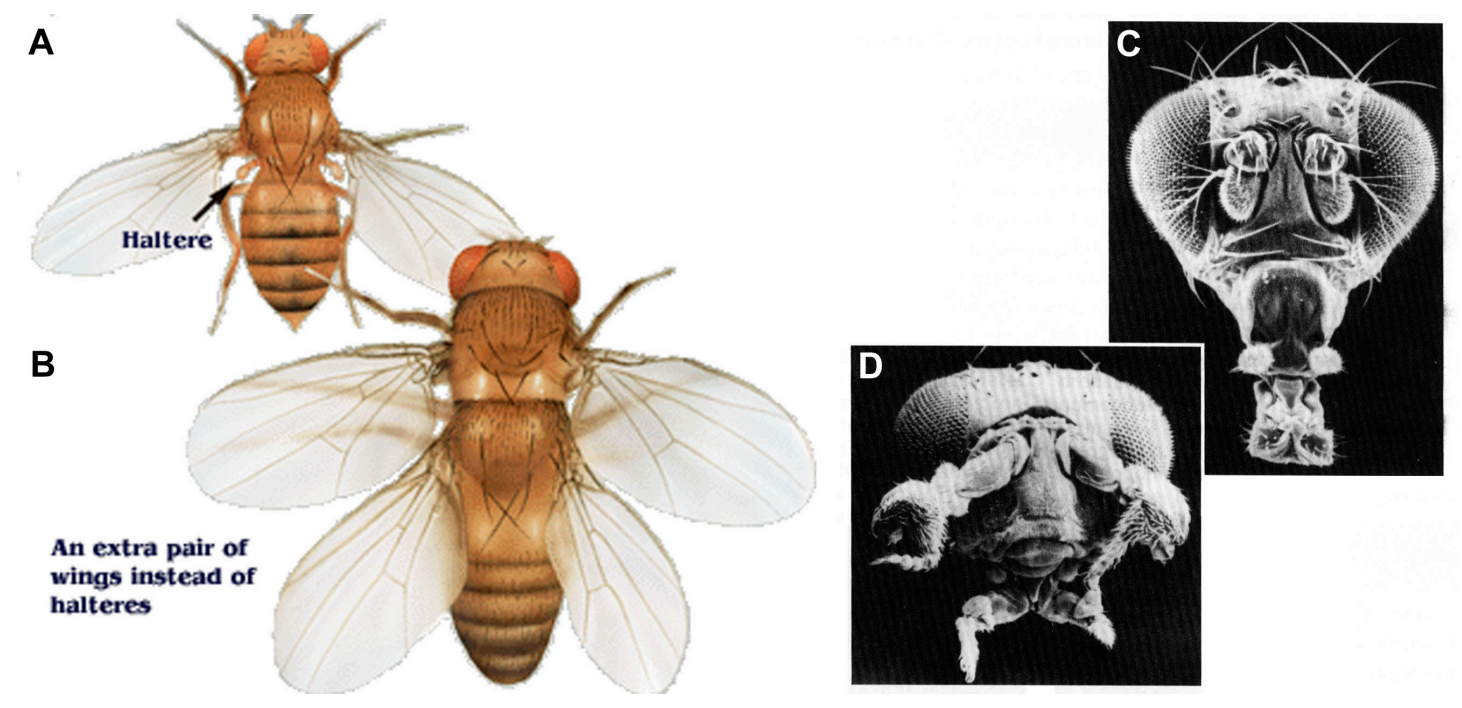

Figure 1-7: Homeotic transformation phenotypes resulted from mutations of homeotic genes in Drosophila. When the $U b x$ gene is deleted, the third thoracic segment is transformed into another second thoracic segment that is a fly with four wings at the expense of halteres (B) in contrast to the wild type fly (A). When Antp gene is misexpressed in the head, legs sprout from the head sockets (D) instead of antenna in wild type flys (C) (Kaufman et al., 1990). 
Since the homeotic genes provide the positional specific information to define the embryonic structures along the body axis, mutations in them lead to bizarre homeotic transformation phenotypes. When the $U b x$ gene is deleted, the third thoracic segment is transformed into another second thoracic segment, resulting in a fly with four wings but without halteres (Fig. 1-7A, B). Similarly, Antp usually specifies the second thoracic segment of the fly. When flies carry the mutation wherein the Antp gene is misexpressed in the head in addition to the thorax, legs sprout from the head sockets instead of antenna (Fig. 1-7C, D; Kaufman et al., 1990). In larvae lacking the whole bithorax complex, every segment from 5-13 develops similar to segment 4, which is an embryonic lethal phenotype (Casanova et al., 1987)

However, although the structure and biochemistry of these homeotic genes and proteins have been rapidly deciphered, the mechanism by which such genes can identify or transform the morphologies of given segments or metameres is poorly understood.

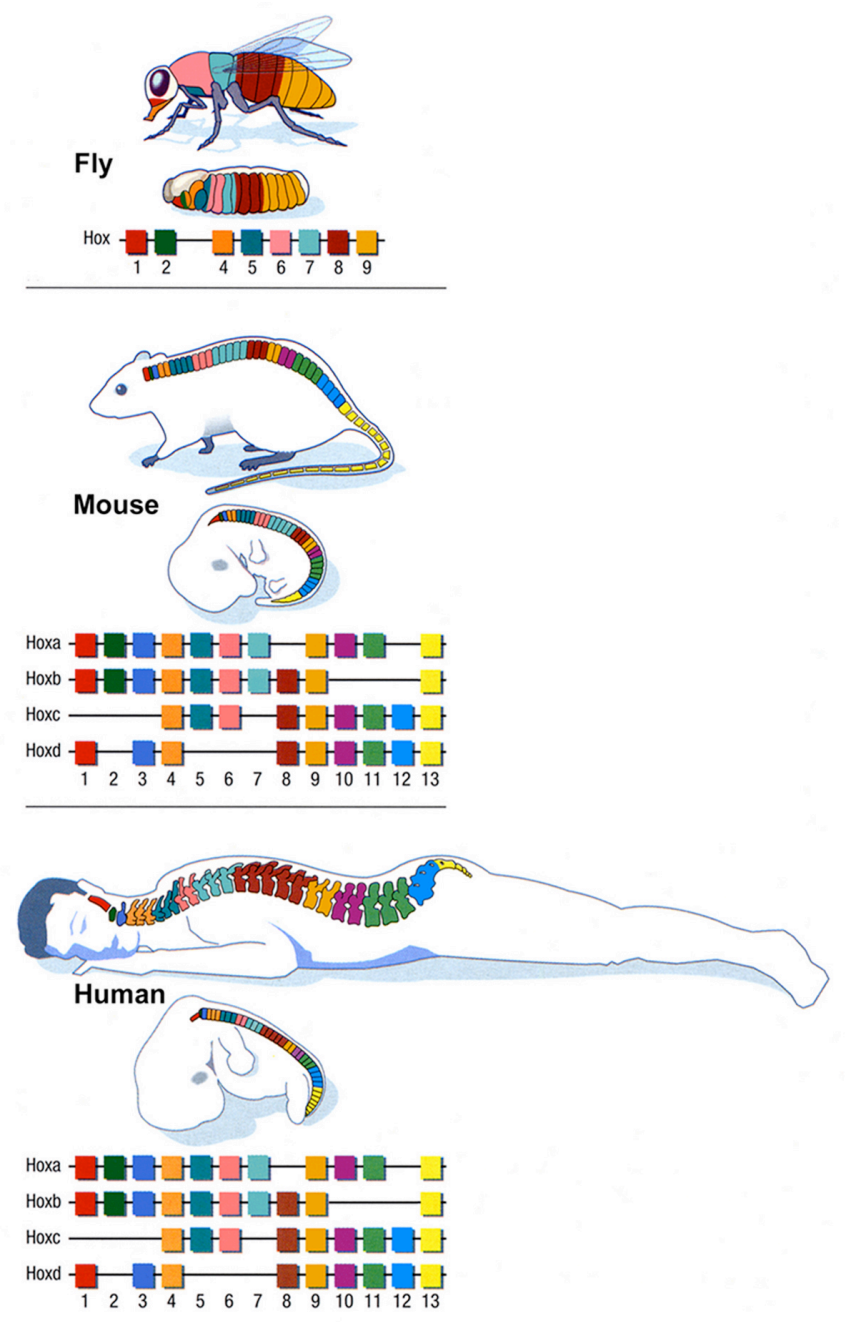

Figure 1-8: Hox gene clusters: the vertebrate homologs of Drosophila homeotic genes. There are four clusters of Hox genes in vertebrates, subdivided into 13 paralogous groups. Note that genes belonging to the same paralogous group and their Drosophila homolog are depicted with the same color. 


\subsubsection{Vertebrate Hox Genes: Clustering and Colinearity}

In vertebrates, there are four Hox gene clusters organized into four complexes on four different chromosomes, totally containing 39 Hox genes. Analyses in mouse, human and all other vertebrates indicate an identical Hox gene organization, and that the genes in each cluster are all oriented in the same direction of transcription. Hox gene clusters are the vertebrate homologs of Drosophila HOM-C. Based on the multiple domains of sequence identity including the homeodomain itself, and on the relative position of the genes within the respective complexes, the 39 Hox genes can be grouped into 13 paralogous groups with the corresponding genes in each cluster (such as Hoxa9, Hoxb9, Hoxc9 and Hoxd9) defined as a paralogous group. Furthermore, the organization and homology relationship between Hox gene clusters and $H O M-C$ can be mapped (Fig. 1-8).

Hox gene expression can be seen along the dorsal axis in the neural tube, neural crest, paraxial mesoderm, and surface ectoderm from the anterior boundary of the hindbrain through the tail, also in the limb, gut, and gonadal tissue (Krumlauf, 1994). A distinguishing hallmark of the Hox/HOM-C clusters is the correlation between the physical order of genes along the chromosome and their expression as well as function along the anteroposterior axis of the embryo. This characteristic was originally recognized by Lewis in Drosophila bithorax complex and referred to as spatial colinearity (Lewis, 1978). It was postulated at that time that the bithorax complex could represent a mechanism for translating genetic information into a combinatorial code for the regulation of regional identity. This property is extended to vertebrate Hox genes, where also a spatial colinear relationship between gene order and their expressions along the anteroposterior axis of vertebrate embryos exists. The more 3 ' the gene located in the cluster along chromosome, the more anterior it expresses along the body axis (Graham et al., 1989; Duboule and Dollé, 1989). There is also a relationship between the organization of the genes along the chromosome and the time of the appearance of gene expression during embryogenesis, named temporal colinearity (Izpisua-Belmonte et al., 1991). Therefore, the famous "colinearities", both spatial and temporal, refer to the prominent characteristics of Hox genes that genes located at the 3' extremity are activated earliest and have most anterior boundaries of expression, whereas moving along the clusters in a 5' direction, the genes are transcribed progressively later in more posterior areas during embryonic development. In addition, there is also a colinear sensitivity in the level and time of 
response of Hox genes to retinoic acid (RA) in cell lines and embryos. Again, the more 3' the gene located in the clusters, the higher sensitive to RA induction (Simeone et al., 1990; Dekker et al., 1993).

Although the biological relevances of Hox gene "clustering" and "colinearity" are well perceived and they are known to be critical for proper vertebrate development, the reasons and mechanisms behind this genomic organization and transcriptional progression remain as one of the major mysteries of Hox genes. Nevertheless, in the past decade, a good deal of effort has been put into the dissection of underlying mechanisms. Two issues should be mentioned here in attempts to decipher the molecular basis of clustering and colinearity. First, it is likely that not all the animals implement their colinearities in the same way. These alternatives are probably made necessary by the important divergence in developmental strategies between different animals, even though the outcome of the Hox system is identical throughout metazoans. Second, the problem of Hox gene clustering is related but not identical to that of colinearity. Understanding why and how Hox genes are clustered may not tell us about colinearity as this latter phenomenon may represent only one of the many reasons why Hox genes are clustered together (Duboule, 1998).

So far, what are the understandings nowadays? What is the rationale of spatial and temporal colinearities and how are they achieved? Unlike the situation in flies, where the activation mechanism depends on factors unequally distributed by the segmentation process, four classes of mechanisms have been evoked to implement colinearity in vertebrates, alone or in combination.

The first mechanism relies on the progressive transcriptional availability of Hox genes, from one end of the cluster to the other, a process that may or may not be independent of their own transcription. For example, repressive or silencing factors like promyelocytic leukemia zinc finger (Plzf) and the Polycomb complex (Barna et al., 2002; Gould 1997) could be released through a passive transition in chromatin states (Kondo and Duboule, 1999). Alternatively, transcription of the genes themselves could help remodel chromatin to allow the next gene to be accessed. The latter possibility is supported by the failure of the posterior HoxD cluster to efficiently repress the early expressed Hoxb1/lacZ transgene, which suggests that an early gene can still recruit necessary factors to be activated in a timely manner, even though positioned within a "closed" domain (Kmita et al., 2000). In this view, a chromatin dependent colinear process would involve a transcriptional entry point at one side of 
the cluster that triggers the processing from a closed to an open configuration through a proximity effect. This would allow for progressively more genes to be transcribed toward the other extremity of the cluster.

The second scenario proposes that colinear activation in time and space is orchestrated by the integration of locally cis-acting control sequences. Since local enhancer functions are shared among subsets of neighboring Hox genes, they ultimately provide distinct expression features through unequal partitioning of their activities on the genes they control (Sharpe et al., 1998). Although this strategy accounts for the rather precise activation of randomly integrated transgenes, it may not be a key factor in tightly maintaining genes in clusters. Hence, it is likely not a primary mechanistic basis for the colinearity.

The third mechanism involves the existence of global enhancer sequence, located outside the clusters, which can regulate several Hox genes in a relatively promoter unspecific manner. The positions of these enhancers, close to either end of a Hox cluster, introduce an intrinsic regulatory asymmetry that can be subsequently translated into a colinear mechanism. For an instance, the cycling expression of Hoxd genes in the presomitic mesoderm, in coordination with segmentation, involves a regulatory element located outside the cluster, which can act over several genes at different times. This regulatory element may be the outcome of the segmentation process, setting up the pace of the temporal and spatial colinear activation of Hox genes and thereby keeping these two key aspects of patterning in phase with each other (Zàkàny et al., 2001; Dubrulle et al., 2001). Likewise, colinearity in developing limbs relies on the existence of a global digit enhancer element located far upstream on the other side of the cluster (Spitz et al., 2003). Sequence specific enhancer tropism, as well as promoter competition, eventually induces the terminal genes to be expressed in the most distal structures, with a progressively decreasing efficiency (Kmita et al., 2002). In these cases, colinearity is determined by the action of global enhancers.

As known in the genome, nearly $1 \%$ of the predicted mammalian genes encode microRNAs (miRNAs). Then, the fourth colinear possibility involves the participation of miRNAs in Hox gene regulation. RNA interference is the process of sequence specific, post-transcriptional gene silencing in animal and plants, initiated by a double-stranded RNA that is homologous in sequence to the silenced gene. The mediators of sequence specific mRNA degradation are 21- or 22-nucleotide duplex 
siRNAs (Elbashir et al., 2001). The involvement of miRNAs in Hox gene regulation was first hinted from discoveries that several miRNA encoding sequences are located in the introns or intergenetic regions within Hox clusters (Fig. 1-9; Lagos-Quintana et al., 2003). MiR-196, an miRNA encoded by sequences between Hox-9 and Hox-10 at three paralogous loci in the $\mathrm{A}, \mathrm{B}$, and $\mathrm{C}$ vertebrate Hox clusters, has extensive, evolutionarily conserved complementarity to messages of Hoxb8, Hoxc8, and Hoxd8. Furthermore, this miRNA can direct endogenous cleavage of Hoxb 8 mRNA in mouse embryos, and mediate the inhibition of Hoxc8, Hoxd8, and Hoxa7 expressions predominantly on a translational level (Yekta et al., 2004). Because of the colinearity and progressive opening of Hox gene clusters, the transcription of Hoxb 8 precedes that of miR-196 spatially and temporally. Therefore, the colinear organization of Hox genes ensures the proper spatial domains and temporal phases of functional Hoxb8 during embryogenesis. In addition, this post-transcriptional inhibition serves as one of the possible mechanisms involved in posterior prevalence of Hox genes (see below).

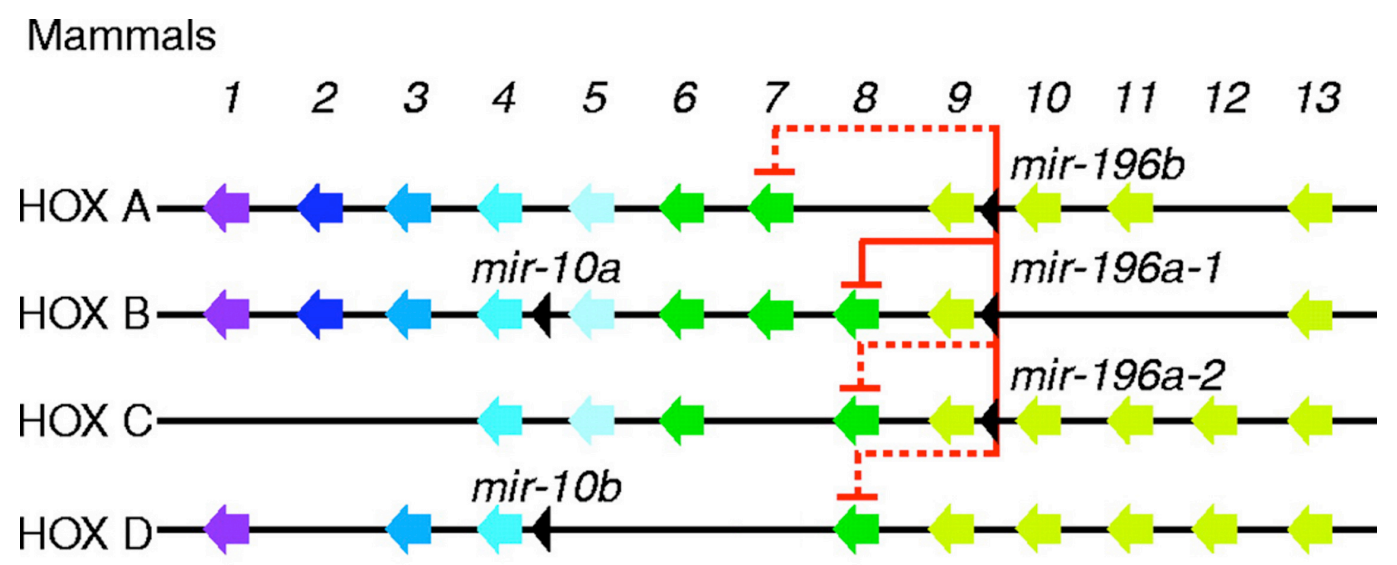

Insects

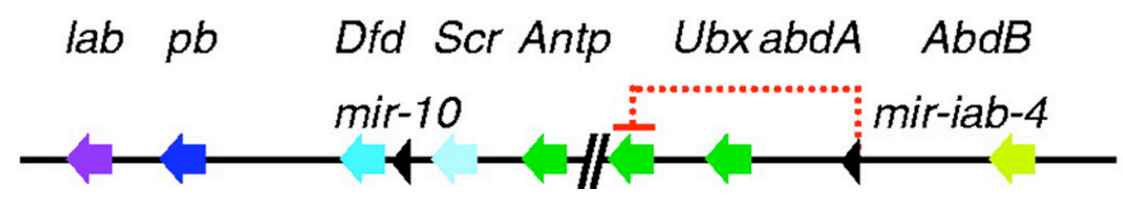

Figure 1-9: The involvement of miRNAs in Hox gene regulation and colinearity. Colored arrows indicate Hox genes representing 13 paralogous groups; black arrowheads depict miRNA genes. Repression supported by bioinformatic evidence only (dotted red line), cell-culture and bioinformatic evidence (dashed line), or in vivo, cell culture, and bioinformatic evidence (solid line) are indicated. The vertical red line indicates that miRNAs from any of the three loci could repress the targets (Yekta et al., 2004). 


\subsubsection{Patterning the Anteroposterior Axis: The Hox Code}

Once gastrulation begins, anterior-posterior polarity in all vertebrates becomes specified by the expression of Hox genes. As discussed above, during embryonic development Hox genes are activated in nonidentical, overlapping expression domains along the body axis of vertebrates, exhibiting a temporal and spatial colinearity with their genomic organization. The expression patterns of murine Hox genes suggest a code whereby a certain combination of Hox genes specifies a particular regional identity along the anteroposterior axis (Kessel and Gruss, 1991; Hunt and Krumlauf, 1991). Therefore, the term "Hox code" was proposed, so that each segment along the body axis has a special combination of functional active Hox genes, that is, a special Hox code, to provide its positional identity (Fig. 1-10). Evidence for such a code comes from the following three sources.

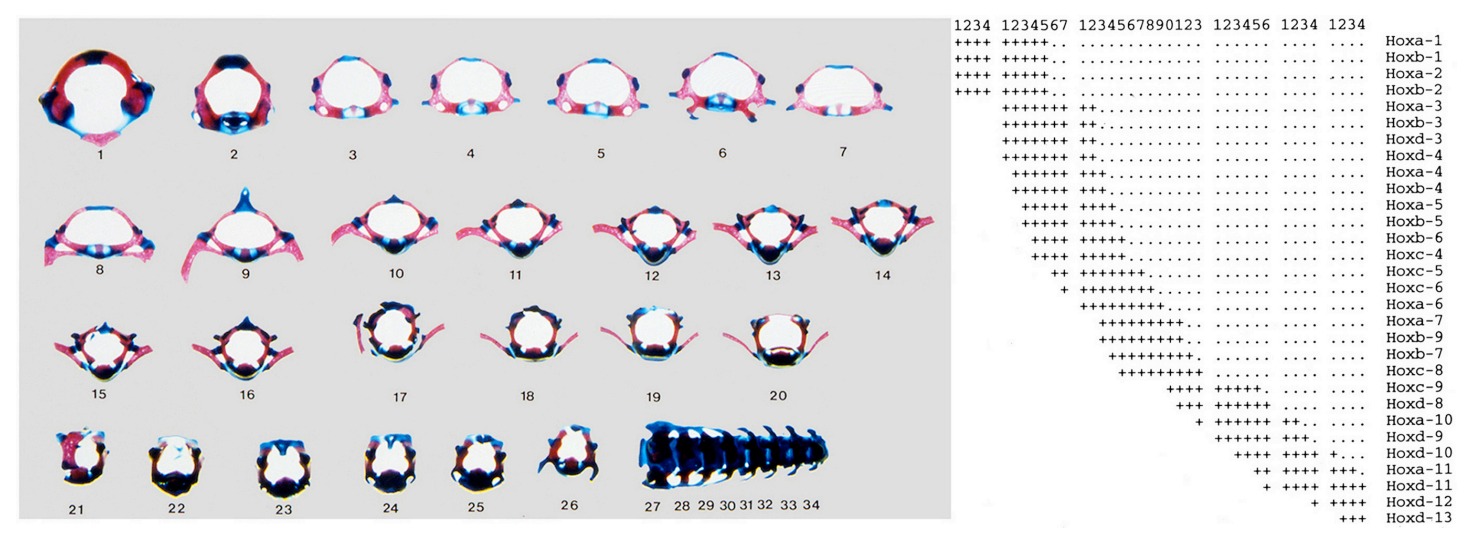

Figure 1-10: Hox code: each segment along the anteroposterior axis has a special combination of functionally active Hox genes. The left side shows the morphological identities of each vertebra, whereas the right side indicates the Hox gene combinations of each vertebral segment that determine their identities during embryogenesis.

The first evidence comes from knockout experiments of murine Hox genes. Absence of a Hox gene affects patterning in a way in agreement with the idea that Hox code provides the cells with positional identity. For an instance, mouse loss-offunction mutants of Hoxa2, Hoxd3, Hoxb4, Hoxa5, Hoxc8, Hoxa11, Hoxd13 all display various forms of anterior or posterior homeotic transformations in the axial skeleton or neural crest (Reviewed by Krumlauf, 1994). These mutations illustrate that altering a single gene can cause changes of the Hox code in given segments, resulting in changes in cell fate and consequent homeotic transformations. The 
correlation between changes of Hox code and transformations of segment identities can be clearly demonstrated, exampled by Hoxb4 loss-of-function mutant (RamirezSolis et al., 1993). Knockout of Hoxb4 gene leads to a switch of the Hox code of the second cervical segment into that of the first cervical segment, which exactly correlates with the morphological transformation of axis (the second cervical vertebra) into another atlas (the first cervical vertebra).

The second evidence comes from the RA induced teratogenesis. Many Hox genes have RA receptor binding sites in their enhancers, and a gradient of RA has been established by day 7 of development that is high in the posterior regions and low in the anterior portions of the embryo (Sakai et al., 2001). This gradient appears to be controlled by the differential synthesis or degradation of RA in different parts of the embryo. Exogenous RA applied to mouse embryos in uteri can lead to certain Hox genes to become expressed in groups of cells that usually do not express them. These ectopically expressed Hox genes cause alterations of Hox codes and concomitant homeotic transformations of vertebrae and axons, again demonstrating the biological relevance of Hox code in the specification of embryonic structures along the anteroposterior axis (Kessel and Gruss, 1991; Kessel, 1992; Kessel, 1993).

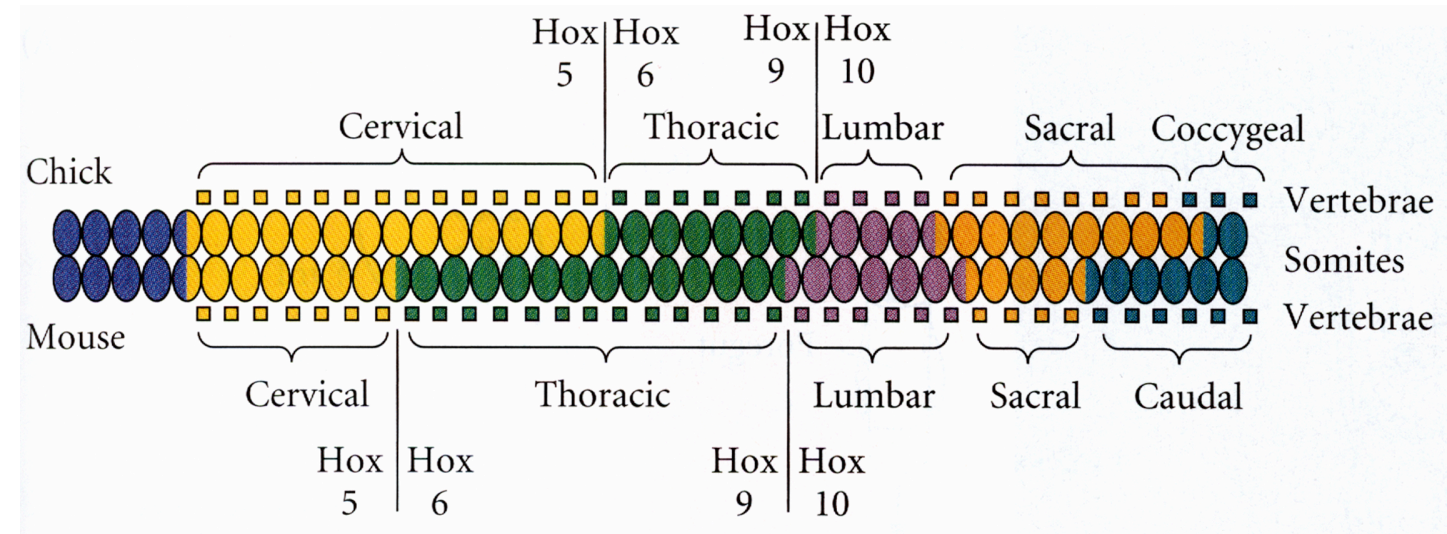

Occipital Ocervical Thoracic O Lumbar O Sacral

Figure 1-11: Schematic representation of the mouse and chick vertebral pattern along the anteroposterior axis. The boundaries of expression of certain Hox gene paralogous groups have been mapped onto these domains (For further explanation, see body text) (Burke et al., 1995).

The third evidence comes from the comparative anatomy of mouse and chick vertebrae. Although mouse and chick have a similar number of vertebrae, they 
apportion them differently. The constellation of expressed Hox genes predicts the type of vertebrae formed rather than the relative position of the vertebrae (Fig. 1-11). For an instance, in the mouse, the transition between cervical and thoracic vertebrae is between 7 and 8, whereas in the chick it is between vertebrae 14 and 15 . In both cases, the Hox -5 paralogous are expressed in the last cervical vertebra, while the anterior boundary of the Hox-6 paralogous extends to the first thoracic vertebra. Similarly, in both animals, the thoracic-lumbar transition is seen at the boundary between the Hox-9 and Hox-10 paralogous groups. Therefore, it appears that there is a code of differing Hox gene expression along the anteroposterior axis, and that Hox code determines the type of vertebra formed (Burke et al., 1995).

Hox gene clusters have 39 genes consisting of 13 groups of paralogous genes, which are highly related to each other in the sequences of the encoded homeodomain. The resulting functional overlaps between paralogous proteins, highlighted as their functional redundancies (Wellik and Capecchi, 2003), suggest that the developmental pathways concerned may rely on strong quantitative parameters. Likewise, the subtle morphological differences of some vertebral structures along the body axis also suggest that the qualitative combination of Hox genes in anteroposterior patterning is not the sole underlying mechanism. For an instance, mouse homozygous for null alleles at Hoxa3 are characterized by perinatal lethality, absence of the thymus, and malformation of the hyoid bone. However, in mice lacking any Hoxa3 protein but instead expressing Hoxd3 protein from both Hoxa3 and Hoxd3 loci, the Hoxa 3 null mutant phenotypes are dramatically rescued, indicating that the Hoxd3 protein complements the absence of Hoxa3 protein when expressed at the Hoxa3 locus. Vice versa, the expression of Hoxa3 protein from Hoxd3 locus complements the Hoxd3 function and rescues Hoxd3 null mutant phenotypes. Hence, the proteins encoded by the paralogous genes, Hoxa3 and Hoxd3, can carry out identical biological functions, and that the different roles attributed to these genes are the result of quantitative modulations in gene expression (Greer et al., 2000).

In vertebrates, successively more caudal body levels tend to show an increasing amount and diversity of Hox products, resulting from the expression strategy. Yet segmented structures do not become more elaborate toward the caudal end of the embryo, nor do they display a greater potential for variation after gene inactivation experiments, thus excluding a strict combinatorial input. The most posteriorly expressed gene usually imposes its function over that of more anterior genes through 
a suppressive mechanism that does not involve transcriptional repression (Schock et al., 2000). This so-called posterior prevalence (Duboule, 1991) explains why the phenotypes induced by vertebrate Hox mutations are restricted either to a few body segments or to the upper morphological window in which a given group of paralogs is at work (Horan et al., 1995; van den Akker et al., 2001). Posterior prevalence is an interesting property for morphological evolution, given that an anterior shift in the expression of a caudal gene would lead to the functional inactivation of more rostral components. Therefore, the functional interplay between Hox proteins is the result of their colinear distribution along the body, and is the essential constraint of the system. Consequently, any mechanism generating this protein distribution may have been evolutionarily selected and implemented in the numerous instances in which this strategy is used.

Together, during embryonic development, vertebrate Hox genes are activated in nonidentical, overlapping expression domains along the anteroposterior axis, exhibiting a temporal and spatial colinearity with their genomic organization. Qualitative and quantitative combinatorial distributions of Hox proteins along the body axis provide positional specific information, thus defining embryonic structures.

\subsubsection{Maintenance of Hox Gene Transcription or Inhibition}

The initial domains of homeotic gene expressions are established by the gap genes and pair-rule genes in Drosophila. However, gap gene and pair-rule gene proteins are transient, whereas the identities of segments must be stabilized during development. Thus, once the transcription patterns of homeotic genes have become set up, they are locked into an active or repressive state epigenetically by the transcriptional memory system.

On the basis of reciprocal homeotic phenotypes, two classes of genes have been identified to involve in the epigenetic maintenance of Hox/HOM-C gene transcription. The trithorax group $(\operatorname{tr} x G)$ is responsible for sustaining the active state of Hox/HOM$C$ gene transcription, while the Polycomb group $(P c G)$ encodes a stable repressor system (Schumacher and Magnuson, 1997). Activation of a eukaryotic gene depends upon the coordinated action of chromatin remodeling factors, histone modifying enzymes, gene specific and general transcription factors, and RNA polymerase. Chromatin remodeling complexes and histone modifying enzymes play significant roles in maintaining on or off state of transcription after an initial gene expression 
decision is made. Polycomb and trithorax group proteins are evolutionarily conserved chromatin components that maintain spatial patterns of Hox/HOM-C gene transcription. Several lines of evidence indicate that numerous members of $\operatorname{trx} G$ and $P c G$ products (Tab. 1-1) form multiprotein complexes, which are required to keep Hox/HOM-C and other potential target genes activated or repressed.

\begin{tabular}{|c|c|c|c|c|c|}
\hline $\begin{array}{l}\text { Murine } \\
\text { gene }\end{array}$ & Class & Identification & $\begin{array}{l}\text { Drosophila } \\
\text { homologs }\end{array}$ & $\begin{array}{l}\text { Vertebrate } \\
\text { homologs }\end{array}$ & Conserved domains \\
\hline Bmil & PcG & $\begin{array}{l}\text { Proviral integration } \\
\text { site in Mo-MLV- } \\
\text { induced B-cell } \\
\text { lymphomas }\end{array}$ & $P s c, S u(z) 2$ & $\begin{array}{l}\text { Human BMI1 } \\
\text { Xenopus Xbmil }\end{array}$ & $\begin{array}{l}\text { Ring-finger motif, } \\
\text { C-terminal } \\
\text { proline/serine-rich, } \\
\text { putative } \\
\text { transactivation } \\
\text { domain }\end{array}$ \\
\hline Mell8 & $\mathrm{PcG}$ & $\begin{array}{l}\text { Expression cloning } \\
\text { using mouse } \\
\text { melanoma B16 cells }\end{array}$ & $P s c, S u(z) 2$ & Human $M E L 18$ & $\begin{array}{l}\text { Ring-finger motif, } \\
\text { C-terminal proline/ } \\
\text { serine-rich, putative } \\
\text { transactivation } \\
\text { domain }\end{array}$ \\
\hline $\begin{array}{l}\text { Cbx2 } \\
(M 33)\end{array}$ & $\mathrm{PcG}$ & $\begin{array}{l}\text { Homology screen } \\
\text { using Drosophila } \\
\text { Polycomb }\end{array}$ & $P c$ & $\begin{array}{l}\text { Human } C B X 2 \\
\text { Xenopus } \\
\text { Xpolycomb }\end{array}$ & $\begin{array}{l}\text { Chromodomain, C- } \\
\text { terminus }\end{array}$ \\
\hline $\begin{array}{l}\text { Rae28 } \\
(\text { Mph1) }\end{array}$ & $\mathrm{PcG}$ & $\begin{array}{l}\text { Induced in retinoic } \\
\text { acid treated F9 cells, } \\
\text { and in yeast two- } \\
\text { hybrid screen with } \\
\text { Bmil }\end{array}$ & $p h-p, p h-d$ & Not identified & $\begin{array}{l}\text { Zinc finger, } \\
\text { glutamine rich } \\
\text { region, a-helical } \\
\text { domain, SPM } \\
\text { (SEP) domain }\end{array}$ \\
\hline Enxlb & $\mathrm{PcG}$ & $\begin{array}{l}\text { Homology screen } \\
\text { using human } E N X 1 \text {, } \\
\text { which was isolated } \\
\text { by yeast two-hybrid } \\
\text { screen with } V A V \\
\text { proto-oncogene }\end{array}$ & $E(z)$ & Human $E Z H 2$ & $\begin{array}{l}\text { SET domain, CXC } \\
\text { domain }\end{array}$ \\
\hline Ezhl & $\mathrm{PcG}$ & $\begin{array}{l}\text { Homology screen } \\
\text { using Drosophila } \\
E(z)\end{array}$ & $E(z)$ & Human EZHI & $\begin{array}{l}\text { SET domain, CXC } \\
\text { domain }\end{array}$ \\
\hline
\end{tabular}




\begin{tabular}{|c|c|c|c|c|c|}
\hline Eed & $\mathrm{PcG}$ & Positional cloning & $E s c$ & Human $E E D$ & $\begin{array}{l}\text { High conservation } \\
\text { throughout protein, } \\
\text { five WD motifs }\end{array}$ \\
\hline Mll & $\operatorname{trxG}$ & $\begin{array}{l}\text { Homology screen } \\
\text { using human } A L L 1, \\
\text { which was isolated } \\
\text { from translocation } \\
\text { breakpoints in human } \\
\text { acute leukemias }\end{array}$ & $\operatorname{trx}$ & Human $A L L$ & $\begin{array}{l}\text { AT hook domain, } \\
\text { DNA } \\
\text { methyltransferase } \\
\text { domain, PHD } \\
\text { finger, SET domain }\end{array}$ \\
\hline Brgl & $\operatorname{trxG}$ & $\begin{array}{l}\text { Homology screen } \\
\text { using human } B R G 1 \text {, } \\
\text { which was isolated } \\
\text { by homology screen } \\
\text { using Drosophila brm }\end{array}$ & brm & $\begin{array}{l}\text { Human } B R G 1 \\
\text { Chicken } B R G 1\end{array}$ & $\begin{array}{l}\text { DNA helicase } \\
\text { domain, } \\
\text { bromodomain, } \mathrm{P} / \mathrm{Q} \\
\text { domain }\end{array}$ \\
\hline $\begin{array}{l}\text { Not } \\
\text { identifi } \\
\text { ed }\end{array}$ & $\operatorname{trxG}$ & $\begin{array}{l}\text { SNF2L2 isolated by } \\
\text { homology screen } \\
\text { using Drosophila brm }\end{array}$ & brm & $\begin{array}{l}\text { Human } S N F 2 L 2, \\
\text { Chicken } S N F 2 L 2\end{array}$ & $\begin{array}{l}\text { DNA helicase } \\
\text { domain, } \\
\text { bromodomain, } \mathrm{P} / \mathrm{Q} \\
\text { domain }\end{array}$ \\
\hline
\end{tabular}

Tabel 1-1: Murine Polycomb- and trithorax-group members and their Drosophila homologs

Four different complexes contain trxG proteins and at least two of them are demonstrated as pivotal components to maintain active Hox gene transcription. Trithorax acetyltransferase complex 1 (TAC1) contains Trx, Sbf1, and dCBP, a member of the $\mathrm{CBP} / \mathrm{p} 300$ family of acetyltransferase. TAC1 acetylates all four core histones as well as mononucleosomes and nucleosome arrays. Trx, dCBP, and Sbf1 colocalize at many sites on polytene chromosomes, including a trithorax response element (TRE) at the regulatory region of $U b x$. Trx and $d C B P$ mutations reduce expression of both endogenous $U b x$ gene and reporter genes under TRE control. Therefore, the role of TAC1 complex in the maintenance of active Hox gene transcription is carried out through promoting histone acetylation in the vicinity of TREs (Petruk et al., 2001). Another substantial trithorax complex, BRM complex, contains the trxG proteins Brahma, Moira, OSA, and SNR1. This complex is highly related to SWI/SNF, a chromatin remodeling complex, and catalyzes ATP dependent alterations of nucleosome organization. Other trxG proteins may target the BRM complex to specific promoters or modulate its activity. Thus, the BRM complex facilitates transcriptional activation on nucleosomal templates by remodeling chromatin structure at a step subsequent to activator binding (Kal et al., 2000).

Two distinct Polycomb complexes have been identified and exhibit high conservation among metazoans: Polycomb repressive complex 1 (PRC1) and ESC- 
$\mathrm{E}(\mathrm{Z})$ complex. The inhibition of Hox/HOM-C gene transcription by PRC1 is achieved through blocking of nucleosome remodeling. And the binding of PRC1 to chromatin occludes subsequent SWI/SNF or trithorax complex binding, further suggesting that the remodeling block is due to reduced positive regulator access to common or overlapping template sites (Francis et al., 2001). The second Polycomb ESC-E(Z) complex is physically linked to histone deacetylases (HDACs). HDAC1 and HDAC2 co-fractionate and co-immunoprecipitate with EED and EZH2, the human homologs of ESC and $\mathrm{E}(\mathrm{Z})$. The immunoprecipitants contain HDAC enzyme activity and EED mediated repression in cells is sensitive to an HDAC inhibitor trichostatin A, indicating that ESC-E(Z) complex inhibits Hox/HOM-C gene transcription through recruiting HDACs and thereby modifying chromatin structures (van der Vlag and Otte, 1999). In mouse, PRC1 contains Bmil, Mel18, Rae28 (also known as Mph1), M33, sex comb on midleg homolog 1 (Scmh1), Ring1A, Ring1B etc., while ESCE(Z) complex contains EED1, EZH1, Enx1B, and yin yang 1 (YY1). Most of these PcG member loss-of-function mutants exhibit derepressions of Hox gene transcription, concomitant with posterior homeotic transformations of embryonic structures along the anteroposterior body axis (Akasaka et al., 1996; Coré et al., 1997; Suzuki et al., 2002), further demonstrating the maintenance of Hox gene transcription inhibition by Polycomb complexes.

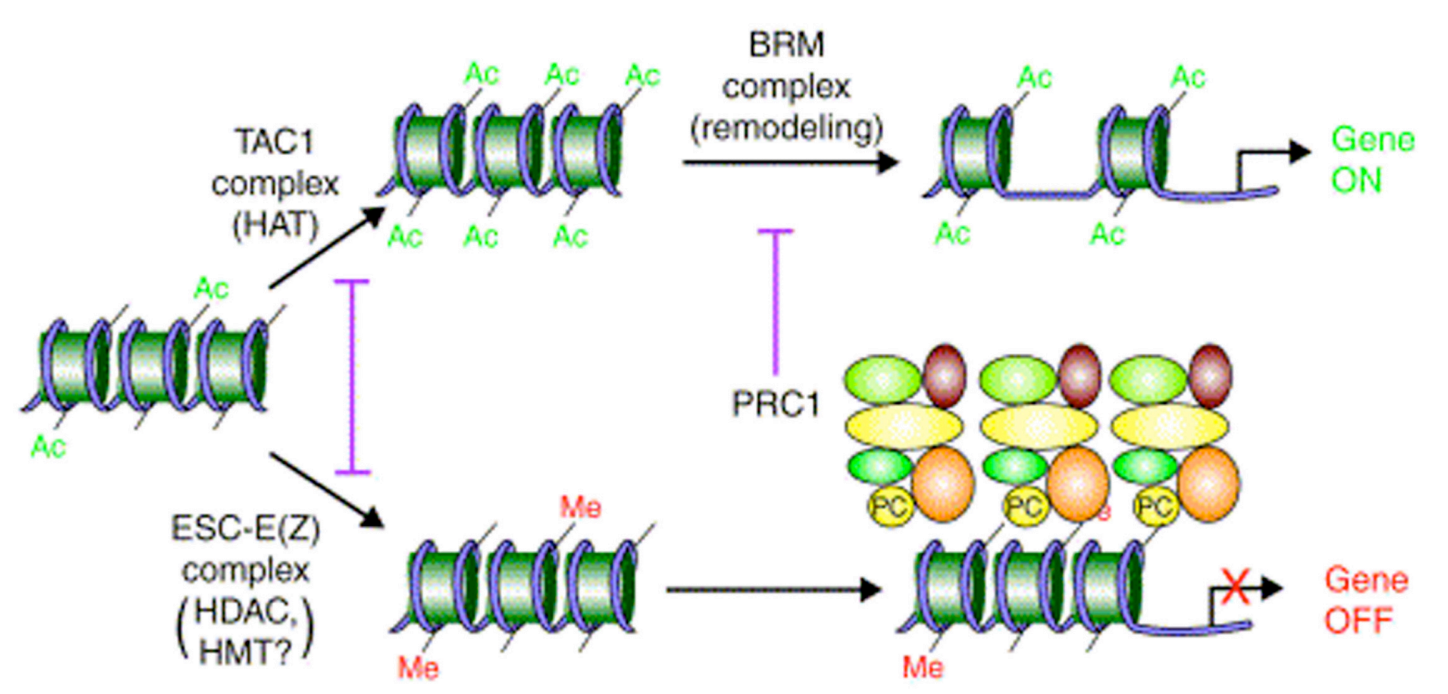

Figure 1-12: Model for multistep mechanisms of trxG and $P c G$ chromatin complexes. The cartoon depicts a nucleosome array at a target Hox gene under trxG/PcG control. The activating pathway through trxG is shown at the top and the alternative repressive pathway mediated by PcG is shown below. "Ac" represents acetylation on histone tails and "Me" represents methylation. In the model, 
TAC1 acetylates nucleosomes and ESC-E(Z) deacetylates. "HMT?" indicates the possibility that ESC$\mathrm{E}(\mathrm{Z})$ might also harbor or recruit a histone methyltransferase. Distinct histone codes created in the first step then help attract either the BRM complex (trxG pathway) or PRC1 (PcG pathway), whose actions produce the indicated Hox gene transcription outcomes (For further explanation, see body text). Vertical purple bars indicate opposing effects of complexes at each step (Simon and Tamkun, 2002).

Together, the maintenance of Hox/HOM-C gene transcription state by trithorax or Polycomb complexes is accomplished through multistep mechanisms that involve nucleosome modification and chromatin remodeling (Fig. 1-12).

\subsection{Aims of the Work}

Growth and patterning are two major themes in embryogenesis. Embryonic patterning has to be strictly coordinated with cell cycle in order to guarantee correct timing and allocation of cells as well as structures during development. Geminin is a bifunctional protein, which is involved in both cell cycle regulation and embryonic development. On one hand, it directly binds to Cdt1 thereby inhibits DNA rereplication from early $\mathrm{S}$ phase to the end of mitosis. On the other hand, it is also functional in neuralization and eye development. The aim of my work is to investigate further roles of Geminin in embryonic development especially in patterning, then to understand the relationship between Geminin as a cell cycle regulator and as a developmental controller, that is, how Geminin coordinates cell cycle and embryonic development. 


\section{Materials and Methods}

\subsection{Isolation of Nucleic Acids}

\subsubsection{Plasmid DNA Isolation from $E$. coli}

E. coli containing a certain plasmid were inoculated into $3.5 \mathrm{ml}$ (Miniprep) or 90 ml (Maxiprep) LB Standard Medium (1\% Bacto-Tryptone (Gibco BRL), 0.5\% BactoYeast Extract (Gibco BRL), $1 \% \mathrm{NaCl}$ in Millipore water) with $50 \mu \mathrm{g} / \mathrm{ml}$ ampicillin or kanamycin, and incubated at $37^{\circ} \mathrm{C}$ shaking for 16 hours. Then, the plasmid was extracted using Plasmid Mini or Maxi Kit (Qiagen) as described by the manufacturer and the concentration was measured using a BioPhotometer (Eppendorf). For cell transfection or embryo electroporation, the maxiprep DNA should be further extracted with 1 volume of phenol/chloroform/isoamylalcohol $(25: 24: 1)$ once or twice, followed by 13,500 rpm centrifugation using Centrifuge C5417 (Eppendorf) for 2 minutes. The supernatant was carefully collected and subjected to 1 volume of chloroform extraction once, again followed by centrifugation and supernatant collection. Then, the DNA was precipitated with $0.7-1$ volume of isopropanol and 0.1 volume of $3 \mathrm{M} \mathrm{NaAc}, \mathrm{pH} 5.2$ at $-20{ }^{\circ} \mathrm{C}$ for 15 minutes. Afterwards, the DNA was pelleted by centrifugation at 13,500 rpm for 15 minutes, washed with $300 \mu 170 \%$ ethanol, centrifuged at 13,500 rpm for another 5 minutes, air dried, and dissolved in a proper volume of Millipore $\mathrm{H}_{2} \mathrm{O}$.

\subsubsection{Genomic DNA Extraction from Mammalian Cells or Mouse Tissue}

The cultured mammalian cells in an $8.5 \mathrm{~cm}$ dish were trypsinized and washed with PBS twice. Then, the cell pellet was resuspended in $1 \mathrm{ml}$ Cell Lysis Buffer (100 mM Tris, $\mathrm{pH}$ 8.0, $200 \mathrm{mM} \mathrm{NaCl}, 5 \mathrm{mM}$ EDTA, 0.2\% SDS, freshly added $100 \mu \mathrm{g} / \mathrm{ml}$ Proteinase K) and incubated at $50{ }^{\circ} \mathrm{C}$ shaking for 6 hours. Then, the lysis product was extracted with 1 volume of phenol/chloroform/isoamylalcohol (25:24:1) twice, and precipitated with 1 volume of isopropanol plus 0.1 volume of $3 \mathrm{M} \mathrm{NaAc}, \mathrm{pH}$ 5.2. The precipitated pellet was washed with $500 \mu 170 \%$ ethanol, air dried, and dissolved in 50 $\mu 1$ Millipore $\mathrm{H}_{2} \mathrm{O}$.

The mouse tissue was washed once with PBS before digestion in $500 \mu 1$ Tissue Lysis Buffer (100 mM Tris, pH 8.5, $200 \mathrm{mM} \mathrm{NaCl,} 5 \mathrm{mM}$ EDTA, 0.2\% SDS, freshly 
added $250 \mu \mathrm{g} / \mathrm{ml}$ Proteinase $\mathrm{K}$ ) at $55^{\circ} \mathrm{C}$ shaking overnight. Then, the treatments were the same as described above in mammalian cells.

\subsubsection{DNA Electrophoresis and Purification from Agarose Gel}

$0.5-2 \%$ agarose gel was prepared by melting agarose (Invitrogen) in 1×TBE Buffer (90 mM Tris-borate, 2 mM EDTA, pH 8.0) and subsequently adding ethidium bromide to a final concentration of $0.3 \mu \mathrm{g} / \mathrm{ml}$. DNA sample was mixed with $5 \times \mathrm{DNA}$ Loading Buffer (25\% Ficoll, $100 \mathrm{mM}$ EDTA, 0.05\% Bromophenol Blue), and electrophoresis was performed under $1-7 \mathrm{~V} / \mathrm{cm}$ in $1 \times \mathrm{TBE}$ buffer. For fragment purification, the band cut down was put into a small dialyse membrane pocket with $500 \mu 10.5 \times$ TBE buffer. Then, the gel in the sealed pocket underwent electroelution in $0.5 \times \mathrm{TBE}$ buffer under $7.5 \mathrm{~V} / \mathrm{cm}$ for 20 minutes, followed by 20 seconds with opposite polarity of electricity. After that the eluted DNA solution in the pocket was collected, $500 \mu 10.5 \times$ TBE buffer was used to wash the pocket and merged with 500 $\mu l$ elution. This $1 \mathrm{ml}$ solution was extracted by phenol/chloroform/isoamylalcohol (25:24:1) once, precipitated with isopropanol plus $3 \mathrm{M} \mathrm{NaAc}$ plus $1 \mu 110 \mathrm{mg} / \mathrm{ml}$ glycogen, and washed with $70 \%$ ethanol as described above. The dried pellet was finally dissolved in $15 \mu \mathrm{l} \mathrm{H}_{2} \mathrm{O}$.

\subsubsection{Total RNA Isolation from Eukaryotic Cells or Embryos}

Total RNA from cultured cells or mouse embryos was isolated using RNeasy Mini Kit (Qiagen) as described by the manufacturer.

\subsubsection{Labeled Nucleic Acids Purification}

The labeled nucleic acids were purified using ProbeQuant G-50 Sephadex Micro Column (Amersham) (Tab. 2-1).

1. Resuspend the resin in the column by vortexing.

2. Loosen the cap one-fourth turn and snap off the bottom closure of the column.

3. Place the column in a $1.5 \mathrm{ml}$ screw-cap microcentrifuge tube for support, and prespin the column at $770 \times \mathrm{g}$ for 1 minute to generate the sample-loading surface.

4. Place the column in a new $1.5 \mathrm{ml}$ tube and slowly apply $50 \mu 1$ labeling reaction 
product $\left(20 \mu \mathrm{l}\right.$ labeling reaction plus $\left.30 \mu \mathrm{l} \mathrm{H}_{2} \mathrm{O}\right)$ to the loading surface.

5. Spin the column at $770 \times \mathrm{g}$ for 2 minutes, and the purified sample was collected in the support tube.

Tabel 2-1: Purification of labeled nucleic acids using ProbeQuant G-50 Sephadex Micro Column.

\subsection{Modifications and Manipulations of Nucleic Acids}

\subsubsection{DNA Digestion with Restriction Enzymes}

For DNA analysis, 200-500 ng DNA was digested with 5-10 U restriction enzymes by treating with $800 \mathrm{~W}$ microwave for 12 seconds twice, then incubating at $37^{\circ} \mathrm{C}$ for 10 minutes. For DNA preparation, 1-10 $\mu \mathrm{g}$ DNA was incubated with 20-80 U restriction enzymes at $37{ }^{\circ} \mathrm{C}$ for 4 hours. For end-cutting of PCR product, crude PCR product was purified with PCR Purification Kit (Qiagen) and then incubated with 30$60 \mathrm{U}$ restriction enzymes at $37^{\circ} \mathrm{C}$ overnight.

\subsubsection{Dephosphorylating or Blunting the Ends of DNA Fragment}

5 '-ends of DNA fragment dephosphorylation was performed by directly adding 1 $\mu l$ Alkaline Phophatase (1U/ $\mu 1$, Roche) into the restriction enzyme digestion mixture and incubating at $37^{\circ} \mathrm{C}$ for 1 hour.

DNA polymerase I large fragment (Klenow fragment) (5U/ $\mu 1, \mathrm{NEB})$ was used to fill-in the ends of 5'-overhang DNA fragment. DNA in restriction enzyme NEBuffer supplemented with $33 \mu \mathrm{M}$ dNTPs was incubated with Klenow at a concentration of 1 $\mathrm{U}$ per $\mu \mathrm{g}$ DNA at $25^{\circ} \mathrm{C}$ for 30 minutes.

3'-overhang DNA fragment was sharpened blunt using Pwo DNA Polymerase (5U/ $\mu 1$, Roche), $0.5 \mu 1$ of which was mixed with $5 \mu 1$ 10xconc. PCR Buffer with 20 $\mathrm{mM} \mathrm{MgSO}_{4}$ (Roche), $0.5 \mu 120 \mathrm{mM}$ dNTPs, $4 \mu 1 \mathrm{H}_{2} \mathrm{O}$, and $40 \mu \mathrm{l}$ DNA fragment elution in a total volume of $50 \mu 1$, then incubated at $72{ }^{\circ} \mathrm{C}$ for 15 minutes to achieve the reaction.

\subsubsection{Annealing of Complementary Single-Stranded DNAs}

The annealing mixture contains $5 \mu$ l each of the complementary DNA single strand (0.1 nmol/ $\mu 1, \mathrm{IBA}), 2 \mu 1 \mathrm{10 \times Transcription} \mathrm{Buffer} \mathrm{(Roche),} \mathrm{and} 8 \mu 1 \mathrm{H}_{2} \mathrm{O}$ in a total volume of $20 \mu \mathrm{l}$. This annealing mixture was heated at $95{ }^{\circ} \mathrm{C}$ for 5 minutes and 
slowly cooled down to $25^{\circ} \mathrm{C}$ in an incubator (Eppendorf). Then, this annealed double-stranded DNA fragment can be directly used for ligation after a series of dilutions $(1: 1,1: 100,1: 1000)$.

\subsubsection{Ligation}

25-100 ng purified vector fragment was mixed with 3-10 folds (molecular ratio) of purified insert fragment, $1 \mu 1$ 10×T4 DNA ligase buffer (MBI Fermentas), and $1 \mu 1$ T4 DNA ligase (3 U/ $\mu 1$, MBI Fermentas) in a total volume of $10 \mu 1$. This ligation mixture was incubated at RT for at least 2 hours or overnight.

\subsection{Polymerase Chain Reaction (PCR)}

\subsubsection{Standard and Genomic PCRs}

The TaKaRa LA Tag system (TaKaRa) was used for standard and genomic PCR. In this system, primers should be 22-26 nucleotides with Tm higher than $68{ }^{\circ} \mathrm{C}$. The reaction mixture contains $1 \mu 1$ template DNA (10pg-1ng plasmid DNA, or $200 \mathrm{ng}$ genomic DNA), $1 \mu 110 \mathrm{pmol} / \mu 1$ forward primer, $1 \mu 110 \mathrm{pmol} / \mu 1$ reverse primer, $5 \mu 1$ 10×LA PCR Buffer, $5 \mu 125 \mathrm{mM} \mathrm{MgCl} 2,4-8 \mu 12.5 \mathrm{mM}$ dNTPs, and 0.5 $\mu 1$ LA Tag Polymerase $(5 \mathrm{U} / \mu \mathrm{l})$ in a total volume of $50 \mu \mathrm{l}$. The thermocycling program (Tab. 2-2) was carried out using Mastercycler Gradient (Eppendorf). If the PCR product will be directly inserted into pGEM-T Easy T/A vector (Promega) or pCRII-TOPO vector (Invitrogen), $1 \mu 1$ Tag polymerase (Gene Craft) was added into the reaction mixture immediately after the Step 5 final elongation and incubated at $72{ }^{\circ} \mathrm{C}$ for 30 minutes.

\begin{tabular}{l|l|l}
\hline \hline Step & Temperature & Duration \\
\hline 1. Initial Denaturation & $94{ }^{\circ} \mathrm{C}$ & 1 minute \\
\hline 2. Denaturation & $98^{\circ} \mathrm{C}$ & 10 seconds \\
\hline 3. Annealing and Elongation & $68^{\circ} \mathrm{C}$ & $1-10$ minutes (about 1 minute $/ \mathrm{kb})$ \\
\hline 4. Go to Step 2, Repeat 29 to 39 times $(30-40$ cycles $)$ \\
\hline 5. Final Elongation & $72{ }^{\circ} \mathrm{C}$ & $3-15$ minutes \\
\hline \hline
\end{tabular}

Tabel 2-2: The thermocycling program for genomic PCR using LA Tag system. 


\subsubsection{RT-PCR}

The One-Step RT-PCR Kit (Qiagen) was used to carry out RT-PCR thermocycling program (Tab. 2-3), in which the reaction mixture contains $1 \mu 1$ Total RNA (0.1-0.5 $\mu \mathrm{g} / \mu \mathrm{l}), 3 \mu \mathrm{l} 10 \mathrm{pmol} / \mu \mathrm{l}$ forward primer, $3 \mu \mathrm{l} 10 \mathrm{pmol} / \mu \mathrm{l}$ reverse primer, $10 \mu \mathrm{l} 5 \times$ OneStep RT-PCR Buffer, $2 \mu 110$ mM dNTPs, $2 \mu 1$ Enzyme Mix (Reverse Transcriptase plus Tag Polymerase), and $29 \mu 1 \mathrm{RNase}-$ free $\mathrm{H}_{2} \mathrm{O}$ to a total volume of $50 \mu 1$.

\begin{tabular}{l|l|l}
\hline \hline Step & Temperature & Duration \\
\hline 1. Reverse Transcription & $50{ }^{\circ} \mathrm{C}$ & 30 minutes \\
\hline 2. Reverse Transcriptase Inactivation & $95{ }^{\circ} \mathrm{C}$ & 15 minutes \\
\hline 3. Denaturation & $94{ }^{\circ} \mathrm{C}$ & 30 seconds \\
\hline 4. Annealing & $55-65{ }^{\circ} \mathrm{C}$ & 45 seconds \\
\hline 5. Elongation & $72{ }^{\circ} \mathrm{C}$ & $\begin{array}{l}0.5-3 \text { minutes (about } 1 \\
\text { minute/kb) }\end{array}$ \\
\hline 6. Go to Step 3, Repeat 29-39 times $(30-40 \mathrm{cycles})$ & $72{ }^{\circ} \mathrm{C}$ & $3-10$ minutes \\
\hline 7. Final Elongation & \multicolumn{2}{|l}{} \\
\hline \hline
\end{tabular}

Tabel 2-3: The thermocycling program for one-step RT-PCR.

\subsubsection{Detection and Purification of PCR Product}

$5 \mu 1$ crude PCR product was loaded on the agarose gel and analyzed by electrophoresis. The left $45 \mu 1$ PCR product can be purified by using PCR Purification Kit (Qiagen) as described by the manufacturer.

\subsection{Transformation of $E$. coli}

\subsubsection{Preparation of Electrocompetent Cells}

Preparation of electrocompetent cells was performed as described below (Tab. 2-4)

\footnotetext{
1. Inoculate two single colonies of E. coli (DH5 $\alpha$ ) into $2 \times 10 \mathrm{ml} \mathrm{LB}$ medium and cultured at $37^{\circ} \mathrm{C}$ shaking overnight $(250 \mathrm{rpm})$.

2. Inoculate the $2 \times 10 \mathrm{ml}$ overnight cultures into $2 \times 1$ liter prewarmed LB medium and culture them at $37{ }^{\circ} \mathrm{C}$ shaking until the O.D.600 reached 0.6-0.8 (about 3
} 
hours).

3. Chill the cells on ice for 10-30 minutes.

4. Centrifuge at 5,000 rpm at $4{ }^{\circ} \mathrm{C}$ for 20 minutes to harvest the cells.

5. Discard the supernatant, wash each pellet from 1 liter culture with 1 liter prechilled water (1:1 wash), then centrifuge at $5,000 \mathrm{rpm}$ at $4{ }^{\circ} \mathrm{C}$ for 20 minutes.

6. Discard the supernatant, wash each pellet with $100 \mathrm{ml}$ prechilled $10 \%$ glycerol (1:10 wash), then centrifuge at $6,000 \mathrm{rpm}$ (Sorvall HS-4 rotor) at $4{ }^{\circ} \mathrm{C}$ for 10 minutes.

7. Discard the supernatant, wash each pellet with $20 \mathrm{ml}$ prechilled $10 \%$ glycerol (1:50 wash), then centrifuge at $6,000 \mathrm{rpm}$ at $4{ }^{\circ} \mathrm{C}$ for 10 minutes.

8. Discard the supernatant, wash each pellet with $2 \mathrm{ml}$ prechilled $10 \%$ glycerol (1:500 wash), then centrifuge at $6,000 \mathrm{rpm}$ at $4{ }^{\circ} \mathrm{C}$ for 5 minutes.

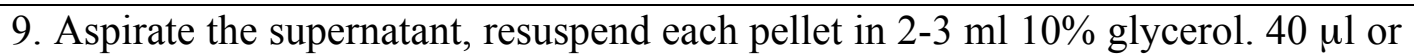
$80 \mu \mathrm{l}$ resuspension was aliquoted into each tube on ice, frozen in liquid nitrogen, and stored at $-80{ }^{\circ} \mathrm{C}$.

Tabel 2-4: Preparation of electrocompetent $E$. coli cells.

\subsubsection{Preparation of Competent Cells for Heat Shock Transformation}

The competent cells for heat shock transformation were prepared as described below (Tab. 2-5)

1. Inoculate a single colony of E. coli (DH5 $\alpha$ or XL-1 Blue) into $50 \mathrm{ml} \mathrm{LB}$ medium and cultured at $37^{\circ} \mathrm{C}$ shaking overnight (250 rpm).

2. Transfer $4 \mathrm{ml}$ of the overnight culture into $400 \mathrm{ml} \mathrm{LB}$ medium and incubate at $37^{\circ} \mathrm{C}$ shaking to an O.D.600 of 0.35-0.4.

3. Aliquot the culture into eight $50 \mathrm{ml}$ prechilled sterile polypropylene tubes (BD Falcon), and incubate them on ice for 5-10 minutes.

4. Centrifuge at $1,600 \times \mathrm{g}(3,000 \mathrm{rpm}$, Sorvall HS-4 rotor $)$ at $4{ }^{\circ} \mathrm{C}$ for 7 minutes.

5. Discard the supernatants, gently resuspend each pellet in $10 \mathrm{ml}$ prechilled $\mathrm{CaCl}_{2}$ solution (60 mM CaCl $2,15 \%$ glycerol, $10 \mathrm{mM}$ PIPES, $\mathrm{pH} 7.0$ ), and centrifuge at $1,100 \times \mathrm{g}$ at $4{ }^{\circ} \mathrm{C}$ for 5 minutes. 
6. Discard the supernatants, resuspend each pellet in another $10 \mathrm{ml}$ prechilled $\mathrm{CaCl}_{2}$ solution, and incubate them on ice for 30 minutes.

7. Centrifuge at $1,100 \times \mathrm{g}$ at $4{ }^{\circ} \mathrm{C}$ for 5 minutes.

8. Discard the supernatants, and resuspend each pellet completely in $2 \mathrm{ml}$ prechilled $\mathrm{CaCl}_{2}$ solution.

9. Aliquot $200 \mu 1$ into each tube on ice, freeze immediately in liquid nitrogen, and store them at $-80{ }^{\circ} \mathrm{C}$.

Tabel 2-5: Preparation of chemical competent $E$. coli cells.

\subsubsection{Transformation of $E$. coli by Electroporation}

$40 \mu \mathrm{l}$ competent cells were thawed on ice and transferred into a prechilled $0.1 \mathrm{~cm}$ electrode Gene Pulser Cuvette (Bio-Rad). $1 \mu 1$ DNA solution $(1 \mathrm{ng} / \mu \mathrm{l})$ or $1.5 \mu 1$ ligation product was added directly into the competent cells and mixed well by gently flicking. Then, the surface of the cuvette was completely dried and the electroporation was performed using Gene Pulser (Bio-Rad) under the condition of $1.8 \mathrm{kV}$ voltage, $200 \Omega$ resistance, $25 \mu \mathrm{F}$ capacitance. Afterwards, $960 \mu 1$ prewarmed LB medium was immediately supplied to the electroporated E. coli for recovery. The cells were recovered at $37{ }^{\circ} \mathrm{C}$ rotating for 1 hour, followed by plating $100 \mu 1$ and $900 \mu 1$ on separate plates.

\subsubsection{Transformation of $E$. coli by Heat Shock}

50-100 $\mu \mathrm{l}$ competent cells were thawed on ice and transferred into a Falcon 2059 polypropylene tube (BD Falcon). $10 \mathrm{ng}$ pure DNA or $10 \mu \mathrm{l}$ ligation product was directly added into the competent cells and mixed well by gently flicking. The mixture was incubated on ice for 30 minutes, heat shocked at $42{ }^{\circ} \mathrm{C}$ for 45 seconds, and incubated on ice for another 2 minutes. Then, $900 \mu 1$ prewarmed LB or SOC medium (Invitrogen) was supplied to the heat shocked cells, and incubated at $37^{\circ} \mathrm{C}$ rotating for 1 hour. The recovered cells were subsequently spun down at 3,000 rpm for 2 minutes, resuspended in $200 \mu 1$ medium and plated.

\subsection{Protein Purification and Analysis}

\subsubsection{GST-Fused Recombinant Protein Expression and Purification}


GST-fused recombinant protein was expressed in E. coli and purified as described below (Tab. 2-6)

1. Mouse Geminin cDNA was inserted into pGEX-KG vector (Amersham) between BamHI and HindIII sites in frame with GST.

2. Heat shock transform the pGEX-KG-Geminin construct into BL21 DE3 C41 competent cells. Inoculate a single colony into $100 \mathrm{ml} \mathrm{LB}$ medium with $50 \mu \mathrm{g} / \mathrm{ml}$ ampicillin, and culture at $37^{\circ} \mathrm{C}$ shaking overnight.

3. Add prewarmed LB medium with $50 \mu \mathrm{g} / \mathrm{ml}$ ampicillin into the $100 \mathrm{ml}$ overnight culture up to 1 liter, and continuously incubate at $37^{\circ} \mathrm{C}$ shaking to an O.D.600 of 0.7-0.8 (about 1 hour).

4. Add IPTG to a final concentration of $1 \mathrm{mM}$ to induce the protein expression at $25^{\circ} \mathrm{C}$ shaking for 6 hours (or at $37^{\circ} \mathrm{C}$ shaking for 2 hours).

5. Centrifuge at $5,000 \mathrm{rpm}$ at $4{ }^{\circ} \mathrm{C}$ for 25 minutes to harvest the cells.

6. Briefly discard the supernatant, resuspend the pellet with the remaining medium, and transfer the resuspension into a $50 \mathrm{ml}$ Falcon tube.

7. Centrifuge at $4,000 \mathrm{rpm}$ at $4{ }^{\circ} \mathrm{C}$ for 30 minutes. Discard the supernatant and freeze the pellet at $-20{ }^{\circ} \mathrm{C}$ overnight.

8. Resuspend the pellet with $40 \mathrm{ml}$ resuspension buffer $(50 \mathrm{mM}$ Tris, $\mathrm{pH} 7.5,500$ $\mathrm{mM} \mathrm{NaCl}, 2 \mathrm{mM}$ EDTA, freshly added protease inhibitor tablet (Roche)) on ice.

9. Sonicate the resuspension on ice for $5 \times 1$ minute with $1 \mathrm{~cm}$ tip using Cell Disruptor B15 (Branson Sonifier) under the condition of Output Option 7 and 50 $\%$ Duty Cycle.

10. Ultracentrifuge in a vacuum environment at $25,000 \mathrm{rpm}$ at $4{ }^{\circ} \mathrm{C}$ for 25 minutes using L7 Ultracentrifuge (Beckman).

11. Collect the supernatant, add $500 \mu \mathrm{l}$ prewashed Glutathione Sepharose 4B (Amersham), and incubate at $4{ }^{\circ} \mathrm{C}$ rotating for at least 1 hour.

12. Centrifuge at $800 \mathrm{rpm}$ at $4{ }^{\circ} \mathrm{C}$ for 1 minute and discard the supernatant.

13. Wash with $15 \mathrm{ml}$ prechilled washing buffer (50 mM Tris, $\mathrm{pH} 7.5,1000 \mathrm{mM}$ $\mathrm{NaCl}, 2 \mathrm{mM}$ EDTA, freshly added protease inhibitor) twice. Centrifuge at $800 \mathrm{rpm}$ at $4{ }^{\circ} \mathrm{C}$ for 1 minute and discard the supernatant in between.

14. Resuspend the beads with $5 \mathrm{ml}$ washing buffer and transfer them into a $5 \mathrm{ml}$ 
column (Pierce). Flow through the buffer and wash the beads in the column once more with $4 \mathrm{ml}$ washing buffer.

15. Elute the GST-Geminin fusion protein by incubating the beads with $1.2 \mathrm{ml} 20$ $\mathrm{mM}$ Glutathione (Sigma) at $4{ }^{\circ} \mathrm{C}$ rotating for 1 hour. Collect the elution.

16. Further elute the protein from the beads with another $2 \mathrm{ml} 20 \mathrm{mM}$ Glutathione at $4{ }^{\circ} \mathrm{C}$ rotating for another 1 hour. Collect the elution.

17. Measure the protein concentration with Bradford Assay (Bio-Rad), in which 1 $\mu \mathrm{l}$ of protein elution was mixed with $800 \mu 1 \mathrm{H}_{2} \mathrm{O}$ and $200 \mu \mathrm{l}$ Bradford Reagent was added. Then, the O.D.595 of the sample was measured and the concentration of protein was determined according to the standard curve (Fig. 2-1).

18. Aliquot the purified protein, freeze them in liquid nitrogen and store at $-80{ }^{\circ} \mathrm{C}$.

Tabel 2-6: Expression and purification of GST-fused recombinant protein from E. coli.

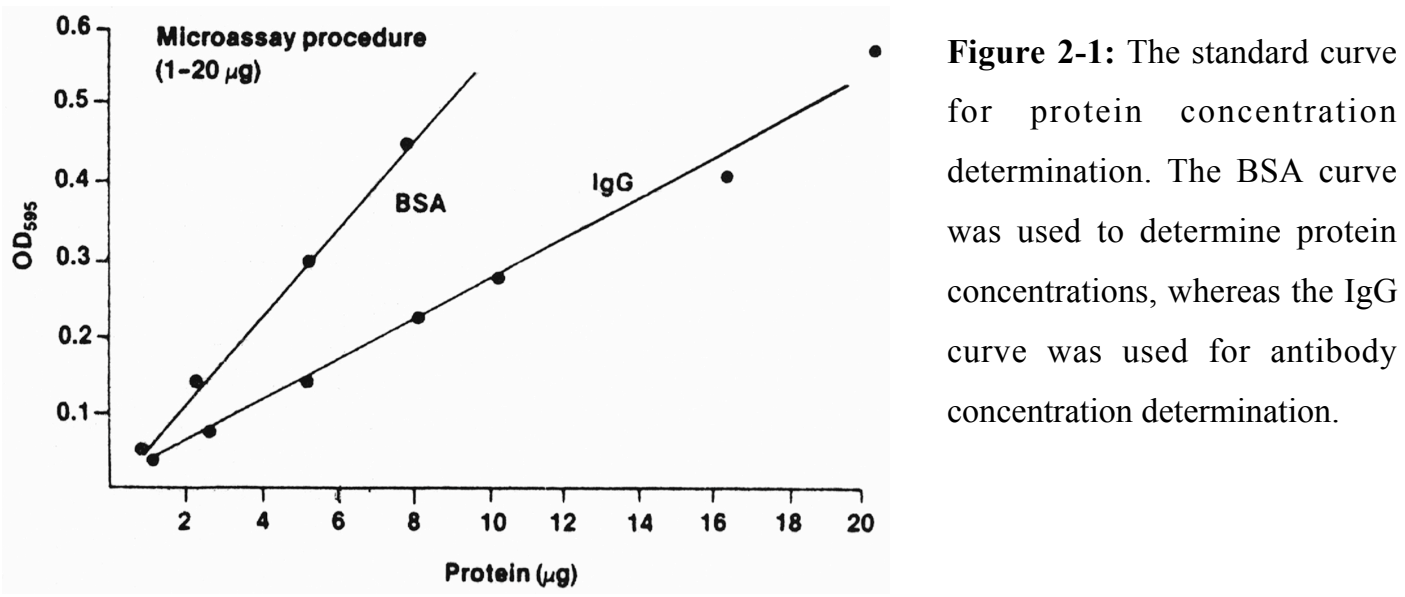

\subsubsection{His-Tagged Recombinant Protein Expression and Purification}

His-tagged recombinant protein was expressed in E. coli and purified as described below (Tab. 2-7).

1. Mouse Geminin cDNA was inserted into pQE30 vector (Qiagen) between BamHI and HindIII sites in frame with N-terminal His-tag.

2. Heat shock transform the pQE30-Geminin construct into XL-1 Blue competent cells. Inoculate a single colony into $100 \mathrm{ml} \mathrm{LB}$ medium with $50 \mu \mathrm{g} / \mathrm{ml}$ ampicillin, 
and culture at $37^{\circ} \mathrm{C}$ shaking overnight.

3. Add prewarmed LB medium with $50 \mu \mathrm{g} / \mathrm{ml}$ ampicillin into the $100 \mathrm{ml}$ overnight culture up to 1 liter, and continuously incubate at $37{ }^{\circ} \mathrm{C}$ shaking to an O.D.600 of 0.7-0.8 (about 1 hour).

4. Add IPTG to a final concentration of $1 \mathrm{mM}$ to induce the protein expression at $25^{\circ} \mathrm{C}$ shaking for 6 hours (or at $37^{\circ} \mathrm{C}$ shaking for 2 hours).

5. Centrifuge at 5,000 rpm at $4{ }^{\circ} \mathrm{C}$ for 25 minutes to harvest the cells.

6. Briefly discard the supernatant, resuspend the pellet with the remaining medium, and transfer the resuspension into a $50 \mathrm{ml}$ Falcon tube.

7. Centrifuge at $4,000 \mathrm{rpm}$ at $4{ }^{\circ} \mathrm{C}$ for 30 minutes. Discard the supernatant and freeze the pellet at $-20{ }^{\circ} \mathrm{C}$ overnight.

8. Resuspend the pellet with $40 \mathrm{ml}$ resuspension buffer $\left(50 \mathrm{mM} \mathrm{NaH} \mathrm{PO}_{4}\right.$ $\mathrm{Na}_{2} \mathrm{HPO}_{4}$, pH 8.0, $300 \mathrm{mM} \mathrm{NaCl}, 10 \mathrm{mM}$ imidazole, 10\% glycerol, freshly added protease inhibitor) on ice.

9. Sonicate the resuspension on ice for $5 \times 1$ minute with $1 \mathrm{~cm}$ tip using Cell Disruptor B15 under the condition of Output Option 7 and $50 \%$ Duty Cycle.

10. Ultracentrifuge in a vacuum environment at $25,000 \mathrm{rpm}$ at $4{ }^{\circ} \mathrm{C}$ for 25 minutes using L7 Ultracentrifuge.

11. Collect the supernatant, add $1 \mathrm{ml}$ prewashed Ni-NTA beads (Qiagen), and incubate at $4{ }^{\circ} \mathrm{C}$ rotating for at least 1 hour.

12. Centrifuge at $800 \mathrm{rpm}$ at $4{ }^{\circ} \mathrm{C}$ for 1 minute and discard the supernatant.

13. Wash with $15 \mathrm{ml}$ prechilled washing buffer $\left(50 \mathrm{mM} \mathrm{NaH}{ }_{2} \mathrm{PO}_{4}-\mathrm{Na}_{2} \mathrm{HPO}_{4}, \mathrm{pH}\right.$ 8.0, $300 \mathrm{mM} \mathrm{NaCl}, 20 \mathrm{mM}$ imidazole, $10 \%$ glycerol, freshly added protease inhibitor) twice. Centrifuge at $800 \mathrm{rpm}$ at $4{ }^{\circ} \mathrm{C}$ for 1 minute and discard the supernatant in between.

14. Resuspend the beads with $5 \mathrm{ml}$ washing buffer and transfer them into a $5 \mathrm{ml}$ column. Flow through the buffer and wash the beads in the column once more with $4 \mathrm{ml}$ washing buffer.

15. Elute the protein with $2.5 \mathrm{ml} 250 \mathrm{mM}$ imidazole in washing buffer, collect the flow through immediately with $500 \mu 1$ per tube.

16. Measure the protein concentration with Bradford Assay, in which $2 \mu 1$ of protein elution was mixed with $800 \mu \mathrm{H}_{2} \mathrm{O}$ and $200 \mu \mathrm{l}$ Bradford Reagent was 
added. Then, the O.D.595 of the sample was measured and the concentration of protein was determined according to the standard curve (Fig. 2-1).

17. Aliquot the purified protein, freeze them in liquid nitrogen and store at $-80{ }^{\circ} \mathrm{C}$.

Tabel 2-7: Expression and purification of His-tagged recombinant protein from E. coli.

\subsubsection{Total Protein Extraction from Mouse Embryos}

11.5 d.p.c. mouse embryos were dissected out from the uterus in PBS, and solubilized in $500 \mu 1 /$ embryo lysis buffer 1 (20 mM Tris, pH 7.5, $100 \mathrm{mM} \mathrm{KCl,} 2 \mathrm{mM}$ EDTA, 1\% Triton X-100, $1 \mathrm{mM} \beta$-mecaptoethanol, freshly added protease inhibitor) on ice, using glass homogenizer. The solubilized embryo extracts were centrifuged at 13,000 rpm at $4{ }^{\circ} \mathrm{C}$ for 15 minutes, and the supernatant was collected. The protein concentration of the soluble extracts was measure at absorbance of $280 \mathrm{~nm}$ by BioPhotometer (Eppendorf) and normalized by BSA standards. The total protein extracts were aliquoted, frozen in liquid nitrogen, and stored at $-80{ }^{\circ} \mathrm{C}$.

Alternatively, mouse embryos were homogenized briefly with pipette, and sonicated on ice with continuous pulses for $3-4 \times 10$ seconds in $400 \mu 1 /$ embryo lysis buffer 2 (20 mM HEPES, pH 7.85, 30 mM NaCl, 10\% glycerol, 0.2 mM EDTA, 1 $\mathrm{mM}$ DTT, and freshly added protease inhibitor) using Cell Disruptor B15 and $3 \mathrm{~mm}$ tip. The following treatment was the same with using glass homogenizer.

\subsubsection{In Vitro Transcription/Translation}

For in vitro transcription/translation, cDNA fragment with single ATG was cloned into pSP64 or pSP65 vector (Promega) and maxipreped. The assay was performed using TNT Reticulocyte Lysate System (Promega). The reaction mixture containing 2 $\mu \mathrm{g}$ maxiprep DNA, $4 \mu \mathrm{l}$ TNT reaction buffer, $2 \mu 1$ amino acids mixture without methionine, $4 \mu 1\left[{ }^{35} \mathrm{~S}\right]$-methionine, $1.5 \mu 1$ RNasin, $1.5 \mu 1$ TNT SP6 RNA polymerase, $50 \mu \mathrm{l}$ reticulocyte lysate, and proper volume of DEPC treated $\mathrm{H}_{2} \mathrm{O}$ in a total volume of $100 \mu \mathrm{l}$ was mixed well by flicking and incubated at $30{ }^{\circ} \mathrm{C}$ for 2 hours.

\subsubsection{Protein Gel Electrophoresis}

SDS-polyacrylamide gels were prepared with protein gel preparation system (BioRad). 12\% separating gel and 6\% stacking gel (Tab. 2-8) were applied to detect 
proteins smaller than $50 \mathrm{kDa}$, while 10\% separating gel and 5\% stacking gel (Tab. 28) were used to analyze proteins larger than $50 \mathrm{kDa}$. A protein sample was mixed with the same volume of $2 \times$ SDS loading buffer (125 mM Tris, pH 6.8, 20\% glycerol, $0.02 \%$ bromophenol blue, $2 \% \beta$-mercaptoethanol, $4 \%$ SDS), and heated at $95{ }^{\circ} \mathrm{C}$ for 5 minutes or in boiling water for 3 minutes. A maximum of $25 \mu 1$ sample was loaded into the slot and electrophoresis was performed in $1 \times \operatorname{SDS}$ buffer $(25 \mathrm{mM}$ Tris-base, $0.1 \%$ SDS, $192 \mathrm{mM}$ glycine, $\mathrm{pH} 8.75$ ) under $20 \mathrm{~mA} / \mathrm{gel}$, following 30 minutes preelectrophoresis under the same condition. Then, the gel could be subjected to western blotting directly, or fixed in fixation solution ( $45 \%$ methanol, $7.5 \%$ acetate) for 5 minutes and stained with Coomassie blue staining solution $(0.25 \%$ Coomassie brilliant blue R 250, 45\% methanol, $10 \%$ acetate; or $0.1 \%$ Serva R 250, 50\% methanol, $10 \%$ acetate) at RT for 0.5-1 hour. The Coomassie stained gel was subsequently destained with $10 \%$ acetate for several hours or overnight.

\begin{tabular}{l|l|l}
\hline \hline Separating Gel & $10 \%$ & $12 \%$ \\
\hline $1.5 \mathrm{M}$ Tris, $\mathrm{pH} 8.8$ & $7.5 \mathrm{ml}$ & $6 \mathrm{ml}$ \\
\hline $30 \%$ Acrylamide-Bisacrylamide Solution (Roth) & $10 \mathrm{ml}$ & $10 \mathrm{ml}$ \\
\hline $\mathrm{H}_{2} \mathrm{O}$ & $11.9 \mathrm{ml}$ & $7.5 \mathrm{ml}$ \\
\hline $10 \%$ SDS & $300 \mu \mathrm{l}$ & $240 \mu \mathrm{l}$ \\
\hline $10 \%$ APS & $300 \mu \mathrm{l}$ & $240 \mu \mathrm{l}$ \\
\hline TEMED & $15 \mu \mathrm{l}$ & $12 \mu 1$ \\
\hline Total Volume & $30 \mathrm{ml}$ & $24 \mathrm{ml}$ \\
\hline
\end{tabular}

\begin{tabular}{l|l|l}
\hline Stacking Gel & $5 \%$ & $6 \%$ \\
\hline $1 \mathrm{M}$ Tris, pH 6.8 & $1.5 \mathrm{ml}$ & $1.25 \mathrm{ml}$ \\
\hline $30 \%$ Acrylamide-Bisacrylamide Solution & $2 \mathrm{ml}$ & $2 \mathrm{ml}$ \\
\hline $\mathrm{H}_{2} \mathrm{O}$ & $8.25 \mathrm{ml}$ & $6.38 \mathrm{ml}$ \\
\hline $10 \%$ SDS & $120 \mu \mathrm{l}$ & $100 \mu \mathrm{l}$ \\
\hline $10 \%$ APS & $120 \mu \mathrm{l}$ & $100 \mu \mathrm{l}$ \\
\hline TEMED & $15 \mu \mathrm{l}$ & $12 \mu \mathrm{l}$ \\
\hline Total Volume & $12 \mathrm{ml}$ & $10 \mathrm{ml}$ \\
\hline \hline
\end{tabular}

Tabel 2-8: The components of SDS-polyacrylamide gels. 


\subsubsection{Western Blotting}

Western blotting and subsequent immunostaining were performed as described below (Tab. 2-9) using antibodies against Geminin (see 2.5.8), Rae28 (Tomotsune et al., 1999), FGF2 (Chemicon), Cdt1 (Wohlschlegel et al., 2000), Vimentin (Elbashir et al., 2001), or His-tag (Novagen).

1. Cut a Protran Nitrocellulose Transfer Membrane (Schleicher \& Schell BioScience) and 4 pieces of Whatman paper into a similar size to the gel, with the Whatman paper slightly larger. And presock them in blot buffer (48 mM Tris-base, $3.9 \mathrm{mM}$ glycine, $0.037 \%$ SDS, 20\% methanol).

2. Between two double-layered presocked Whatman paper, the SDSpolyacrylamide gel was placed tightly onto a presocked nitrocellulose membrane avoiding any air bubble in between, with the membrane close to the anode and the gel close to the cathode.

3. Press this sandwich including Whatman paper, gel, and membrane tightly together into a clamp. Electroblot was performed in blot buffer using western blotting system (Bio-Rad) under $15 \mathrm{~V}$ overnight or under $30 \mathrm{~V}$ for 1-2 hours with a cooling chamber.

4. Stop the membrane transfer, and stain the membrane with $0.1 \%$ Ponceau $\mathrm{S}$ to check the membrane transfer efficiency.

5. Destain the Ponceau $\mathrm{S}$ with water and then western buffer A (10 mM Tris, $\mathrm{pH}$ $7.4,0.9 \% \mathrm{NaCl}, 0.05 \%$ Tween 20 ).

6. Block the membrane in blocking solution (1-5\% low fat milk powder in western buffer A) at RT for 1 hour, rocking on a rocky machine (Biometra).

7. Dilute the primary antibody 1:100-1:1000 in blocking solution, and incubate at 4 ${ }^{\circ} \mathrm{C}$ shaking overnight (preferred) or at RT rocking for 1-2 hours.

8. Wash with western buffer A at RT rocking for 5-10 minutes.

9. Wash with western buffer $\mathrm{B}(0.9 \% \mathrm{NaCl}, 0.5 \%$ Triton $\mathrm{X}-100,0.1 \%$ SDS, freshly added $0.1 \%$ BSA) twice at RT rocking for 5-10 minutes each.

10. Wash with western buffer A at RT rocking for 5-10 minutes.

11. Incubate the membrane with 1:5000 diluted Horseradish Peroxidase (HRP) conjugated anti-rabbit or mouse IgG secondary antibody (Amersham or Biotrend) in blocking solution at RT rocking for 45 minutes. 
12. Repeat the washing steps 8-10.

13. Mix well $500 \mu 1$ Renaissance Oxidizing Reagent and $500 \mu 1$ Renaissance

Enhanced Luminol Reagent (NEN) as the chemiluminescent substrate for HRP, and equally distribute the mixture onto the membrane. The chemiluminescence was observed by exposing the membrane to a Lumi-Imager (Boehringer Mannheim) for 10 seconds to 20 minutes.

Tabel 2-9: Western blotting onto nitrocellulose membranes and subsequent immunostainings

\subsubsection{N-Terminal Coupling of Protein}

His-Geminin recombinant protein was N-terminally coupled to agarose matrix at 4 ${ }^{\circ} \mathrm{C}$ using AminoLink Plus Coupling Gel Kit (Pierce) (Tab. 2-10).

1. Dialyse the purified His-Geminin protein against PBS at $4{ }^{\circ} \mathrm{C}$ overnight to exclude ammonia from the protein solution.

2. Resuspend the beads to mix well, take $4 \mathrm{ml}$ ( $3 \mathrm{ml}$ bed volume) into a $15 \mathrm{ml}$ column, and flow through the buffer.

3. Wash the beads with 2.5 volumes $(7.5 \mathrm{ml})$ of coupling buffer, $\mathrm{pH} 7.0$.

4. Incubate the beads with $6 \mathrm{mg}$ His-Geminin recombinant protein in $3 \mathrm{ml}$ coupling buffer at $4{ }^{\circ} \mathrm{C}$ rotating overnight.

5. Add $50 \mu \mathrm{l}$ (about 1/60-1/50 volume) $5 \mathrm{M}$ Sodium Cyanoborohydride $\left(\mathrm{NaCNBH}_{3}\right)$ reduction reagent, and incubate at $4{ }^{\circ} \mathrm{C}$ rotating for 4 hours.

6. Flow through the liquid in the column and collect it. Wash the beads with 2.5 volumes $(7.5 \mathrm{ml})$ of coupling buffer and collect the flow through.

7. Measure the protein concentration of the flow throughs $(1.5 \mathrm{mg}$ in $10 \mathrm{ml})$ and calculate the coupling efficiency (4.5 mg coupled, 75\%).

8 . Wash the protein coupled beads with 2 volumes $(6 \mathrm{ml})$ of quench buffer.

9. Incubate the beads with 1 volume $(3 \mathrm{ml})$ of quench buffer plus $50 \mu 1$ reduction reagent $\left(5 \mathrm{M} \mathrm{NaCNBH}_{3}\right)$ at $4{ }^{\circ} \mathrm{C}$ rotating for 1 hour.

10. Flow through the liquid and wash the beads with 2.5 volumes $(7.5 \mathrm{ml})$ of $0.2 \mathrm{M}$ glycine, $\mathrm{pH} 2.5$.

11. Wash the beads with 2.5 volumes $(7.5 \mathrm{ml})$ of $50 \mathrm{mM}$ Tris, $\mathrm{pH} 7.5$. 
12. Resuspend the protein coupled beads with 1 volume $(3 \mathrm{ml})$ of $50 \mathrm{mM}$ Tris, $\mathrm{pH}$

7.5 and store at $4{ }^{\circ} \mathrm{C}$.

Tabel 2-10: N-terminal coupling of recombinant proteins to agarose matrix.

\subsubsection{Antibody Purification from Crude Serum}

The crude anti-Geminin antiserum was purified by chromatograph at $4{ }^{\circ} \mathrm{C}$ (Tab. 2$11)$, then aliquoted and stored at $-80{ }^{\circ} \mathrm{C}$.

1. Transfer the $4.5 \mathrm{mg} \mathrm{N}$-terminally coupled His-Geminin recombinant protein (7 $\mathrm{ml}$ ) into a $50 \mathrm{ml}$ Falcon tube.

2. Wash the column with $2 \mathrm{ml} 50 \mathrm{mM}$ Tris, $\mathrm{pH} 7.5$ and merge with the beads.

3. Incubate the beads with crude anti-Geminin antiserum at $4{ }^{\circ} \mathrm{C}$ rotating overnight to bind the antibody to the antigen.

4. Transfer the beads together with the serum into a $25 \mathrm{ml}$ column, flow through the serum and collect it.

5. Wash the beads with 10 volumes $(30 \mathrm{ml})$ of western buffer A.

6. Wash the beads with 10 volumes $(30 \mathrm{ml})$ of western buffer B.

7. Wash the beads with 5 volumes $(15 \mathrm{ml})$ of western buffer $\mathrm{A}$.

8. Elute the anti-Geminin antibodies with 3 volumes $(7.5 \mathrm{ml})$ of $200 \mathrm{mM}$ glycine, pH 2.5, collect every $500 \mu$ l elution with tubes containing $75 \mu 11.5 \mathrm{mM}$ Tris, $\mathrm{pH}$ 8.8 .

9. Measure the IgG concentration of each tube by Bradford Assay (Fig. 2-1).

10. Merge the tubes with high IgG concentration and dialyse against 1 liter PBS at $4{ }^{\circ} \mathrm{C}$ overnight. Measure the concentration again and aliquot it.

Tabel 2-11: Antibody purification from crude antiserum using chromatography.

\subsection{Yeast Two-Hybrid Screen}

The yeast two-hybrid screen was performed using ProQuest Two-Hybrid System (Gibco BRL). 


\subsubsection{Constructs for the Two-Hybrid Screen}

The BanII/Pwo-NotI cDNA fragment encoding murine Geminin excised from pCMV3-Geminin eukaryotic expression construct was inserted into the MscI-NotI sites of pDBLeu vector (Gibco BRL) in frame with the GAL4 DNA binding domain. The resulted pDBLeu-Geminin construct was used as bait plasmid in the yeast twohybrid screen.

The cDNA library from 8.5 d.p.c. mouse embryos has been cloned into pPC86 vector (Gibco BRL) in frame with the GAL4 activation domain. $2 \mu 1$ E. coli containing the library DNA was inoculated into $100 \mathrm{ml} \mathrm{LB}$ medium with $50 \mu \mathrm{g} / \mathrm{ml}$ ampicillin and maxipreped.

\subsubsection{Cotransformation Efficiency Evaluation of MaV203 Competent Cells}

The cotransformation efficiency of MaV203 competent cells was evaluated as described below (Tab. 2-12).

1. Thaw the PEG/LiAc (Gibco BRL) solution at RT, mix the solution well before dispensation.

2. Thaw the MaV203 Competent Yeast Cells (Library Scale, Gibco BRL) in a 30

${ }^{\circ} \mathrm{C}$ incubator for 90 seconds (or less). Invert the tube several times immediately, and transfer $100 \mu \mathrm{l}$ into a $1.5 \mathrm{ml}$ eppendorf tube.

3. Add $1 \mu \mathrm{g}$ pDBLeu-Geminin and $1 \mu \mathrm{g}$ pPC86 vector to the competent cells, mix well by flicking the tube.

4. Add $600 \mu 1 \mathrm{PEG} / \mathrm{LiAc}$ solution into the mixture, mix well by inverting the tube until the competent cells are totally homogenous.

5. Incubate in a $30{ }^{\circ} \mathrm{C}$ incubator for 30 minutes, inverting the tube every 10 minutes.

6. Add 35.5 $\mu 1$ DMSO and mix well by inverting the tube.

7. Heat shock the cells at $42{ }^{\circ} \mathrm{C}$ for 20 minutes, inverting the tube occasionally.

8. Centrifuge the tube at 2,000 rpm for 5 seconds and aspirate the supernatant.

9. Resuspend the pellet in $1 \mathrm{ml}$ autoclaved $\mathrm{H}_{2} \mathrm{O}$ and make 1:10, 1:100 and 1:1000 dilutions.

10. Plate $100 \mu \mathrm{l}$ from crude resuspension and each dilution onto the selection 
medium plate SD-L-W (21.36 g SD medium (Clontech), 0.512 g DO-Leu-Trp (Clontech), $17.6 \mathrm{~g}$ Agarose (Gibco BRL) in a total volume of $800 \mathrm{ml}$, autoclaved, $25 \mathrm{ml} /$ dish).

11. Incubate the plate upside down at $30{ }^{\circ} \mathrm{C}$ for 72 hours.

12. After 72 hours incubation $100 \mu 1$ 1:100 dilution generated 10 transformants, which means $1 \mu \mathrm{g}$ DNA can generate $10^{4}$ transformants. For library screen, $1 \mu \mathrm{g}$ DNA should generate at least $10^{5}$ transformants. So, the MaV203 Competent Yeast Cells was not suitable for library screen.

Tabel 2-12: The cotransformation efficiency evaluation of MaV203 yeast competent cells.

\subsubsection{Determination of the 3AT Concentration}

$3 \mathrm{AT}$ was used to inhibit background colonies during the first round of library screen. 2 single yeast colonies each from five control strains A-E (Gibco BRL) as well as yeast cotransformed with pDBLeu-Geminin and pPC86 on SD-L-W plates were patched onto SD-L-W-H plates (8.01 g SD medium, 0.186 g DO-Leu-Trp-His (Clontech), $6.6 \mathrm{~g}$ agarose in a total volume of $300 \mathrm{ml}$, autoclaved, $25 \mathrm{ml} / \mathrm{dish}$ ) supplemented with different concentrations of $3 \mathrm{AT}(0 \mathrm{mM}, 10 \mathrm{mM}, 25 \mathrm{mM}, 50 \mathrm{mM}$, $60 \mathrm{mM}, 75 \mathrm{mM}, 100 \mathrm{mM}$, diluted from $2 \mathrm{M}$ stock). After incubation for 18 hours at $30{ }^{\circ} \mathrm{C}$, the highest $3 \mathrm{AT}$ concentration inhibiting the growth of control strain A and permitting the growths of other control strains was selected for the library screen, which is $60 \mathrm{mM}$.

\subsubsection{Total Protein Extraction from Yeast}

Total proteins of yeast were extracted as described below (Tab. 2-13).

1. Inoculate a single colony into $5 \mathrm{ml}$ proper broth and incubate at $30^{\circ} \mathrm{C}$ shaking overnight.

2. Check the O.D.600 of overnight culture, and apply 5 O.D. yeast cells for protein extraction (If O.D. $600=1.0$, use $5 \mathrm{ml}$ cultured cells; If O.D. ${ }_{600}=2.0$, use $2.5 \mathrm{ml}$ ).

3. Centrifuge at $13,000 \mathrm{rpm}$ for about 10 seconds to pellet the cells.

4. Aspirate the supernatant, resuspend the pellet in $180 \mu 12 \mathrm{M} \mathrm{NaOH}$ containing $5 \% \beta$-mercaptoethanol, and incubate on ice for 10 minutes. 
5. Add $20 \mu 1110 \%$ TCA (w/v) to precipitate the proteins, incubate on ice for 10 minutes.

6. Centrifuge at 13,000 rpm for 1 minute and carefully remove the supernatant.

7. Neutralize the pellet by resuspending it in $100 \mu 11 \mathrm{M}$ Tris, $\mathrm{pH} 11.0$.

8. Centrifuge at $13,000 \mathrm{rpm}$ for 1 minute and carefully remove the supernatant.

9. Resuspend the pellet in $100 \mu 12 \times \operatorname{SDS}$ loading buffer, incubate at $95{ }^{\circ} \mathrm{C}$ for 5 minutes.

10. 5-10 $\mu$ l (0.25-0.5 O.D.) sample was subjected to SDS-polyacrylamide gel electrophoresis and western blotting.

Tabel 2-13: Total protein extraction from yeast cells.

\subsection{5 cDNA Library Screen on Histidine Minus Medium}

The first round of cDNA library screen was performed on plates lacking leucine, tryptophan and histidine, and supplemented with $60 \mathrm{mM} 3 \mathrm{AT}$ as described below (Tab. 2-14).

1. Heat shock transform the MaV203 competent yeast cells with pDBLeu-Geminin as described in 2.6.2, then plate on SD-L medium (8.01 g SD medium, $0.207 \mathrm{~g}$ DO-Leu (Clontech), $6.6 \mathrm{~g}$ agarose, autoclaved, $25 \mathrm{ml} / \mathrm{dish})$ and incubate for 48 hours.

2. Inoculate a single pDBLeu-Geminin transformant into $100 \mathrm{ml}$ SD-L broth, and incubate at $30{ }^{\circ} \mathrm{C}$ overnight.

3. Check the O.D.600 of the SC-L broth inoculated (1:5 dilution: O.D.600 $=0.604$ ).

4. For good competent cells, the O.D.600 of the starting culture in YEPG broth (10 g Yeast extract, 20 g Peptone 140, 20 g D-glucose, $20 \mathrm{mg}$ uracil, $20 \mathrm{mg}$ adenine sulphate in a total volume of 1 liter, autoclaved) should be 0.2-0.3. Thus, centrifuge $20 \mathrm{ml}$ overnight culture at 2,500 rpm for 2 minutes, discard the supernatant and resuspend the pellet in $1 \mathrm{ml}$ YEPG broth. Add $200 \mathrm{ml}$ YEPG broth to the resuspension and check O.D. $600=0.316$. So, add $50 \mathrm{ml}$ more YEPG broth.

5. Incubate at $30^{\circ} \mathrm{C}$ for 4.5 hours shaking. Check O.D. ${ }_{600}=0.647$. (The best range for preparing competent cells and transformation is $0.8-1.0$. For one library scale transformation, we always use $100 \mathrm{ml} 1$ O.D. cells (about $10^{9}$ cells). So, we used 
$200 \mathrm{ml}$ O.D. 0.647 cells).

6. Centrifuge $200 \mathrm{ml}$ culture at 2,500 rpm for 2 minutes, discard the supernatant and wash cells with $10 \mathrm{ml}$ LTS buffer (10 mM Tris, pH 7.4, $1 \mathrm{mM}$ EDTA, 0.1 M LiAc, $1 \mathrm{M} \alpha$-Sorbitol).

7. Centrifuge at 2,500 rpm for 2 minutes, discard the supernatant, resuspend the cells in $1.1 \mathrm{ml}$ LTS buffer, and equally distribute it into 22 tubes with $50 \mu \mathrm{leach}$.

8. Centrifuge at 13,000 rpm for about 10 seconds, and aspirate the supernatants.

9. Add $250 \mu 150 \%$ PEG 4000 (It is better to use PEG 3350), $36 \mu 11 \mathrm{M} \mathrm{LiAc,} 20$ $\mu 12 \mathrm{mg} / \mathrm{ml}$ carrier Salmon Sperm DNA (Stratagene) into each tube.

10. Add $50 \mu \mathrm{l}$ DNA solution containing $5 \mu \mathrm{g}$ maxipreped library DNA into each tube. Then use pipette to destroy the pellet slightly, and mix well by vortexing. 11. Incubate at $30{ }^{\circ} \mathrm{C}$ for 45 minutes, inverting the tubes occasionally.

12. Heat shock at $42{ }^{\circ} \mathrm{C}$ for 20 minutes, inverting the tubes occasionally.

13. Centrifuge at 13,000 rpm for about 10 seconds, and aspirate the supernatants.

14. Wash each pellet with $100 \mu \mathrm{H}_{2} \mathrm{O}$ or TE buffer $(10 \mathrm{mM}$ Tris, $\mathrm{pH} 7.4,1 \mathrm{mM}$ EDTA) without destroying the pellets.

15. Resuspend each cell pellet in $500 \mu \mathrm{l}$ YEPG broth and recover the transformed yeast cells at $30{ }^{\circ} \mathrm{C}$ for 3 hours shaking.

16. Centrifuge at 13,000 rpm for about 10 seconds, aspirate $300 \mu 1$ medium, and resuspend the pellet in the left $200 \mu 1$ medium.

17. Plate each resuspension onto a $15 \mathrm{~cm}$ SD-L-W-H plate supplemented with 60 $\mathrm{mM} 3 \mathrm{AT}\left(40 \mathrm{ml}\right.$ medium per $15 \mathrm{~cm}$ dish). Incubate the plates at $30{ }^{\circ} \mathrm{C}$ for 72 hours.

18. One tube was reserved to check the transformation efficiency before the last centrifugation. $20 \mu \mathrm{l}$ from the $500 \mu \mathrm{l}$ resuspension was diluted 1:10, 1:100, 1:1000, and $200 \mu \mathrm{l}$ of these dilutions were plated onto SD-L-W plates.

Tabel 2-14: The first round of cDNA library screen on histidine minus medium.

\subsection{6 cDNA Library Screen by X-gal assay}

The second round of cDNA library screen, X-gal assay, was performed as described below (Tab. 2-15). 
1. Inoculate 177 positive colonies from the first round of screen onto numbered SD-L-W plates. In the meantime, also inoculate all these colonies onto Nytran nylon transfer membranes (Schleicher\&Schuell BioScience) that were wet and tightly attached to SD-L-W medium. Incubate the inoculated plates at $30{ }^{\circ} \mathrm{C}$ overnight.

2. Proper amount of X-gal (Applichem) was dissolved in $100 \mu 1$ DMFA, and then diluted in $7 \mathrm{ml} \mathrm{Z-Buffer}\left(16.1 \mathrm{~g} \mathrm{Na}_{2} \mathrm{HPO}_{4} \cdot 7 \mathrm{H}_{2} \mathrm{O}\right.$ (or $10.7 \mathrm{~g} \mathrm{Na}_{2} \mathrm{HPO}_{4} \cdot 2 \mathrm{H}_{2} \mathrm{O}$ ), $5.5 \mathrm{~g}$ $\mathrm{NaH}_{2} \mathrm{PO}_{4} \cdot \mathrm{H}_{2} \mathrm{O}, 0.75 \mathrm{~g} \mathrm{KCl}, 0.25 \mathrm{~g} \mathrm{MgSO}_{4} \cdot 7 \mathrm{H}_{2} \mathrm{O}$ in a total volume of 1 liter) to a final concentration of $0.3-1 \mathrm{mg} / \mathrm{ml}$.

3. Distribute the $7 \mathrm{ml} \mathrm{X-gal} \mathrm{in} \mathrm{Z-Buffer} \mathrm{onto} \mathrm{a} \mathrm{Whatman} \mathrm{paper} \mathrm{in} \mathrm{a} 9 \mathrm{~cm}$ dish.

4. Freeze the nylon membrane with yeast colonies inoculated in liquid nitrogen for
1 minute.

5. Place the frozen membrane onto the Whatman paper, and incubate at $30{ }^{\circ} \mathrm{C}$.

6. Check the X-gal staining of the colonies after 10 minutes incubation to overnight.

Tabel 2-15: The second round of cDNA library screen using X-gal assay.

\subsubsection{DNA Extraction from Yeast Cells}

$1.5 \mathrm{ml}$ overnight culture was pelleted by centrifugation at 13,000 rpm for about 10 seconds, and resuspended in $30 \mu \mathrm{l}$ STES buffer (100 mM Tris, $\mathrm{pH}$ 8.0, $1 \mathrm{mM}$ EDTA, $100 \mathrm{mM} \mathrm{NaCl}, 0.1 \% \mathrm{SDS}$ ). The resuspension was vortexed, spun down at 13,000 rpm for about 10 seconds, and resuspended in another $30 \mu \mathrm{l}$ STES buffer. Acid washed glass beads were added to $80 \%$ volume, followed by vortexing the sample for $5 \times 1$ minute. Then, $200 \mu \mathrm{l}$ TE buffer was added, and DNA was recovered by phenol/chloroform/isoamylalcohol (25:24:1) extraction and isopropanol precipitation. For the isolation of a certain plasmid, the extracted DNA was transformed into E. coli and selected on an ampicillin or kanamycin plate.

\subsection{Analysis of Protein-Protein Interactions}

\subsubsection{GST Pull-Down Assay}

The in vitro protein-protein interactions were studied using GST pull-down assays (Tab. 2-16). 
1. Prewash $50 \mu$ l Glutathione Sepharose 4B beads (40 $\mu$ l bed volume) with $500 \mu 1$ pull-down binding buffer (20 mM Tris, pH 7.5, $100 \mathrm{mM} \mathrm{NaCl}, 1 \mathrm{mM}$ EDTA, $0.1 \%$ NP-40, freshly added $1 \mathrm{mM}$ PMSF). Spin it down by brief centrifugation at less than 4,000 rpm for several seconds, and aspirate the supernatants.

2. For coupling, incubate the prewashed beads with 40-50 $\mu \mathrm{g}$ recombinant GSTGeminin or GST protein in $500 \mu \mathrm{l}$ pull-down binding buffer at $4{ }^{\circ} \mathrm{C}$ rotating overnight.

3. Spin down the beads by brief centrifugation, and wash the beads once with 500 $\mu 1$ pull-down binding buffer at $4{ }^{\circ} \mathrm{C}$ rotating for 3 minutes to get rid of the unbound proteins.

4. Spin down the beads by brief centrifugation, aspirate the supernatants.

5. Incubate $45 \mu 1$ in vitro transcription/translation product with GST-Geminin or GST coupled beads in $500 \mu \mathrm{l}$ pull-down binding buffer at $4{ }^{\circ} \mathrm{C}$ rotating for $1-2$ hours. Mix $10 \mu \mathrm{l}$ in vitro transcription/translation product as control with $2 \times$ SDS loading buffer and heat at $95{ }^{\circ} \mathrm{C}$ for 5 minutes.

6. Spin down the beads, aspirate the supernatants, and wash the beads with pulldown binding buffer twice at $4{ }^{\circ} \mathrm{C}$ rotating for 3-5 minutes each.

7. Spin down the beads, aspirate the supernatants, and wash the beads with pulldown washing buffer (20 mM Tris, pH 7.5, $150 \mathrm{mM} \mathrm{NaCl,} 1 \mathrm{mM}$ EDTA, 0.1\% $\mathrm{NP}-40$, freshly added $1 \mathrm{mM}$ PMSF) twice at $4{ }^{\circ} \mathrm{C}$ rotating for 3-5 mintues each.

8. Spin down the beads and aspirate the supernatants.

9. Elute the protein from the beads with $40 \mu 12 \times$ SDS loading buffer by heating at $95{ }^{\circ} \mathrm{C}$ for 5 minutes.

10. Spin down the beads, and load $20 \mu 1$ supernatants and $10 \mu 1$ control on the gel.

11. Put the gel on a wet Whatman paper and dry the gel with a vacuum gel drier (Biometra) at $60{ }^{\circ} \mathrm{C}$ for 3 hours.

12. Fix the gel together with the Whatman paper in the cassette, and expose to a BioMax film (Kodak) at $-70{ }^{\circ} \mathrm{C}$ overnight.

13. Develop the film with Curix 60 developing machine (Agfa)

Tabel 2-16: Analysis of in vitro protein-protein interaction using GST pull-down assay. 


\subsubsection{Immunoprecipitation}

The in vivo protein-protein interactions were studied using immunoprecipitations (Tab. 2-17).

\footnotetext{
1. Hydrate $30 \mathrm{mg}$ Protein A Sepharose CL-4B (Amersham) beads with $500 \mu \mathrm{l}$ PBS (about $150 \mu \mathrm{l}$ bed volume), and wash the beads with $1 \mathrm{ml}$ PBS twice.
}

2. Incubate $400 \mu \mathrm{g}$ purified anti-Geminin antibodies $(500 \mu \mathrm{l})$ or $100 \mu \mathrm{l}$ preimmune serum plus $400 \mu \mathrm{l}$ PBS with washed beads at RT rotating overnight.

3. Wash the beads 4 times with $500 \mu \mathrm{l} 0.2 \mathrm{M} \mathrm{Na}_{2} \mathrm{~B}_{4} \mathrm{O}_{7}, \mathrm{pH} 9.0$ for 5 minutes each.

4. Resuspend the beads in $600 \mu \mathrm{l} 0.2 \mathrm{M} \mathrm{Na}_{2} \mathrm{~B}_{4} \mathrm{O}_{7}, \mathrm{pH} 9.0$ and save a $10 \mu \mathrm{l}$ aliquot. Then, add $3.7 \mathrm{mg}$ dimethylpimelimidate (about $20 \mathrm{mM}$ ) into the resuspension and incubate at RT rotating for 30 minutes to crosslink the antibody with beads.

5. Save another $10 \mu \mathrm{l}$ aliquot, and stop the crosslinking reaction by washing with $500 \mu 10.2$ M ethanolamine, $\mathrm{pH} 8.0$.

6. Incubate the beads with $500 \mu 10.2 \mathrm{M}$ ethanolamine, $\mathrm{pH} 8.0$ at RT rotating for 2 hours.

7. Wash the beads with PBS 3 times for 5 minutes each, and incubate with $1.5 \mathrm{ml}$ (40 mg/ml) 11.5 d.p.c. mouse embryonic extracts at $4{ }^{\circ} \mathrm{C}$ rotating for 2 hours.

8. Wash with $500 \mu \mathrm{l}$ IP washing buffer (20 mM Tris, pH 7.5, $150 \mathrm{mM} \mathrm{KCl,} 1 \mathrm{mM}$ EDTA, $1 \mathrm{mM} \beta$-mercaptoethanol, $1 \mathrm{mM}$ PMSF, 0.1\% Triton X-100) three times at $4{ }^{\circ} \mathrm{C}$ rotating for 5 minutes each.

9. Elute the co-precipitated proteins in $100 \mu 12 \times$ SDS loading buffer by heating at $95{ }^{\circ} \mathrm{C}$ for 6 minutes.

10. 15-30 $\mu$ l eluted co-precipitants were loaded on a 10\% SDS-polyacrylamide gel, and western blotting was performed using anti-Rae28 antibodies. Alternatively, the eluted co-precipitants and save aliquots were loaded on a gel and stained by Coomassie.

Tabel 2-17: Analysis of in vivo protein-protein interaction by immunoprecipitation.

\subsubsection{Peptide Array Analysis}


Peptide array membranes were blocked with $10 \mathrm{ml}$ blocking solution (1.5\% BSA in western buffer A) at RT rocking for 1 hour. Then, His-Geminin recombinant protein was added into the blocking solution to a final concentration of $1 \mu \mathrm{g} / \mathrm{ml}$, and incubated at $4{ }^{\circ} \mathrm{C}$ shaking overnight. Afterwards, membranes were sequentially washed with $10 \mathrm{ml}$ western buffer A, western buffer B, western buffer B, and western buffer A for 10 minutes each. The following steps from primary antibody staining are the same with normal western blotting (see 2.5.6) except the blocking solution.

\subsection{Analysis of Protein-Nuclei Acids Associations}

\subsubsection{Electrophoretic Mobility Shift Assays (EMSAs)}

The in vitro protein-DNA interactions were studied using EMSAs (Tab. 2-18).

1. The DNA labeling mixture containing $1 \mu$ l sense strand oligonucleotide $(0.1$ nmol) including a certain protein binding site, $2 \mu 1$ polynucleotide kinase buffer (Roche), $3 \mu 1 \gamma$-32P-dATP (30 mCi), $1 \mu 1$ polynucleotide kinase, and $13 \mu 1 \mathrm{H}_{2} \mathrm{O}$ in a total volume of $20 \mu \mathrm{l}$ was incubated at $37^{\circ} \mathrm{C}$ for 45 minutes.

2. Add $30 \mu 1 \mathrm{H}_{2} \mathrm{O}$ into the labeling mixture and purify it with a G-50 sephadex micro column.

3. Mix the $60 \mu$ flow through with $6 \mu \mathrm{l}(0.1$ volume) $1 \mathrm{M} \mathrm{KCl}$ and $1 \mu \mathrm{l}$ antisense strand oligonucleotides $(0.1 \mathrm{nmol})$.

4. Add $50 \mu 1$ mineral oil (Sigma) onto the top of the mixture. Then, denature at 94

${ }^{\circ} \mathrm{C}$ for 10 minutes and naturally cool it down for 45 minutes to anneal the oligos using a PCR machine.

5. Dilute $2 \mu \mathrm{l}$ labeled double-stranded oligo into $200 \mu 1 \mathrm{H}_{2} \mathrm{O}$, and count the radioactivity with an LS1701 counter (Beckman).

6. Dilute $1 \mu$ labeled double-stranded oligo into a proper volume of $\mathrm{H}_{2} \mathrm{O}$ to get $25,000 \mathrm{cpm} / \mu 1$.

7. In vitro transcription/translation was performed in a total volume of $25 \mu 1$.

8. Preincubate $4 \mu 1$ in vitro transcription/translation protein with $15 \mu 1$ $2 \times$ retardation buffer (40 mM HEPES-NaOH, pH 7.6, 8\% Ficoll, $10 \mathrm{mM} \mathrm{MgCl}$, 80 $\mathrm{mM} \mathrm{NaCl}, 0.2 \mathrm{mM}$ EDTA, $1 \mathrm{mM}$ DTT), $0 \mu 1$ or $8 \mu 11 \mu \mathrm{g} / \mu 1$ His-Geminin recombinant protein, and $8 \mu \mathrm{l}$ or $0 \mu 1 \mathrm{H}_{2} \mathrm{O}$ in a total volume of $27 \mu \mathrm{l}$ on ice for 1 
hour.

9. Add $2 \mu 12.5 \mu \mathrm{g} / \mu 1$ poly[dI-dC] (Roche) and $1 \mu 1$ diluted radioactive oligo $(25,000 \mathrm{cpm})$ into the preincubation mixture, and incubate on ice in a total volume of $30 \mu \mathrm{l}$ for another 1 hour.

10. Prepare a $10 \%$ polyacrylamide gel $\left(48.1 \mathrm{ml} \mathrm{H}_{2} \mathrm{O}, 25 \mathrm{ml} \mathrm{30 \%}\right.$ acrylamidebisacrylamide solution, $1.5 \mathrm{ml} 10 \times \mathrm{TBE}$ buffer, $400 \mu 1$ 10\% APS, and $40 \mu 1$ TEMED in a total volume of $75 \mathrm{ml}$ ) and prerun the gel under $150 \mathrm{~V}$ for 1 hour.

11. Apply $24 \mu 1$ sample $(20,000 \mathrm{cpm})$ from the $30 \mu 1$ on the gel, and the electrophoresis was performed under $80 \mathrm{~V}$ overnight.

12. Fix the gel together with a support glass in the cassette, and expose to a BioMax film at $-70{ }^{\circ} \mathrm{C}$ for 7.5 hours.

13. Develop the film with the Curix 60 developing machine.

Tabel 2-18: Analysis of in vitro protein-DNA interaction using EMSA.

\subsubsection{Chromatin Immunoprecipitation (ChIP) Assay}

The Chromatin Immuoprecipitation from $1.5 \times 10^{6}$ mouse primary cultured fibroblasts (80-90\% confluence in $10 \mathrm{~cm}$ dishes) was performed using anti-Geminin antibodies (see 2.5.8) and ChIP Assay Kit (Upstate) (Tab. 2-19).

1. Crosslink histones to DNA by adding formaldehyde directly into culture medium to a final concentration of $1 \%(270 \mu 137 \%$ formaldehyde into $10 \mathrm{ml}$ culture medium) at $37{ }^{\circ} \mathrm{C}$ for 10 minutes.

2. Aspirate medium, and wash the cells twice with $5 \mathrm{ml}$ ice cold PBS (always containing $1 \mathrm{mM}$ PMSF and protease inhibitor in the ChIP assay).

3. Scrape the cells with a glass slide in $5 \mathrm{ml}$ PBS, and transfer floated cells together with buffer into a $15 \mathrm{ml}$ Falcon tube.

4. Wash the dish twice with $2.5 \mathrm{ml}$ ice cold PBS and collect them into the same tube.

5. Pellet the cells at $2,000 \mathrm{rpm}$ at $4{ }^{\circ} \mathrm{C}$ for 4 minutes. In the meantime, prewarm the SDS Lysis Buffer to room temperatute, then add $1 \mathrm{mM}$ PMSF and protease inhibitor. 
6. Aspirate the supernatant, and resuspend the cell pellet in $300 \mu 1$ SDS Lysis Buffer $\left(200 \mu 1 / 10^{6}\right.$ cells $)$ and incubate on ice for 10 minutes.

7. Sonicate the cell lysate on ice to shear DNA to lengths shorter than $500 \mathrm{bp}$ using $3 \mathrm{~mm}$ tip under the condition of output option 3,5 times 10 seconds continuous pulse.

8. Separate the sonicated cell lysate into two $2 \mathrm{ml}$ tubes with $1.5 \mathrm{ml}$ each. Centrifuge at $13,000 \mathrm{rpm}$ at $4{ }^{\circ} \mathrm{C}$ for 10 minutes. Collect the supernatant and discard the pellet.

9. Dilute the supernatant 10 fold by adding $1350 \mu$ l ChIP Dilution Buffer into 150 $\mu 1$ supernatant. Add $1 \mathrm{mM}$ PMSF and protease inhibitors, and save $7.5 \mu$ dilution for checking shearing efficiency.

10. Preclear $1.5 \mathrm{ml}$ diluted cell supernatant with $60 \mu 1$ Salmon Sperm DNA/Protein A Agarose- $50 \%$ Slurry at $4{ }^{\circ} \mathrm{C}$ rotating for 30 minutes.

11. Pellet the agarose by brief centrifugation and collect the supernatant fraction.

12. Add $150 \mu \mathrm{g}$ anti-Geminin antibodies $(0.8 \mu \mathrm{g} / \mu \mathrm{l})$ to the precleared supernatant and incubate at $4{ }^{\circ} \mathrm{C}$ rotating overnight, using pre-immune serum as control.

13. Add $60 \mu \mathrm{l}$ Salmon Sperm DNA/Protein A Agarose Slurry and incubate at $4{ }^{\circ} \mathrm{C}$ rotating for 1 hour to capture the complexes.

14. Pellet the agarose by gentle centrifugation at $700 \mathrm{rpm}$ at $4{ }^{\circ} \mathrm{C}$ for 1 minute. Carefully remove the supernatant.

15. Wash with $1 \mathrm{ml}$ Low Salt Immune Complex Wash Buffer at $4{ }^{\circ} \mathrm{C}$ rotating for 3-5 minutes.

16. Wash with $1 \mathrm{ml}$ High Salt Immune Complex Wash Buffer at $4{ }^{\circ} \mathrm{C}$ rotating for 3-5 minutes.

17. Wash with $1 \mathrm{ml} \mathrm{LiCl} \mathrm{Immune} \mathrm{Complex} \mathrm{Wash} \mathrm{Buffer} \mathrm{at} 4{ }^{\circ} \mathrm{C}$ rotating for $3-5$ minutes.

18. Wash twice with $1 \mathrm{ml} 1 \times \mathrm{TE}$ Buffer at $4{ }^{\circ} \mathrm{C}$ rotating for 3-5 minutes each.

19. Elute the complex from antibody by adding $250 \mu$ freshly prepared elution buffer $\left(1 \% \mathrm{SDS}, 0.1 \mathrm{M} \mathrm{NaHCO}_{3}\right)$ to the pelleted agarose. Vortex briefly to mix and incubate at room temperature rotating for 15 minutes.

20. Spin down the agarose, collect the supernatant, repeat elution, and combine elutions (about $500 \mu \mathrm{l}$ ). 
21. Add $20 \mu 15 \mathrm{M} \mathrm{NaCl}$ to the combined elution to reverse the crosslinks by incubation at $65{ }^{\circ} \mathrm{C}$ for 4 hours.

22. Add $10 \mu 10.5$ M EDTA, $20 \mu 11 \mathrm{M}$ Tris-HCl, $\mathrm{pH} 6.5$, and $2 \mu 110 \mathrm{mg} / \mathrm{ml}$ Proteinase $\mathrm{K}$ to the combined elution and incubate at $45{ }^{\circ} \mathrm{C}$ for 1 hour.

23. Recover DNA by phenol/chloroform/isoamylalcohol (25:24:1) extraction and isopropanol precipitation. Dissolve the pellet in $10 \mu 1 \mathrm{H}_{2} \mathrm{O}$.

24. $1 \mu \mathrm{l}$ of dissolved DNA was applies as template for PCR using LA Tag system and four pairs of primers (Prom: 5'-CACGAGATTGCTCAGGGCTTAG-3', 5'CAATACTCAGCCAGCGTGGAAAC-3'; Intron: 5'-TTCAGAGCCTGCCTTGC CATC-3', 5'-CACTCTGGCCACTGAGCTAG-3'; UTR1: 5'-CCACTACAGCCT GAGGAAGAG-3', 5'-GACAGTGACTCATGCCCAAAG-3'; UTR2: 5'-CATAA GATGCACAGCAGCTCATGC-3', 5'-GTGGGTCTGGATGTATGAGCCTG-3').

Tabel 2-19: Analysis of in vivo protein-chromatin association using ChIP assay.

\subsection{Cell Culture and Immunocytochemistry}

\subsubsection{Cell Culture Medium}

U2-OS osteosarcoma cells were cultured in McCoy's 5A medium (Gibco BRL) containing $1.5 \mathrm{mM}$ L-glutamine, 10\% FCS, $100 \mathrm{U} / \mathrm{ml}$ penicillin $\mathrm{G}$, and $100 \mu \mathrm{g} / \mathrm{ml}$ streptomycin.

A-375 melanoma cells were cultured in Dulbecco's modified Eagle's medium (DMEM, Gibco BRL) containing $4 \mathrm{mM}$ L-glutamine, 10\% FCS, $1.5 \mathrm{mg} / \mathrm{ml}$ sodium bicarbonate, $4.5 \mathrm{mg} / \mathrm{ml}$ glucose, $100 \mathrm{U} / \mathrm{ml}$ penicillin G, $100 \mu \mathrm{g} / \mathrm{ml}$ Streptomycin.

$\mathrm{NIH} / 3 \mathrm{~T} 3$ cells were cultured in DMEM medium containing $4 \mathrm{mM}$ L-glutamine, $10 \%$ FCS, $1.5 \mathrm{mg} / \mathrm{ml}$ sodium bicarbonate, $4.5 \mathrm{mg} / \mathrm{ml}$ glucose, $100 \mathrm{U} / \mathrm{ml}$ penicillin $\mathrm{G}$, $100 \mu \mathrm{g} / \mathrm{ml}$ Streptomycin.

Hela cells were cultured in DMEM medium containing $2 \mathrm{mM}$ L-glutamine, 10\% FCS, $4.5 \mathrm{mg} / \mathrm{ml}$ glucose, $100 \mathrm{U} / \mathrm{ml}$ penicillin $\mathrm{G}, 100 \mu \mathrm{g} / \mathrm{ml}$ Streptomycin.

\subsubsection{Cell Revival}

Cells from liquid nitrogen are revived in a $37^{\circ} \mathrm{C}$ water bath as quickly as possible, then transferred into a $15 \mathrm{ml}$ Falcon tube containing $5 \mathrm{ml}$ proper culture medium, and centrifuged at 1,000 rpm for 5 minutes. The supernatant medium was aspirated, $5 \mathrm{ml}$ 
fresh medium was added to the cell pellet and pipetted up and down for at least 15 times to break cell aggregates. The, the cell resuspension was distributed in a $10 \mathrm{~cm}$ petridish containing $5 \mathrm{ml}$ culture medium (10 $\mathrm{ml}$ in total). The dish was gently shaken left-right and backward-forward to achieve equally distribution of cells. Then, the cells were cultured in a BBD 6220 incubator (Heraeus) at $37{ }^{\circ} \mathrm{C}$ under $5 \% \mathrm{CO}_{2}$ concentration.

\subsubsection{Cell Passage and Freeze}

The medium of cultured $70-95 \%$ confluent cells in a $10 \mathrm{~cm}$ dish was aspirated. Cells were washed with $10 \mathrm{ml}$ PBS, which was then aspirated from the dish. $2.5 \mathrm{ml}$ $1 \times$ Trypsin-EDTA solution (Gibco BRL) was equally distributed onto the washed cells, and incubatd at $37{ }^{\circ} \mathrm{C}$ for about 2 minutes. The dish was shaken until all the cells became floating. $5 \mathrm{ml}$ culture medium was added to stop the trypsin digestion, pipetted up and down for several times to blow the cells, and then transferred into a $15 \mathrm{ml}$ Falcon tube. Centrifugation was carried out at 1,000 rpm for 5 minutes to pellet the cells, followed by aspirating the supernatant.

For passage, the cell pellet was resuspended in $6 \mathrm{ml}$ culture medium by pipetting 15 to 20 times to break cell aggregates. $2 \mathrm{ml}$ resuspension was finally equally distributed into a $10 \mathrm{~cm}$ dish containing $8 \mathrm{ml}$ medium (1:3 dilution), gently shaken and incubated.

For freeze, the cell pellet was resuspended in $2 \mathrm{ml}$ culture medium, and every 500 $\mu 1$ cell resuspension was transferred into a cryotube (Nunc) containing $500 \mu 1$ culture medium and $10 \%$ DMSO, mixed well by inverting, and sequentially frozen at $-20{ }^{\circ} \mathrm{C}$ overnight, at $-80{ }^{\circ} \mathrm{C}$ for a week to a month, and finally in liquid nitrogen.

\subsubsection{Immunocytochemistry}

The antibody staining on cultured cells was performed as described below (Tab. 220) using antibodies against Geminin (Santa Cruz), Rae28 (Suzuki et al., 2002), or Mel18 (Santa Cruz).

1. Passage cells onto a Lab-Tek Chamber slide (Nunc), and culture the cells in each chamber in $0.5-1 \mathrm{ml}$ medium under $5 \% \mathrm{CO}_{2}$ at $37^{\circ} \mathrm{C}$ overnight.

2. Aspirate the medium and wash the cells in each chamber with $1 \mathrm{ml}$ PBS twice. 
3. Fix the cells with $500 \mu 14 \% \mathrm{PFA} / \mathrm{PBS}$ at $4{ }^{\circ} \mathrm{C}$ for 1 hour or at RT for 20 minutes.

4. Wash with $500 \mu \mathrm{l}$ PBS 3 times for 5 minutes each.

5. Permeabilize the cells with $500 \mu 10.5 \%$ Triton X-100/PBS at RT for 3-5 minutes.

6. Wash with $500 \mu 10.1 \%$ Tween 20/PBS (PBT) twice for 5 minutes each.

7. Block in $500 \mu 110 \%$ FCS/PBT at RT for $1-2$ hours.

8. Incubate the cells with $500 \mu 1$ 1:100-1:1000 diluted primary antibody in 10\% FCS/PBT at $4{ }^{\circ} \mathrm{C}$ overnight (preferred) or at RT for 90 minutes.

9. Wash with $500 \mu 1$ PBT twice for 5 minutes each.

10. Wash with $500 \mu 110 \%$ FCS/PBT for 5 minutes.

11. Incubate the cells with $500 \mu 1$ 1:2000 diluted Alexa conjugated secondary antibody (Molecular Probes) in $10 \% \mathrm{FCS} / \mathrm{PBT}$ at RT for 1 hour. After the application of fluorescence labeled secondary antibody, all the following steps should avoid light.

12. Wash with $500 \mu \mathrm{l}$ PBT 3 times for 5 minutes each.

13. For nuclei staining, incubate the cells with $500 \mu 10.5 \mu \mathrm{g} / \mathrm{ml}$ DAPI in PBT at RT for 5 minutes.

14. Wash with $500 \mu \mathrm{l}$ PBT 3 times for 5 minutes each.

15. Rinse the slide with water briefly, and cover the specimen with $200 \mu$ moviel and a coverslip without air bubble.

16. Apply the sample to a BX-60 fluorescence microscopy (Olympus).

Tabel 2-20: Immunocytostaining of cultured cells.

\subsubsection{Cell Transfections with Plasmids or siRNAs}

The cultured cells were transfected with plasmids or siRNAs using Lipofectamine 2000 transfection reagent (Invitrogen) (Tab. 2-21).

1. One day before transfection, passage cells into a 24-well cell culture plate (Nunc) with a proper dilution in order to get $80-95 \%$ confluence (50\% for siRNA transfection) at the time of transfection. 
2. Culture cells in each well with $500 \mu 1$ proper medium without penicillin/streptomycin under $5 \% \mathrm{CO}_{2}$ at $37^{\circ} \mathrm{C}$ overnight.

3. 3 hours before transfection, refresh the medium (Optional).

4. Dilute $2 \mu \mathrm{l}$ ( $3 \mu \mathrm{l}$ for siRNA transfection) Lipofectamine 2000 into $48 \mu \mathrm{l}$ (47 $\mu \mathrm{l}$ for siRNA transfection) Opti-MEM ${ }^{\circledR}$ I medium (Gibco BRL) to a final volume of $50 \mu 1$. Mix well by gently flicking and incubate at RT for 5 minutes.

5. Dilute $0.8 \mu \mathrm{g}$ DNA or DNA combinations (3 $\mu 120 \mu \mathrm{M}$ siRNA) into Opti$\mathrm{MEM}^{\circledR} \mathrm{I}$ medium to a final volume of $50 \mu \mathrm{l}$. Mix well by gently flicking.

6. Combine the diluted Lipofectamine 2000 and the diluted DNA or RNA (total volume $100 \mu \mathrm{l}$ ). Mix well by gently flicking, and incubate at RT for 30 minutes (20 minutes for siRNA transfection) to form DNA or RNA-Lipofectamine 2000 complexes.

7. Distribute $100 \mu \mathrm{l}$ DNA or RNA-Lipofectamine 2000 complexes to the $80-95 \%$ confluent cells (50\% for siRNA transfection) in each well, mix well by gently rocking the plate and incubate at $37{ }^{\circ} \mathrm{C}$ for 24 hours (48-72 hours for siRNA transfection) in a $5 \% \mathrm{CO}_{2}$ incubator.

8. Cells in each well were trypsinized with $200 \mu 1$ Trypsin-EDTA solution, spun down at 3,000 rpm at $4{ }^{\circ} \mathrm{C}$ for 4 minutes, resuspended in $25 \mu 1 \mathrm{PBS}$, mixed with 25 $\mu 12 \times \operatorname{SDS}$ loading buffer and heated at $95{ }^{\circ} \mathrm{C}$ for $6-8$ minutes.

Tabel 2-21: Transfection of plasmids or siRNAs into cultured cells using lipofectacmine.

\subsubsection{Luciferase Assay}

The luciferase assay was performed using Luciferase Assay System (Promega) (Tab. 2-22).

1. To prepare Luciferase Assay Reagent, add $10 \mathrm{ml}$ Luciferase Assay Buffer to the vial containing the lyophilized Luciferase Assay Substrate.

2. 1:5 dilute $5 \times$ Reporter Lysis Buffer with $\mathrm{H}_{2} \mathrm{O}$.

3. Equilibrate Luciferase Assay Reagent and $1 \times$ Reporter Lysis Buffer at RT.

4. Aspirate the medium of transfected cells in 24-well plates. Wash cells in each well with $500 \mu \mathrm{l}$ PBS once and completely aspirate PBS buffer. 
5. Add $100 \mu 11 \times$ Reporter Lysis Buffer into each well, and apply one freeze-thaw cycle to ensure the lysis.

6. Pipette up and down for several times, and centrifuge the lysate at $12,000 \times \mathrm{g}$ at RT for 20 seconds.

7. Inject $100 \mu \mathrm{l}$ Luciferase Assay Reagent into $20 \mu \mathrm{l}$ cell lysate supernatant in a $75 \times 12 \mathrm{~mm}$ tube (Sarstedt), and measure the luciferase activity for 10 seconds by a Lumat LB9501 luminometer (Berthold)

Tabel 2-22: The preparation of cell lysate and measurement of luciferase activities.

\subsection{Competition Assays}

\subsubsection{In Vitro Competition Assay}

The N-terminally Geminin coupled beads (see 2.5.7) was equilibrated in western buffer A, followed by preincubating $100 \mu \mathrm{l}$ bed volume Geminin coupled beads (1.5 $\mu \mathrm{g}$ protein/ $\mu \mathrm{l}$ ) with $500 \mu \mathrm{g}$ GST-Geminin recombinant or GST protein at $4{ }^{\circ} \mathrm{C}$ rotating for 2 hours. The unbound protein was washed away with $1 \mathrm{ml}$ western buffer A. Then, the preincubated and $100 \mu 1$ non-preincubated Geminin coupled beads were individually incubated with $1 \mathrm{ml} 11.5$ d.p.c. mouse embryonic extracts at $4{ }^{\circ} \mathrm{C}$ rotating for 2 hours. After wash once with $1 \mathrm{ml}$ western buffer A and once with $1 \mathrm{ml}$ western buffer A plus $50 \mathrm{mM} \mathrm{NaCl}$, the bound proteins were eluted with $70 \mu 12 \times \mathrm{SDS}$ loading buffer by heating at $95{ }^{\circ} \mathrm{C}$ for 5 minutes. The samples were loaded on a $10 \%$ SDS-polyacrylamide gel, and western blotting was performed using anti-Cdt1 antibodies.

\subsubsection{In Vivo Competition Assay}

Primary cultured MEFs in $3.5 \mathrm{~cm}$ dishes were transfected with Lipofectamine 2000, and cell lysate was prepared 24 hours after transfection as described in ChIP assay (see 2.8.2). Then, an immunoprecipitation was performed as described above (see 2.7.2), and the co-precipitants were analyzed by western blotting using antiGeminin and anti-Cdt1 antibodies.

\subsection{Manipulation and Analysis of Chick Embryos}

\subsubsection{In Ovo Electroporation}


Fertilized eggs were incubated at $38{ }^{\circ} \mathrm{C}$ in a humid incubator for $36-44$ hours to reach stage HH9-11 (Hamburger and Hamilton, 1951), without rolling during the whole incubation time. For in ovo electroporation, 2-5 $\mu \mathrm{g} / \mu 1$ plasmid or plasmid combination in PBS supplemented with $1 \mathrm{mM} \mathrm{MgCl}_{2}$ and 25-50 ng/ $\mu 1$ Fast Green was pipetted into a microinjection glass needle, which was subsequently connected to and held on a Pneumatic PicoPump PV820 pump system (World Precision Instruments). After incubation, an egg was held on a stander with the orientation that the embryo sits on the top of the yolk, and $2.5 \mathrm{ml}$ albumin was aspirated with a $5 \mathrm{ml}$ syringe (Terumo). Then, a $2 \mathrm{~cm}$ diameter window was opened on the shell exactly above the embryo, several drops of $1 \times$ Tyrods buffer ( $8 \mathrm{~g} \mathrm{NaCl}, 0.2 \mathrm{~g} \mathrm{KCl}, 0.271 \mathrm{~g} \mathrm{CaCl}_{2} \cdot 2 \mathrm{H}_{2} \mathrm{O}$, $0.05 \mathrm{~g} \mathrm{NaH}_{2} \mathrm{PO}_{4} \cdot 2 \mathrm{H}_{2} \mathrm{O}, 0.2 \mathrm{~g} \mathrm{MgCl}_{2} \cdot 6 \mathrm{H}_{2} \mathrm{O}, 1 \mathrm{~g}$ glucose in a total volume of 1 liter, and freshly added $1 \times$ penicillin/streptomycin) were applied on the embryo proper to avoid drying, and 1:75 diluted black ink (Higgins) in 1×Tyrods buffer was injected with a $1 \mathrm{ml}$ syringe (Terumo) into the yolk right beneath the embryo to visualize it. Subsequently, a small hole was broken on the vitelline membrane carefully using a $0.125 \mathrm{~mm}$ diameter wolfram-draht needle (Agar Scientific) to make the neural tube accessible. A parallel platinum electrode (Aldrich) with 5-6 mm length, $0.25 \mathrm{~mm}$ diameter, and $7 \mathrm{~mm}$ distance between two electrodes was placed onto the vitelline membrane flanking the embryo in parallel with neural tube, pressed down to the same horizontal level with the neural tube, and several drops of $1 \times$ Tyrods buffer were applied on each electrode. Afterwards, DNA solution was injected into the neural tube, and 5 square electric pulses were given under the condition of $33 \mathrm{~V}, 50$ miniseconds/pulse with 950 miniseconds intervals by a Electro Square Porator ECM830 electroporator (BTX). Finally, the window on the shell was tightly sealed with tape, and the electroporated embryo was further incubated for 48 hours to reach stage HH18-20. The surviving embryos were dissected out from the yolk in PBS, and GFP expression was assayed with an SZX12 fluorescence microscope (Olympus).

\subsubsection{DIG Labeled RNA Probe Preparation}

5-10 $\mu$ g plasmid DNA was linearized by incubating with $4 \mu 1$ restriction enzyme at $37^{\circ} \mathrm{C}$ for 3 hours, purified with PCR Purification Kit, and eluted in $30 \mu 1 \mathrm{H}_{2} \mathrm{O} .1 \mu \mathrm{l}$ elution was loaded on an agarose gel to check the linearization efficiency. DIG labeled antisense RNA probes were synthesized by incuabting $1 \mu 1$ linearized DNA, 2 
$\mu 1$ 10×Transcription Buffer (Roche), $2 \mu 1$ DIG-Labeling Mixture (Roche), $1 \mu 1$ RNasin, $1 \mu 1 \mathrm{~T} 3$ or T7 RNA Polymerase (Roche), and $13 \mu 1 \mathrm{DEPC}-\mathrm{H}_{2} \mathrm{O}$ in a total volume of $20 \mu \mathrm{l}$ at $37{ }^{\circ} \mathrm{C}$ for $2-2.5$ hours. Then, the transcription product was supplemented with $30 \mu \mathrm{l} \mathrm{H}_{2} \mathrm{O}$ and purified with a G-50 Sephadex Micro Column. $5 \mu \mathrm{l}$ purified probe was checked on an agarose gel.

\subsubsection{Whole-Mount In Situ Hybridization}

48 hours after in ovo electroporation, the GFP positive chick embryos (HH 18-20) without head were fixed in $4 \% \mathrm{PFA} / \mathrm{PBS}$ at $4{ }^{\circ} \mathrm{C}$ for 4 hours to overnight, and subjected to whole-mount in situ hybridization (Tab. 2-23).

\begin{tabular}{l|l|l|l}
\hline \hline & Treatment and Solution & Temperature & Duration \\
\hline \multirow{4}{*}{ Dehydration } & $\begin{array}{l}\text { 1. Wash the fixed embryos with PBT } \\
3 \text { times, shaking. }\end{array}$ & on ice & $\begin{array}{l}10 \text { minutes } \\
\text { each }\end{array}$ \\
\cline { 2 - 4 } & \begin{tabular}{l}
$2.25 \%$ methanol/PBT, shaking. \\
\cline { 2 - 4 }
\end{tabular} & on ice & 10 minutes \\
\cline { 2 - 4 } & \begin{tabular}{l}
$3.75 \%$ methanol/PBS, shaking. \\
\cline { 2 - 4 }
\end{tabular} & on ice & 10 minutes \\
\hline
\end{tabular}

The embryos in $100 \%$ methanol can be stored in $-20{ }^{\circ} \mathrm{C}$ up to 2 weeks.

\begin{tabular}{|c|c|c|}
\hline 1. $75 \%$ methanol/PBT, shaking. & on ice & 10 minutes \\
\hline 2. 50\% methanol/PBS, shaking. & on ice & 10 minutes \\
\hline 3. 25\% methanol/PBT, shaking. & on ice & 10 minutes \\
\hline 4. Wash with PBT twice, shaking. & on ice & $\begin{array}{l}10 \text { minutes } \\
\text { each }\end{array}$ \\
\hline $\begin{array}{l}\text { 5. Bleach with } 6 \% \mathrm{H}_{2} \mathrm{O}_{2} / \mathrm{PBT} \text {, } \\
\text { shaking. }\end{array}$ & on ice & 30 minutes \\
\hline 6. Wash with PBT 3 times, shaking. & on ice & $\begin{array}{l}5 \text { minutes } \\
\text { each }\end{array}$ \\
\hline $\begin{array}{l}\text { 7. Digest with } 10 \mu \mathrm{g} / \mathrm{ml} \text { Proteinase K } \\
(1: 1000 \text { dilution from stock in PBT). }\end{array}$ & on ice & 10 minutes \\
\hline $\begin{array}{l}\text { 8. Stop the Proteinase K digestion } \\
\text { with about } 2 \mathrm{mg} / \mathrm{ml} \text { glycine in PBT. }\end{array}$ & on ice & 5 minutes \\
\hline
\end{tabular}




\begin{tabular}{|c|c|c|c|}
\hline \multirow{8}{*}{ Day 1} & 9. Wash with PBT 3 times, shaing. & on ice & $\begin{array}{l}5-10 \\
\text { minutes } \\
\text { each }\end{array}$ \\
\hline & $\begin{array}{l}\text { 10. Treat with RIPA buffer ( } 10 \mathrm{mM} \\
\text { Tris, pH 8.0, } 150 \mathrm{mM} \mathrm{NaCl,} 2.5 \mathrm{mM} \\
\text { EDTA, 0.1\% SDS, } 1 \% \mathrm{NP}-40 \text {, } \\
0.05 \% \text { Sodium deoxycholate) } 3 \\
\text { times, shaking. }\end{array}$ & on ice & $\begin{array}{l}20 \text { minutes } \\
\text { each }\end{array}$ \\
\hline & 11. Wash with PBT 3 times, shaking. & on ice & $\begin{array}{l}5-10 \\
\text { minutes } \\
\text { each }\end{array}$ \\
\hline & $\begin{array}{l}\text { 12. Refix with } 4 \% \text { PFA, } 0.2 \% \\
\text { glutaraldehyde, and } 0.1 \% \text { Tween } 20 \\
\text { in PBS }\end{array}$ & on ice & 30 minutes \\
\hline & 13. Wash with PBT 3 times, shaking. & on ice & $\begin{array}{l}10 \text { minutes } \\
\text { each }\end{array}$ \\
\hline & $\begin{array}{l}\text { 14. Prehybridize in prewarmed } \\
\text { Prehyb solution ( } 50 \% \text { formamide, } \\
5 \times \mathrm{SSC}, \mathrm{pH} 4.5,1 \% \mathrm{SDS}, 50 \mu \mathrm{g} / \mathrm{ml} \\
\text { yeast tRNA, } 50 \mu \mathrm{g} / \mathrm{ml} \text { heparin), } \\
\text { shaking. }\end{array}$ & $70{ }^{\circ} \mathrm{C}$ & 3 hours \\
\hline & \multicolumn{3}{|c|}{$\begin{array}{l}\text { Or before prehybridization, the embryos can be stored in store mix } \\
(50 \% \text { formamide, } 5 \times \mathrm{SSC}, \mathrm{pH} 4.5) \text { at }-20^{\circ} \mathrm{C} \text { up to } 2 \text { weeks. }\end{array}$} \\
\hline & $\begin{array}{l}\text { 15. 1:100 dilute a DIG labeled RNA } \\
\text { probe into the Prehyb solution to } \\
\text { hybridize }\end{array}$ & $70^{\circ} \mathrm{C}$ & overnight \\
\hline & $\begin{array}{l}\text { 1. Incubate with prewarmed Solution } \\
1(50 \% \text { formamide, } 5 \times \mathrm{SSC}, \mathrm{pH} 4.5 \text {, } \\
1 \% \mathrm{SDS}) \text { twice, shaking. }\end{array}$ & $70^{\circ} \mathrm{C}$ & $\begin{array}{l}30 \text { minutes } \\
\text { each }\end{array}$ \\
\hline & $\begin{array}{l}\text { 2. Incubate with prewarmed Solution } \\
3 \mathrm{~T} \text { ( } 50 \% \text { formamide, } 2 \times \mathrm{SSC}, \mathrm{pH} 4.5 \text {, } \\
0.1 \% \text { Tween } 20) \text { twice, shaking. }\end{array}$ & $70{ }^{\circ} \mathrm{C}$ & $\begin{array}{l}30 \text { minutes } \\
\text { each }\end{array}$ \\
\hline
\end{tabular}




\begin{tabular}{|c|c|c|c|}
\hline \multirow[t]{4}{*}{ Day 2} & $\begin{array}{l}\text { 3. Incubate with MABT ( } 100 \mathrm{mM} \\
\text { maleic acid, } 150 \mathrm{mM} \mathrm{NaCl}, 0.1 \% \\
\text { Tween20) } 3 \text { times, shaking. }\end{array}$ & RT & $\begin{array}{l}5 \text { minutes } \\
\text { each }\end{array}$ \\
\hline & $\begin{array}{l}\text { 4. Incubate with } 2 \% \text { Block Reagent } \\
\text { (Roche) in MABT, shaking. }\end{array}$ & RT & 5 minutes \\
\hline & $\begin{array}{l}\text { 5. Block with blocking solution ( } 2 \% \\
\text { Block Reagent, } 20 \% \text { FCS in MABT), } \\
\text { shaking. }\end{array}$ & RT & $5-8$ hours \\
\hline & $\begin{array}{l}\text { 6. Incubate with 1:2000 diluted Anti- } \\
\text { DIG-AP Fab fragment (Roche) in } \\
\text { blocking reagent, shaking. }\end{array}$ & $4{ }^{\circ} \mathrm{C}$ & overnight \\
\hline \multirow[b]{2}{*}{ Day 3,4} & 1. Wash with MABT 3 times. & RT & $\begin{array}{l}10 \text { minutes } \\
\text { each }\end{array}$ \\
\hline & $\begin{array}{l}\text { 2. Transfer the embryos into a sealed } \\
5 \mathrm{ml} \text { bottle and wash with MABT for } \\
48 \text { hours rotating. Refresh the } \\
\text { solution once in the middle. }\end{array}$ & RT & 48 hours \\
\hline \multirow{6}{*}{ Day 5} & $\begin{array}{l}\text { 1. Equilibrate with freshly prepared } \\
\text { NTMT/Lev (100 mM NaCl, } 100 \mathrm{mM} \\
\text { Tris, pH 9.5, } 50 \mathrm{mM} \mathrm{MgCl}_{2}, 1 \% \\
\text { Tween20, } 2 \mathrm{mM} \text { Levamisol) twice, } \\
\text { shaking. }\end{array}$ & RT & $\begin{array}{l}5 \text { minutes } \\
\text { each }\end{array}$ \\
\hline & 2. Incubate with NTMT/Lev. & RT & 4 hours \\
\hline & $\begin{array}{l}\text { 3. Stain with 1:50 diluted NBT/BCIP } \\
\text { (Roche) in NTMT/Lev in a dark } \\
\text { environment shaking. Control the } \\
\text { staining every } 10 \text { minutes. }\end{array}$ & RT & $\begin{array}{l}10 \text { minutes- } \\
2 \text { hours }\end{array}$ \\
\hline & 4. Wash with PBT twice, shaking. & RT & $\begin{array}{l}5 \text { minutes } \\
\text { each }\end{array}$ \\
\hline & $\begin{array}{l}\text { 5. Incubate with } 50 \% \text { glycerol/PBT, } \\
\text { shaking. }\end{array}$ & RT & $\begin{array}{l}15-60 \\
\text { minutes }\end{array}$ \\
\hline & $\begin{array}{l}\text { 6. Incubate with } 80 \% \text { glycerol/PBT, } \\
\text { shaking. }\end{array}$ & RT & $\begin{array}{l}15-60 \\
\text { minutes }\end{array}$ \\
\hline
\end{tabular}




\begin{tabular}{|c|c|}
\hline & $\begin{array}{l}\text { 7. Take pictures for the embryos } \\
\text { using a binocular (Zeiss) and } \\
\text { Ektachrome 64T film (Kodak) }\end{array}$ \\
\hline
\end{tabular}

Then, the embryos can be stored in $80 \%$ glycerol/PBT at $4{ }^{\circ} \mathrm{C}$.

Tabel 2-23: Whole-mount in situ hybridization of chick embryos 


\section{Results}

\subsection{Geminin Directly Interacts with Hox Proteins and a Polycomb Group}

\section{Member}

In order to identify proteins that interact with Geminin during embryogenesis, a two-hybrid screen was performed using a complementary DNA library prepared from 8.5 d.p.c. mouse embryos. The MaV203 yeast strain containing HIS3 and lacZ reporter genes was first transformed with pDBLeu-Geminin, and then with 8.5 d.p.c. mouse cDNA library in pPC86, using lithium acetate transformation. 177 independent colonies were selected out from the first round of screen on plates lacking leucine, tryptophan and histidine, and supplemented with $60 \mathrm{mM}$ 3AT (Fig. 3-1A). Then, all these clones were applied to the second round of screen, in which $\beta$-galactosidase activity was assayed for every clone. Eight positive cDNA clones were finally identified to encode Geminin-binding proteins (Fig. 3-1B). Three independent cDNAs each encoded parts of the homeodomain proteins Hoxd10 and Hoxa11, respectively. One clone represented the "Sex comb on midleg homolog 1" (Scmh1) protein, the mouse homolog of the Drosophila Scm protein, a member of the Polycomb multiprotein complex (Bornemann et al., 1996; Tomotsune et al., 1999). In order to eliminate the possibility of self-activation, all the eight cDNA clones in pPC86 vector were individually transformed into MaV203 yeast and assayed for $\beta$-galactosidase activities. No self-activation was detected.
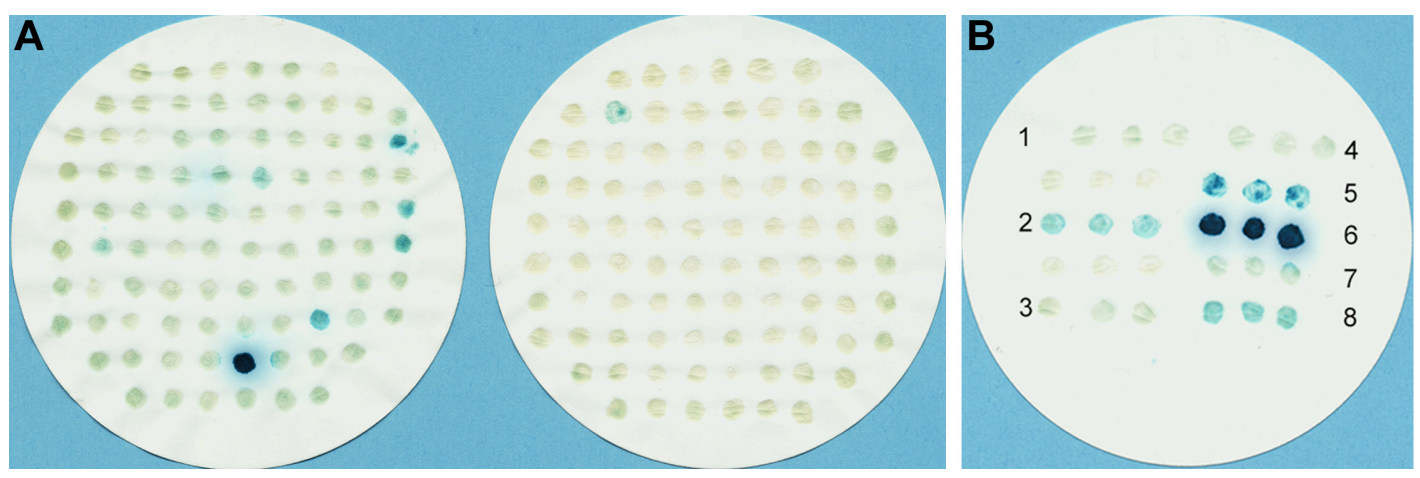

Figure 3-1: Yeast two-hybrid screen. (A) 177 independent colonies were selected out from the first round of screen on medium lacking histidine, and supplemented with $60 \mathrm{mM}$ 3AT. (B) Eight positive clones were shown to encode Geminin-binding proteins, as visualized by lacZ activity in the second round of screen. Clones 1, 2, 8 encode Hoxa11, and clones 3, 4, 7 encode Hoxd10. Clone 6 encodes Scmh1. 
To confirm the protein-protein interactions, full-length Hoxd10, Hoxa11 and Scmh1 proteins were synthesized by in vitro transcription/translation in the presence of $\left[{ }^{35} \mathrm{~S}\right]$-methionine. These radiolabeled proteins were tested for binding to the recombinant GST-Geminin fusion protein, and pure GST as a control (Fig. 3-2). In such pull-down assays, Hoxd10, Hoxa11 and Scmh1 bound directly to GST-Geminin, but exhibited no appreciable binding to GST alone. By means of these pull-down assays, the interactions of Geminin with Hoxd10, Hoxa11 and Scmh1 were confirmed in vitro.

The interactions of Geminin with two abdominal B (Abd-B)-like Hox proteins raised the question whether it also binds to other Hox proteins. GST pull-down assays were performed with in vitro transcribed/translated Hoxa7, Hoxc8, Hoxc9, Hoxa10, and Msx1 proteins (Fig. 3-2). Also these full-length proteins except Msx1 were able to bind directly and specifically to GST-Geminin, but not to GST. Together, the results identify homeodomain proteins of the Hox family, as well as the Polycomb group member Scmh1, as binding partners of the cell cycle regulator Geminin.

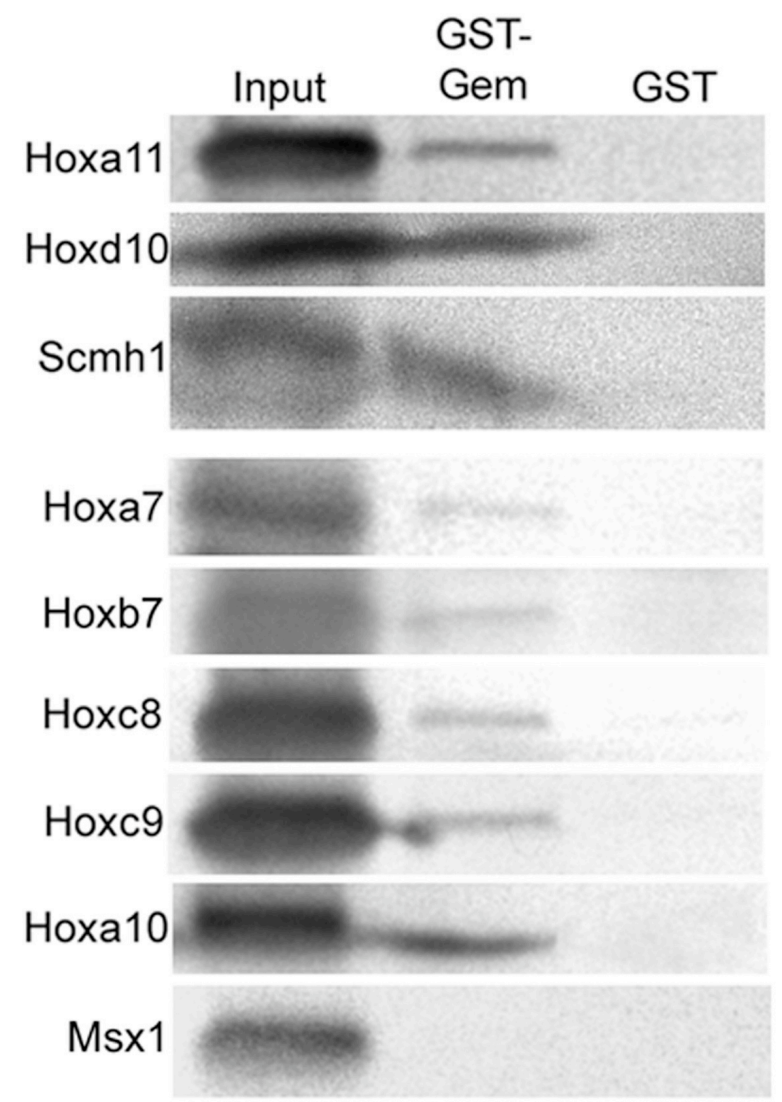

Figure 3-2: Pull-down assays. All the fulllength in vitro transcription/translation products of the indicated genes except Msx1 were specifically bound by a GSTGeminin fusion protein but not by GST alone. 
A

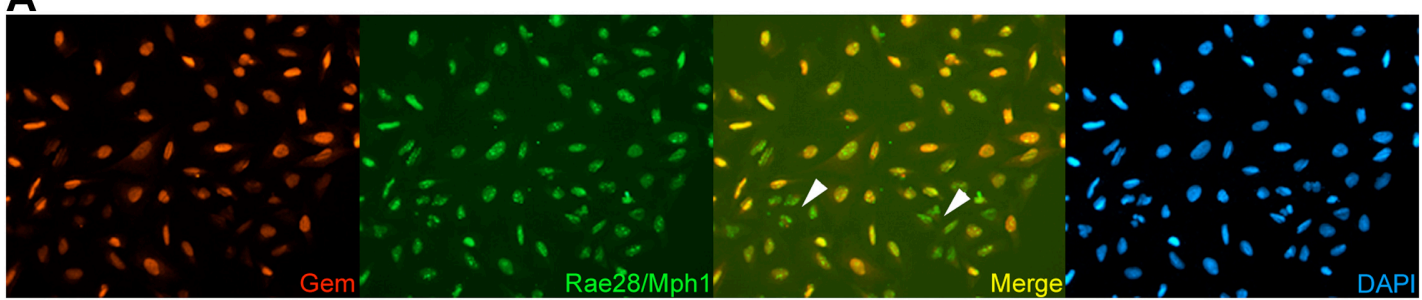

B

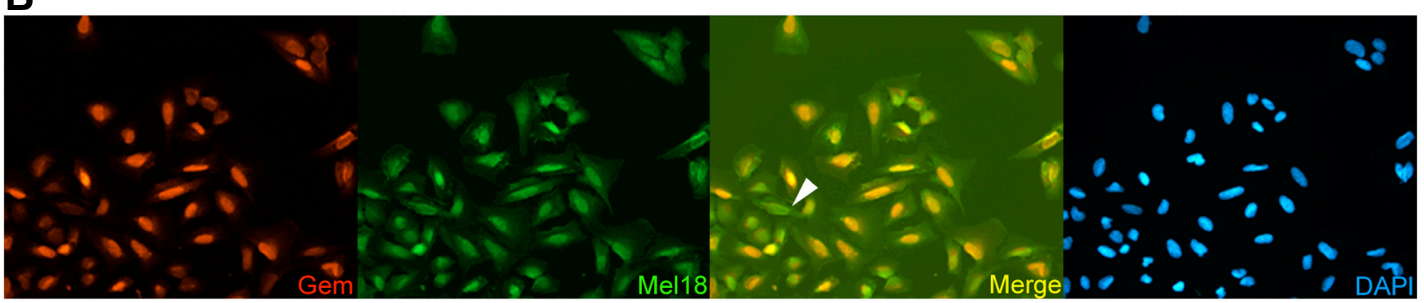

Figure 3-3: Subcellular colocalization between Geminin and Polycomb members. Double immunofluorescence stainings with antibodies against Geminin and Polycomb members Rae28 (A) or Mel18 (B) were performed on U2OS cells. DAPI indicates the nuclei of all cultured cells. Arrowheads denote cells with Polycomb member Rae28 or Mel18, but without Geminin expression.

\subsection{Geminin Associates with the Polycomb Complex}

The in vitro interaction between Geminin and the Polycomb member Scmh1 was demonstrated above. In order to test if Geminin also associates with other members of the Polycomb complex, we first analysed its in vivo co-localizations with Rae28 (Takihara et al., 1997) and Mel18 (Akasaka et al., 1996), respectively. Double immunofluorescence stainings of U2-OS cells were performed with anti-Geminin antibodies, and antibodies against Rae28 or Mel18, respectively (Fig. 3-3). The endogenous Geminin colocalized with Rae28 or Mel18 in the nuclei of the cultured cells. However, whereas the two Polycomb proteins were detected in the nuclei of all observed cells, several nuclei were significantly negative for Geminin (Fig. 3-3, arrow heads). A close inspection of these U2-OS cells revealed that the expression of Geminin depended on the phase of the cell cycle (Fig. 3-4). Geminin protein was not detectable during the interphase. Then, it accumulated in the nucleus and persisted throughout mitosis until the anaphase-telophase transition. On the contrary, the expression of Rae28 or Mel18 was continuous in all phases of the cell cycle.

Direct evidence for an in vivo association between Geminin and a Polycomb protein was obtained by immunoprecipitation from 11.5 d.p.c. mouse embryonic extracts using anti-Geminin antibodies. A pre-immune rabbit serum was used as a negative control. A band with a mobility corresponding to $120 \mathrm{kDa}$ in the precipitated 


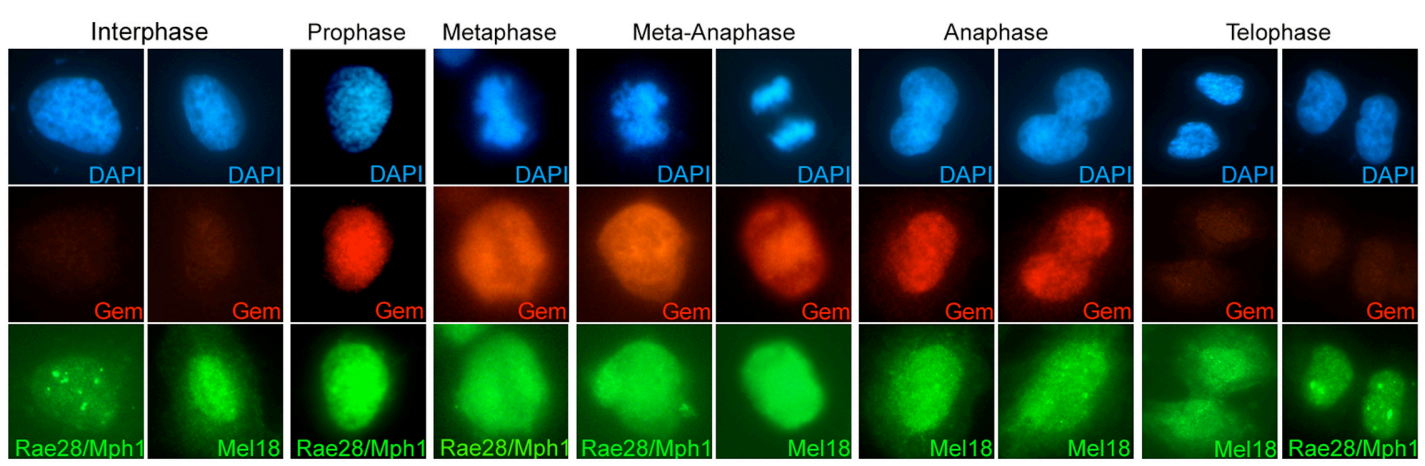

Figure 3-4: The cell cycle dependent expression of Geminin. Geminin protein was not detectable during the interphase. Then, it accumulated in the nucleus and persisted throughout mitosis until the anaphase-telophase transition. On the contrary, the expression of Rae28 or Mel18 was continuous in all phases of the cell cycle.

materials was recognized by anti-Rae28 antibodies (Fig. 3-5), which indicates that the protein complex isolated from mouse embryos containing Geminin, in addition also contained Rae28. Together, these data demonstrate the association of Geminin and the Polycomb complex in vivo. However, this association is cell cycle dependent, since Geminin is absent in some phases of cell cycle in contrast to the Polycomb members.

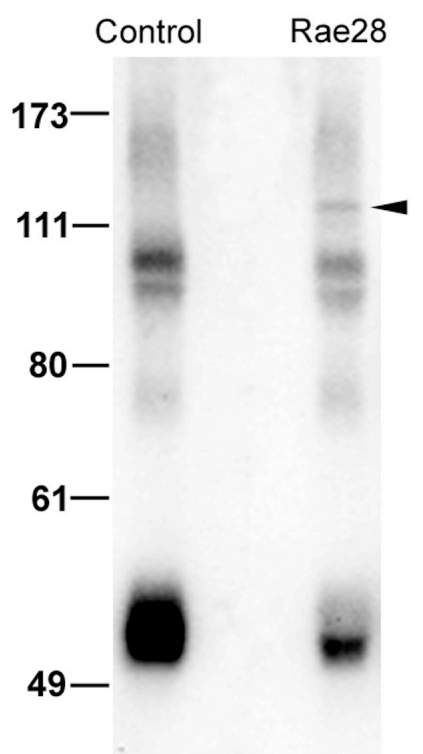

Figure 3-5: Co-immunoprecipitation of Geminin and Rae28 from 11.5 d.p.c. mouse embryonic extracts. The arrowhead indicates that Rae28 was specifically co-precipitated by anti-Geminin antibodies, but not by the pre-immune serum as control.

\subsection{Geminin Associates with Hox Regulatory DNA Elements In Vivo}

The Polycomb complex was previously demonstrated to associate with Hox regulatory DNA elements on the chromatin (Barna et al., 2002). A fraction of 
Geminin was also proved to be chromatin-associated previously (Kulartz et al., 2003). To further investigate whether Geminin associates with these Hox regulatory elements in vivo, chromatin immunoprecipitation (ChIP) assays were performed to isolate DNA fragments bound by Geminin-including protein complexes in primary cultured mouse embryonic fibroblasts. Four Hox regulatory elements within the Hoxd11 gene bind to Plzf, a protein that associates with Polycomb complex members and mediates transcriptional repression of Hox genes (Fig. 3-6A, Barna et al., 2002). Three of these Plzf binding sites, located within the Hoxd11 intron or 3' UTR, were specifically coprecipitated by Geminin antibodies but not by pre-immune serum (Fig. 3-6B). These results demonstrate that Geminin substantially associates in vivo with the Hox regulatory DNA elements that anchor Plzf together with Polycomb members.

A

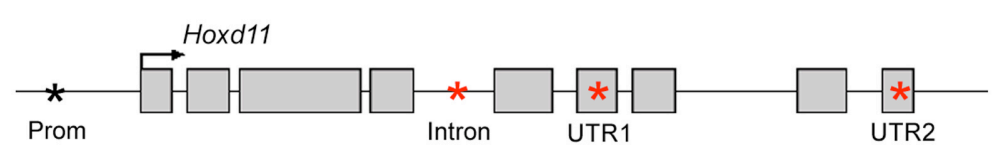

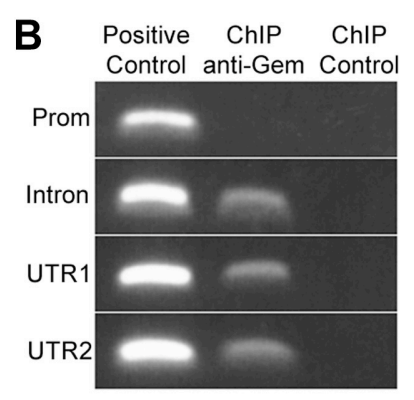

Figure 3-6: Chromatin immunoprecipitation assays using anti-Geminin antibodies. (A) The genomic organization of Hoxd11 gene. The gray boxes indicate the exons of Hoxd11 gene, and the asterisks indicate four Plzf-binding Hox regulatory elements within Hoxd11 gene. (B) Three of these Hox regulatory DNA elements within the Hoxd11 intron and 3'UTR (red asterisks) were identified by ChIP assays to be associated with Geminin protein. The Hox regulatory element in the promoter region (black asterisk) was not detected.

\subsection{Overexpression of Geminin Represses Hox Gene Transcription}

From the results depicted above, Geminin was elucidated to associate in vivo with the Polycomb complex, together with which Geminin further associates with Hox regulatory elements on the chromatin. These associations raised the question whether Geminin is involved in Hox gene transcriptional repressions by the Polycomb complex. To characterize the effect of ectopically expressed Geminin on Hox gene transcription, we overexpressed Geminin unilaterally in the neural tube of chicken embryos by in ovo electroporation, a strategy previously applied to Polycomb members (Suzuki et al., 2002). For these experiments, expression vectors were 
applied, driving either the murine Geminin cDNA, or an EGFP-Geminin fusion by the cytomegalovirus (CMV) enhancer/promoter. CMV-EGFP-Gem plus pCMV-Gem or the control vector CMV-EGFP were injected into the neural tube of HH9-11 stage chicken embryos, that is, at an embryonic time, when $A b d-B$ related Hox genes like Hoxb 9 become activated in the posterior body region. The plasmids were electroporated to the right side of the neural tube, where the expression of GFP was confirmed after 24 hours of incubation by in vivo green fluorescence and recorded (Fig. 3-7A,B). Then, embryos were incubated for another 24 hours, fixed at about stage HH18-20, and submitted to whole-mount in situ hybridization. The Hoxb9 anterior transcription boundary was posteriorly shifted by one to two somites length on the electroporated, right side (Fig. 3-7C, 5/8). By contrast, there was no posterior shift of the endogenous Hoxb 9 transcription domain in those control embryos, where only CMV-EGFP was electroporated (Fig. 3-7D, 6/6). This result demonstrates that overexpressed Geminin represses Hox gene transcription, which suggests a Polycomb like activity of Geminin.
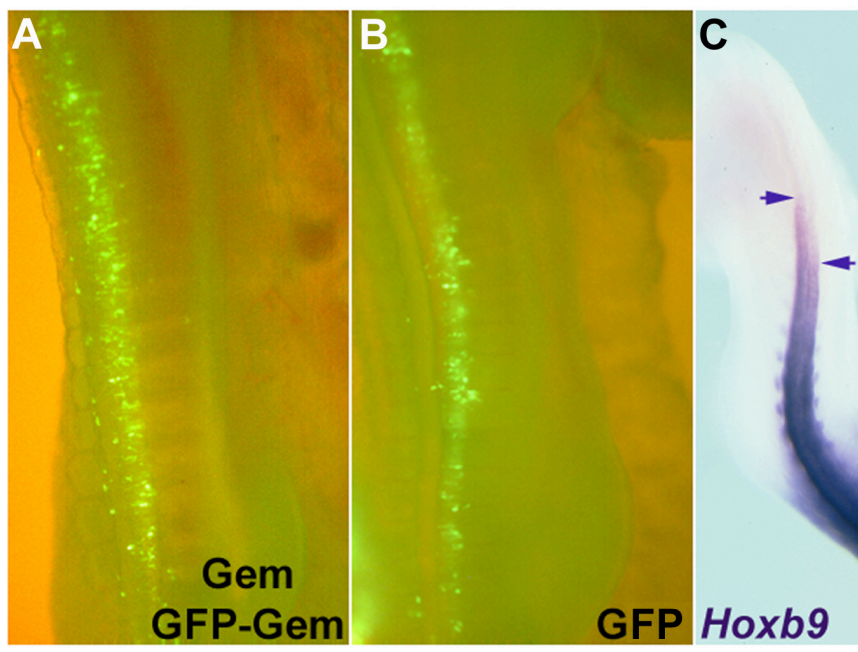

D

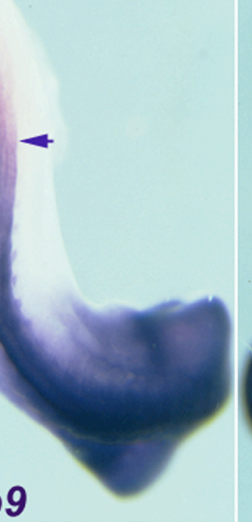

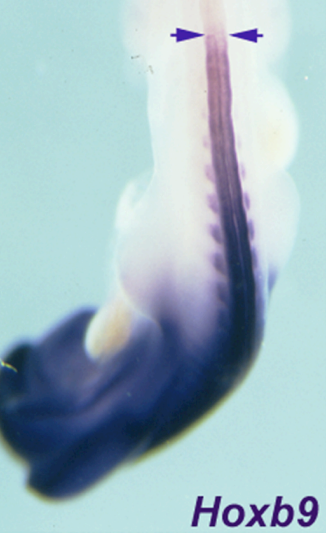

Figure 3-7: Overexpression of Geminin inhibits endogenous Hoxb9 transcription. (A, B) GFP expressions were documented 24 hours after unilateral electroporation of expression plasmids to the right side of the neural tube of HH9-11 stage chick embryos. (C, D) Endogenous Hoxb9 transcripts were detected by whole-mount in situ hybridization in the same embryos depicted in (A) and (B), respectively, at stage HH18-19. Arrowheads indicate the anterior transcription boundary of Hoxb9. 


\subsection{Loss of Geminin Function Derepresses Hox Gene Transcription}

To ensure that the inhibition of Hox gene transcription by Geminin is really due to a Geminin-Polycomb interaction and better characterize the role of Geminin in the Polycomb complex, the Geminin-binding domains of Scmh1 was delineated precisely. The amino acids sequence of Scmh1 was subdivided into 20-amino acidlength peptides from $\mathrm{N}$ - to $\mathrm{C}$-terminus, with 17 amino acids overlapping between adjacent peptides. All these peptides were synthesized and arrayed onto a cellulose membrane. Binding of recombinant His-Geminin protein to arrayed Scmh1 peptides revealed a basic amino acid rich domain of Scmh1 (amino acids 540-568) as the Geminin-binding region lying outside the SPM domain (Fig. 3-8A), through which Scmh1 associates with other Polycomb members (Tomotsune et al., 1999). From this information a dominant-negative form of Scmh1 (amino acids 508-585, dnScmh1), which included the Geminin-binding domain but not the SPM domain, was designed (Fig. 3-8B). The binding of dnScmh1 to Geminin was confirmed using a pull-down assay (Fig. 3-8C).

A

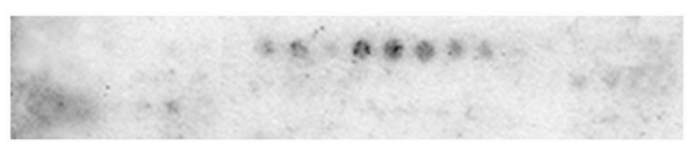

11. PLSTVSAVRRLCSKGVLKGK

12. TVSAVRRLCSKGVLKGKKER

13. AVRRLCSKGVLKGKKERRDV

14. RLCSKGVLKGKKERRDVESF
B

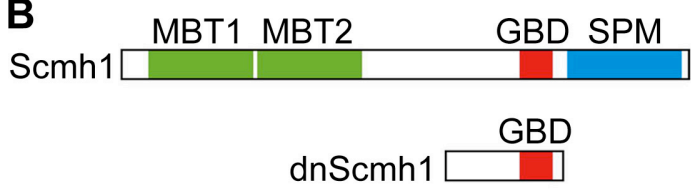

C

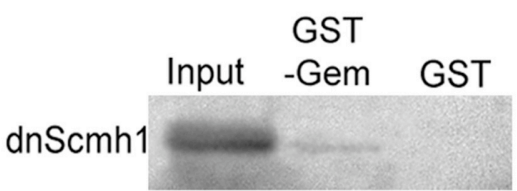

Figure 3-8: The design of a dominant-negative $\mathrm{Scmh} 1(\mathrm{dnScmh} 1)$ molecule. (A) Binding of Histagged Geminin to a Scmh1 peptide array. Below, His-Geminin bound peptides are listed (number 1114). Amino acids 540-568 of Scmh1 comprise the Geminin-binding domain. (B) Amino acids 508-585 of Scmh 1 protein was designed as a dnScmh1 protein, including the Geminin-binding domain (GBD) but not the SPM domain. (C) Confirmation of dnScmh1-Geminin binding through a GST-Geminin pull-down assay.

The introduction of abundant dnScmh1 protein into cells was supposed to compete for Geminin binding with endogenous Scmh1 protein, and remove Geminin out of the Polycomb complex (Fig. 3-9). In ovo co-electroporations of a dnScmh1 expression vector and CMV-EGFP to the right side of the neural tube (Fig. 3-10A), controlled by 


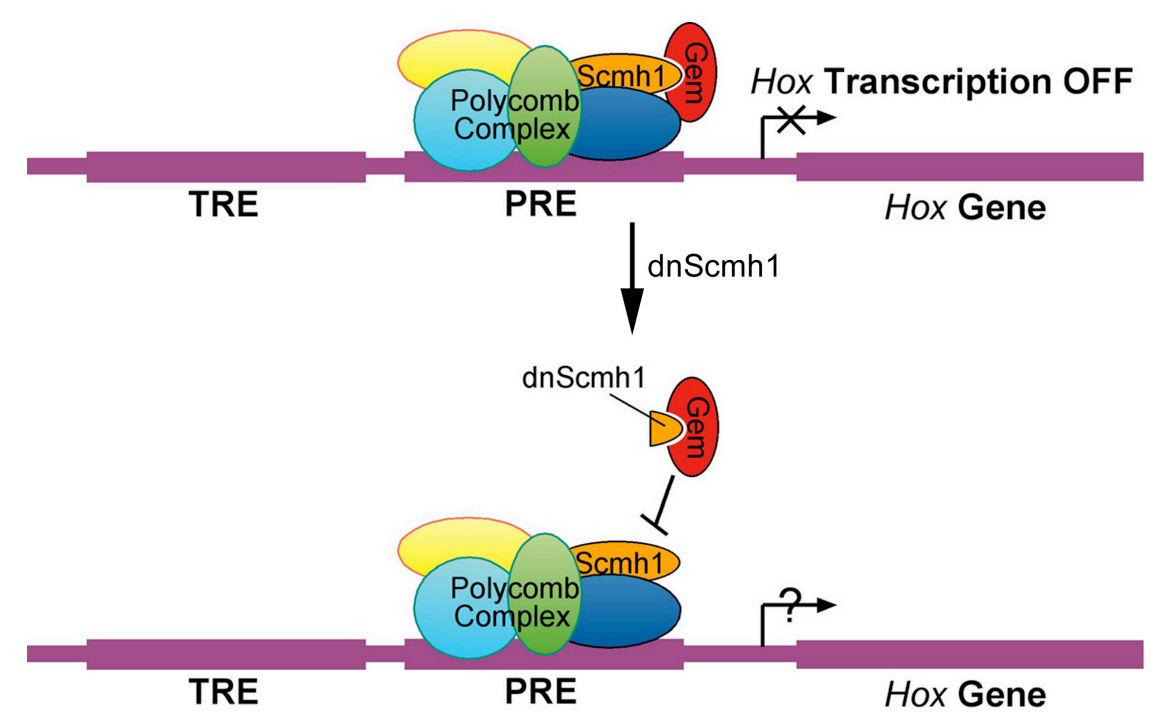

Figure 3-9: Schematic representation of the dominant negative inactivation of Geminin by dnScmh1.

single electroporations of CMV-EGFP (Fig. 3-10B), and whole-mount in situ hybridization to Hoxb9 (Fig. 3-10C,D) were performed as described above. In contrast to the control (Fig. 3-10D, 5/5), a derepression of Hoxb9 transcription, one somite length anterior of the normal expression boundary (Fig. 3-10C, 6/8), was observed. This result demonstrates that the inhibition of Hox gene transcription by Geminin is due to a Geminin-Polycomb interaction, that is, that Geminin behaves like a Polycomb protein in vivo.

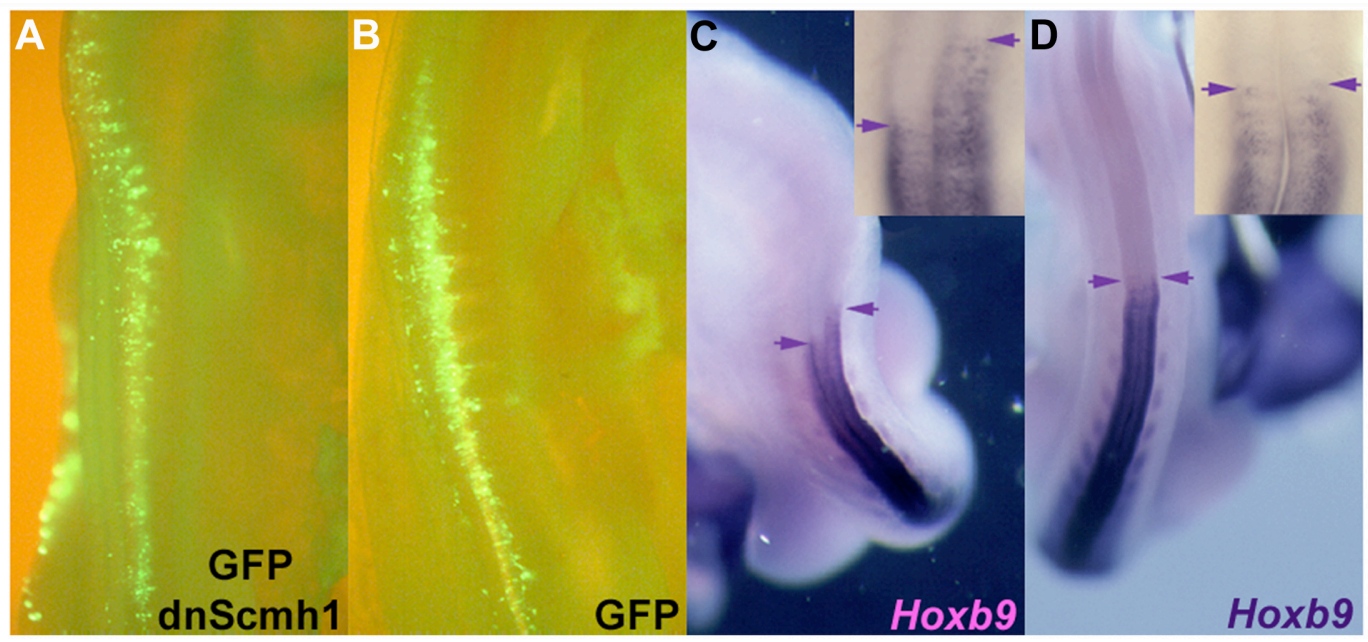

Figure 3-10: In vivo Geminin loss-of-function by a dominant-negative Scmh1 derepresses Hoxb 9 transcription. (A, C) Ectopically expressed dnScmh1 derepresses the Hoxb 9 transcription and shifts its transcription domain anteriorly in the right side of the neural tube, but not in the control embryo shown in (B, D). Arrowheads indicate the anterior transcription boundary of Hoxb9. 
A direct elimination of Geminin was carried out by the co-electroporation of siRNA against chick Geminin (siGem) and CMV-EGFP, controlled by siRNA against luciferase (siLuc; Fig 3-11). Similarly, a pronounced derepression of Hoxb9 transcription by one and a half to two somites length was observed (Fig. 3-11C, 5/7). This finding indicates that the downregulation of endogenous Geminin derepresses Hoxb9 transcription, further confirming that Geminin behaves like a Polycomb protein in vivo.
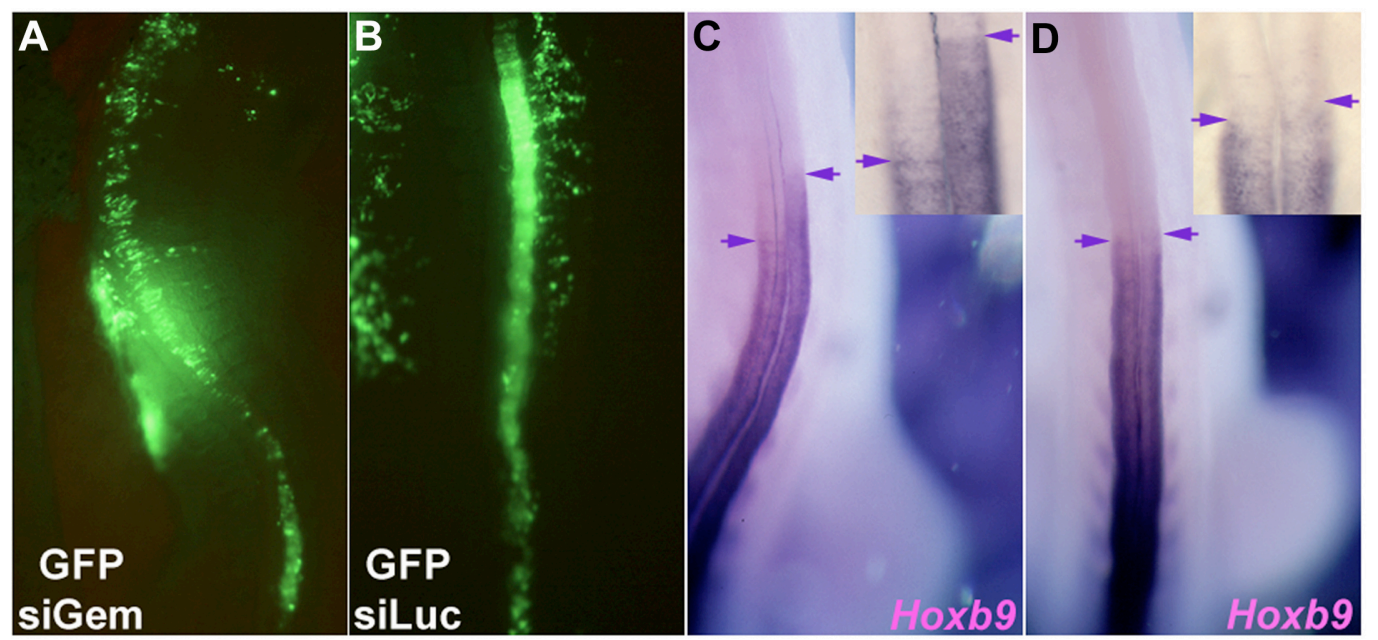

Figure 3-11: Direct elimination of endogenous Geminin by siRNA derepresses Hoxb 9 transcription. (A, C) The Hoxb9 anterior transcription boundary was anteriorly shifted by siRNA against Geminin, but not by the control siRNA against luciferase (B, D). Arrowheads indicate the anterior transcription boundary of Hoxb9.

\subsection{Geminin Directly Interacts with the Homeodomain of Hox Proteins}

From the yeast two-hybrid screen and GST pull-down assays, Geminin not only binds to the Hox repressive Polycomb member Scmh1, but also interacts direcly with Hox proteins. Through the application of peptide arrays, the homeodomain of Hoxa1 1 protein was identified as the Geminin binding region, with two clusters of basic amino acids as the core binding sequences (Fig. 3-12A,B, red frames).

The N-terminus of Hoxa11 had a slightly positive influence on Geminin binding, as indicated in lacZ activities in two-hybrid screen (Fig. 3-1B). Clone 1, 2 and 8 all indicated the interaction between Geminin and Hoxa11, but the lacZ activity that reflected the binding affinity in clone 1 was weaker than the others. Further investigations of Hoxa11 encoding sequences in these three clones revealed that the 
Hoxa11 complementary DNA sequence in clone 1 encoded a truncated Hoxa11 protein with the N-terminal 163 amino acids missing. Therefore, the N-terminal region of Hox proteins regulates their interactions with Geminin, although the Cterminal homeodomain is the direct Geminin biniding site. This N-terminal effect also explains why the homeobox protein Msx1 does not interact with Geminin. The deletion of N-terminal 90 or 140 amino acids resulted in two truncated Msx1 proteins. In contrast to the full-length Msx1, both of the truncated Msx1 proteins were detected to interact with Geminin using a GST pull-down assay. In addition, the longer sequence deleted from the N-terminus, the stronger the interaction was (Fig. 3-12C). Thus, N-terminal Msx1 sequences inhibited the interaction of Geminin with the Msx1 homeodomain, which lead to the loss of affinity between Geminin and full-length Msx1 proteins. From these results, I conclude that the N-terminus has an influence on the binding of Geminin to a homeodomain protein.

A

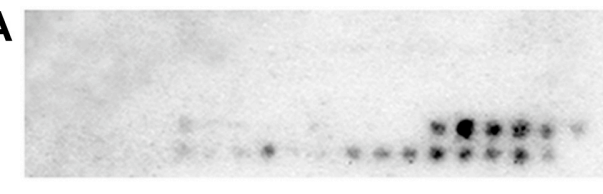

75. SSSGHTEDKAGGSGGQRTRK

76. GHTEDKAGGSGGQRTRKKRC

77. EDKAGGSGGQRTRKKRCPYT

78. AGGSGGQRTRKKRCPYTKYQ

79. SGGQRTRKKRCPYTKYQIRE

80. QRTRKKRCPYTKYQIRELER

93. LNLTDRQVKIWFQNRRMKEK

94. TDRQVKIWFQNRRMKEKKIN

95. QVKIWFQNRRMKEKKINRDR

96. IWFQNRRMKEKKINRDRLQY

97. QNRRMKEKKINRDRLQYYSA

98. RMKEKKINRDRLQYYSANPL

99. MKEKKINRDRLQYYSANPLL
B

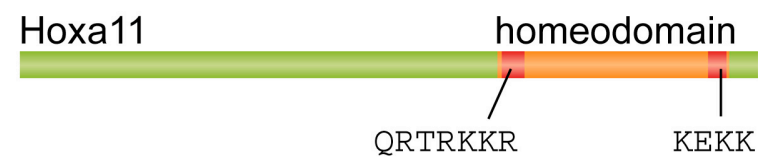

C

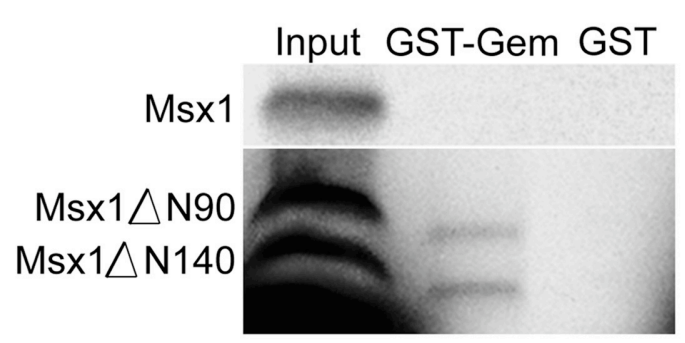

Figure 3-12: Geminin binds to the homeodomain of Hox proteins. (A) Binding of His-Geminin to a Hoxa11 peptide array. Bound peptides are listed, and the common core sequences are framed in red. (B) The Geminin binding domains of Hoxa11 are localized inside its homeodomain (orange), with the core binding sequences marked with red. (C) N-terminal sequences affect the Geminin-homeodomain interaction. Full-length Msx1 does not interact with Geminin, whereas the two N-terminal truncated forms of Msx1 do interact with Geminin. The longer sequence deleted from the N-terminus, the stronger the interaction was. Msx $1 \Delta 90$ or Msx $1 \Delta 140$ represents truncated Msx1 proteins with Nterminal 90 or 140 amino acids deleted. 


\subsection{The Interaction with Geminin Inhibits the DNA Binding of Hox Proteins}

Since the homeodomain is the DNA binding domain of Hox protein, this finding suggest that Geminin might represent a specific antagonist of DNA binding by the Hox homeodomains. We performed electrophoretic mobility shift assays (EMSA), applying in vitro transcribed/translated Hoxd10, Hoxa11, Hoxb7 and Msx1 proteins, radioactive labeled double-stranded oligonucleotides including their respective, consensus binding sequences, and recombinant His-Geminin protein. The Hox proteins led to prominent shifts of oligonucleotide bands during electrophoresis (Fig. 3-13, lane 2,4,6,9). Pre-incubations of Geminin with Hox proteins resulted in the release of free probe, hence a significant reduction of the shifted bands (Fig. 3-13, lane 3,5,7,10). In contrast, the binding of Msx1 to its target sequence was not attenuated by Geminin (Fig. 3-13, lane 11,12). In summary, Geminin inhibits the binding of Hox proteins to their target DNA sequences as a result of interacting with, and thus blocking, their homeodomains.

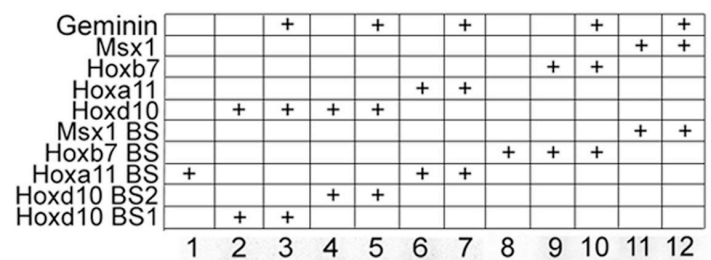

Figure 3-13: Geminin interferes with the binding of Hox proteins to specific double stranded DNAs in vitro. In the EMSAs, HisGeminin recombinant protein, in vitro transcribed/translated Hoxb7, Hoxd10,

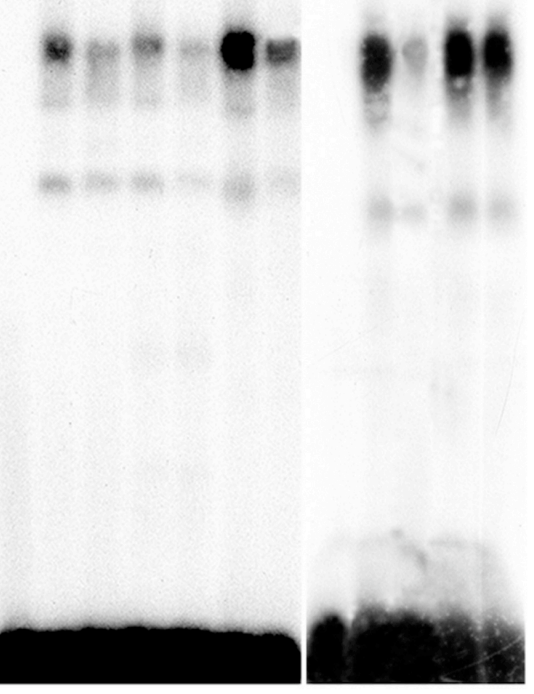
Hoxa11, and Msx1 proteins, and five different binding sites (BS) were applied.

\subsection{Geminin Inhibits Hox Dependent Transcriptional Activations of Reporter}

\section{Gene}

Since Geminin blocks Hox homeodomains, in order to examine whether Geminin inhibits the transcriptional activation promoted by Hox in vivo, a reporter construct 
was designed by inserting a triple Hoxa11 binding sequence before a SV40 basic promoter, followed by a luciferase reporter gene (Fig. 3-14A, a11Luc). As expression vectors, CMV-Hoxal1 and CMV-Gem were applied. A positive control was represented by pGL3-Control, where the SV40 promoter is driven by the SV40 enhancer. Different combinations of expression vectors were co-transfected with a11Luc into NIH/3T3 cells and luciferase activities were measured 24 hours after transfection. Expression of the reporter gene was 10-fold enhanced by the overexpression of Hoxa11. This increased level was reduced by $60 \%$ if in addition to Hoxa11 also Geminin was overexpressed (Fig. 3-14B). Similarly, another reporter plasmid was constructed by inserting a 500 bp FGF2 promoter fragment including a Hoxb7 binding site (Care et al., 1996) before the luciferase gene (Fig. 3-15A, FgfLuc). The luciferase activity was increased dramatically by the overexpressed Hoxb7 in Hela cells, and this increment was reduced by $40 \%$ by Geminin (Fig. 3-15B, column 1-3). No appreciable change of the luciferase activity was observed, when a control DNA fragment with mutated Hoxb7 binding site was inserted and applied (ConLuc; Fig. 3-15B, column 4-6). Together, these data show that the Geminin-Hox interaction interferes with the role of Hox proteins as transcriptional activators.
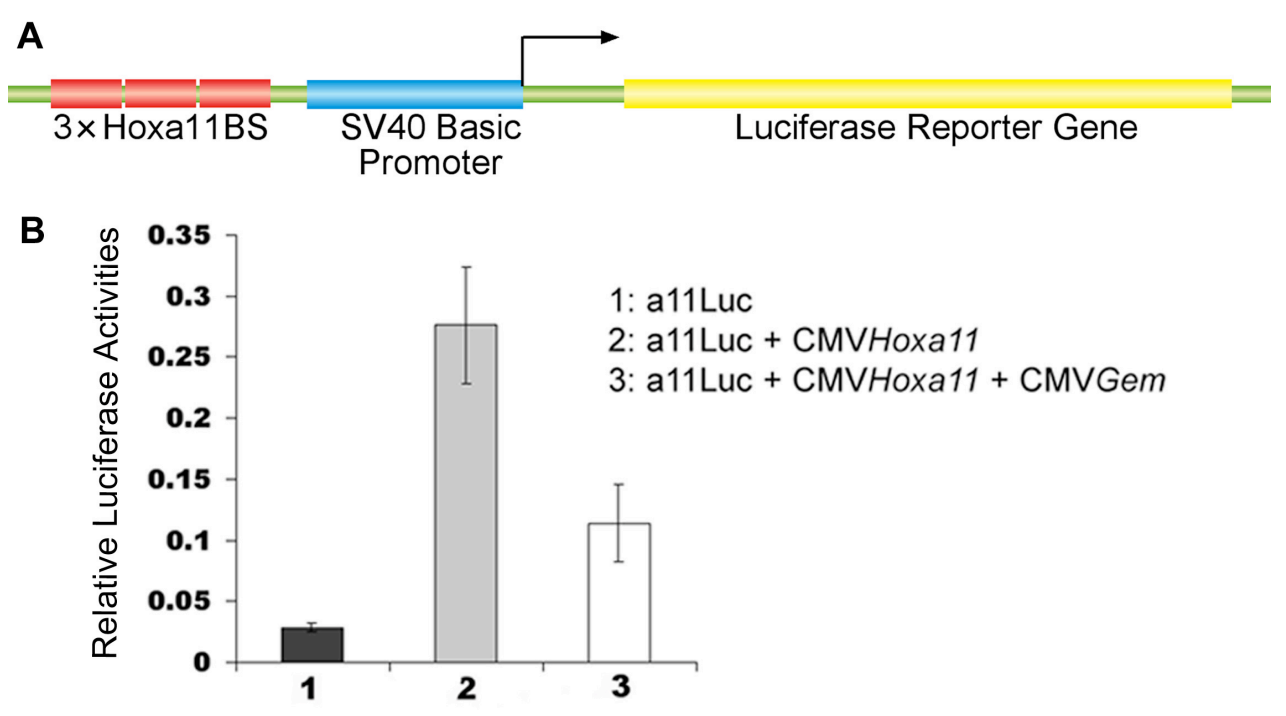

Figure 3-14: Geminin inhibits Hoxa11 dependent transcriptional activation of luciferase reporter gene. (A) Schematic representation of the a11Luc luciferase reporter construct with a triple Hoxa11 binding site (BS) inserted before an SV40 basic promoter. (B) The transcriptional activation of luciferase reporter gene promoted by Hoxa11 was inhibited by Geminin. The values of measured luciferase activities were brought to ratios of the positive control pGL3-Control, which was set as "1" in arbitrary units. 

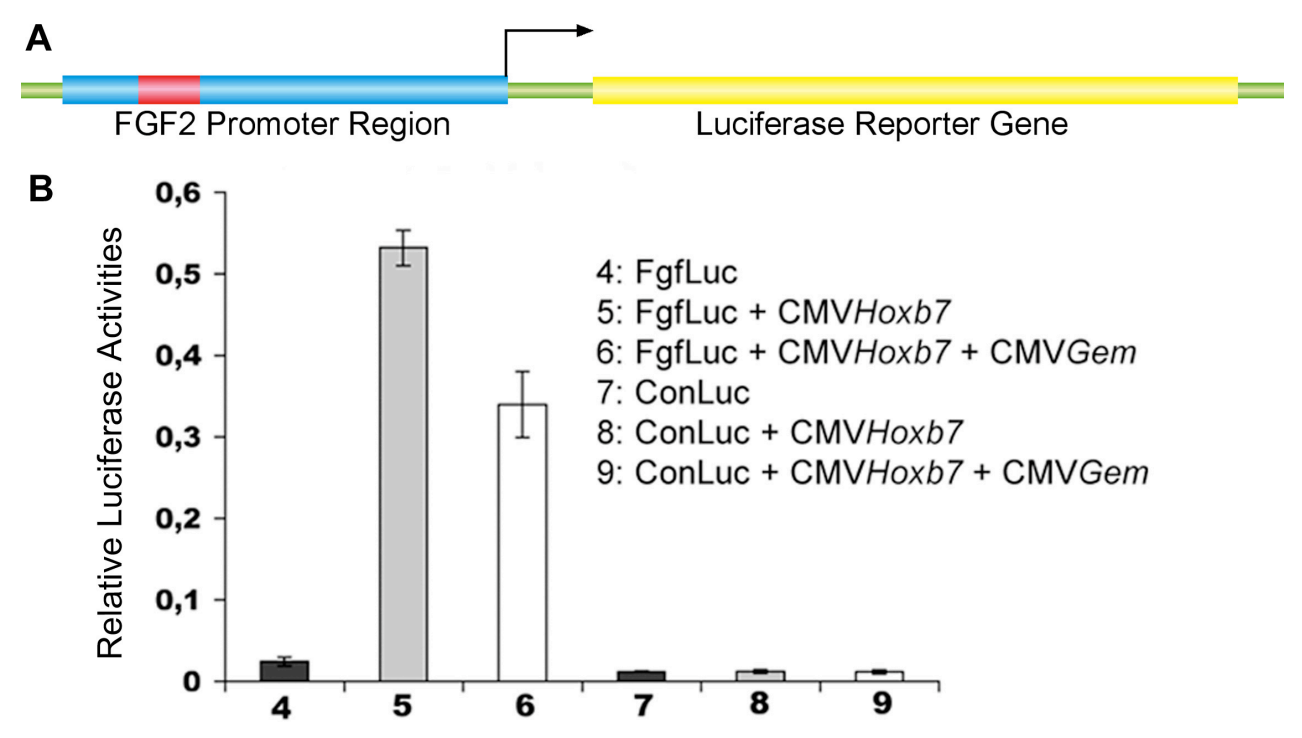

Figure 3-15: Geminin inhibits Hoxb7 dependent transcriptional activation of luciferase reporter gene. (A) Schematic representation of the FgfLuc luciferase reporter construct with an FGF2 promoter region including a Hoxb7 binding site (red) inserted before the luciferase reporter gene. (B) The transcriptional activation of luciferase reporter gene promoted by Hoxb7 was inhibited by Geminin, but not the control reporter construct with the Hoxb7 binding site mutated. The values of measured luciferase activities were brought to ratios of the positive control pGL3-Control, which was set as "1" in arbitrary units.

\subsection{Geminin Inhibits Hox Dependent Transcriptional Activation of Endogenous Downstream Target Gene}

FGF2 is a downstream target gene of Hoxb7 in the melanoma cell line A375 (Care et al., 1996). This well defined system was used to study the influence of Geminin on the function of Hox proteins. CMV-Gem, a siRNA targeting human Geminin mRNA (sihGem), or siLuc were transfected into cultured A375 cells. Subsequently, Geminin, FGF2 or Vimentin levels were detected by western blotting (Fig. 3-16). We observed a decrease of FGF2 level in parallel with an elevated level of Geminin, and an increase of FGF2 in parallel to the suppression of Geminin caused by specific siRNA. These results suggest that the level of Geminin modulates the function of the Hoxb7 protein in vivo, as detected here by measuring the product of its direct target FGF2. In addition, the FGF2 promoter region could not be detected, when a ChIP assay was performed using an A375 cell extract and Geminin antibodies (data not shown), indicating that Geminin is not recruited with Hoxb7 to its DNA target. Taken together, Geminin binds to the homeodomain of Hox proteins, blocks their DNA 
binding, and inhibits Hox dependent transcriptional activations of reporter and endogenous downstream target genes.

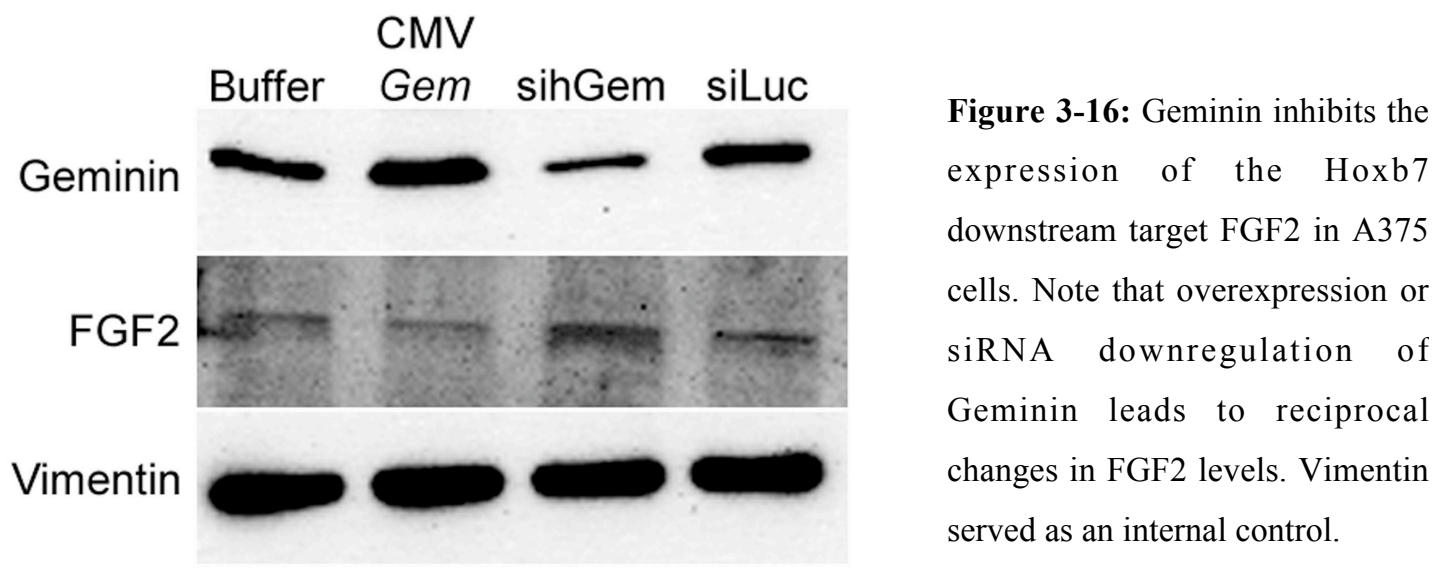

\subsection{Hox and Cdt1 Compete for Geminin Binding}

Since the Hox binding regions of Geminin partially overlap with its coiled-coil domain, which is also the Cdt1 binding domain, I further investigated whether Hox proteins compete for the binding of Cdt1 to Geminin. The Cdt1 protein in the 11.5 d.p.c. mouse embryonic extracts was pulled-down with Geminin-coupled beads. The pull-down of Cdt1 was prominently decreased by a pre-incubation of the Geminincoupled beads with GST-Hoxa11 recombinant protein, but not with GST alone (Fig. 3-17A). This result indicated the competition of Hoxa11 and Cdt1 proteins for Geminin binding in vitro.

The in vitro result was further supported in vivo using primary cultured MEFs. When Hoxb7 or Hoxa11 was overexpressed, the amount of Cdt1 co-precipitated by Geminin antibodies was significantly reduced in contrast to the control cells transfected with empty vector, whereas the level of Geminin itself was not affected (Fig. 3-17B). This result indicated that the overexpressed Hox proteins in the cells competed with endogenous Cdt1 for Geminin binding, thus leading to reductions of co-precipitated Cdt1 with Geminin. Together, these data indicate that Hox proteins can compete with Cdt1 for Geminin binding and displace Geminin from the Cdt1Geminin complex. 
A

$$
\begin{array}{ccc}
\text { Gem+ } & \text { Gem+ } \\
\text { Gem } & \text { GST-Hoxa11 } & \text { GST }
\end{array}
$$

Cdt1
B

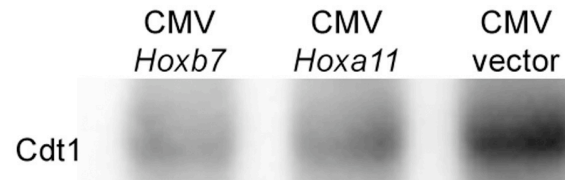

Geminin

Figure 3-17: Competition for Geminin binding between Cdt1 and Hox proteins. (A) Competition for Geminin binding between Cdt1 and Hoxa11 in vitro. Note that the binding of endogenous Cdt1 was significantly reduced when GST-Hoxa11, but not GST alone, was pre-bound to immobilized Geminin. (B) Competition for Geminin binding between Cdt1 and Hox proteins in vivo. Note that the coprecipitated endogenous Cdt1 was significantly reduced when Hoxb7 or Hoxa11 was overexpressed in the cells, whereas the level of Geminin itself was not affected. 


\section{Discussion}

\subsection{The Roles of Hox and Polycomb Proteins in Cell Cycle Regulation and the Involvement of Geminin}

Embryonic growth and patterning along an axis and the colinear activation of Hox genes have to be precisely coordinated during development. Positive or negative controls of proliferation must feed back on Hox gene activation or repression in order to guarantee proper formations of morphologic structures and to prevent homeosis (Duboule, 1995). Thus, it is not surprising that several indications were reported for roles of Hox as well as Polycomb proteins in proliferation, cell cycle control, and transformation.

In many cases, Hox proteins themselves are involved in proliferation, cell cycle regulation, and transformation. For an instance, $\mathrm{Hoxb} 7$ is constitutively expressed in many proliferating melanoma cell lines, but not in normal quiescent melanocytes. To better understand the mechanisms underlying this phenomenon, mechanistic investigations of one of the melanoma cell line demonstrated that basic fibroblast growth factor $(F G F 2)$ is one of the Hoxb7 direct downstream target genes. Hoxb7 protein transactivates $F G F 2$ gene transcription through direct binding to its promoter region. Antisense oligonucleotides targeting Hoxb7 mRNA specifically abolish FGF2 mRNA transcription and markedly inhibit cell proliferation (Care et al., 1996). Other examples include Hoxb3 or Hoxb4, which can induce cellular proliferation and transformation in Rat-1 cells in cooperation with $\mathrm{Pbx}$ homeodomain protein (Krosl et al., 1998). Primary bone marrow cells, retrovirally engineered to overexpress Hoxa9 and co-factors, induce growth factor-dependent leukemic transformation (Kroon et al., 1998). Furthermore, the upregulation of AP-1 activity was identified as one of the molecular mechanisms underlying Hox-induced cellular proliferation and transformation (Krosl and Sauvageau, 2000). Here, my work suggests another possible mechanism through interacting with Geminin thereby releasing Cdt1 by Hox proteins. Then, the released Cdt 1 is available for the licensing process, thus promoting DNA replication and cell proliferation.

Not only the Hox proteins, but also the Polycomb complex members are involved in proliferation and cell cycle regulation. Bmi-1 has a key role in regulating the proliferative activity of normal stem and progenitor cells. The proliferative potential of leukemic cells lacking Bmi-1 is compromised, so that these cells finally undergo 
proliferation arrest, and show signs of differentiation and apoptosis. These proliferative defects can be completely rescued by Bmi-1 replenishment (Lessard and Sauvageau, 2003). Ring1B deficiency leads to cell cycle inhibition and gastrulation arrest during murine development (Voncken et al., 2003). Obviously, these proliferative effects of Polycomb complex members are probably not achieved through their Hox transcription inhibition pathway, since the Hox proteins also play positive roles in cellular proliferation as described above. Nevertheless, if we consider that the Geminin-Polycomb association plausibly resembles Geminin-Hox interaction to reduce the availability of Geminin to Cdt1 binding, cellular proliferation can also be promoted by Polycomb members through a similar mechanism like Hox proteins.

\subsection{The Association between Geminin and the Polycomb Complex}

In the study, an overexpression or a loss-of-function of Geminin along the whole right side of neural tube resulted in a shift of Hoxb9 anterior transcription boundary only within one or two segments instead of the whole neural tube (Fig. 3-7, 10, 11). Similarly in previous studies, despite the ubiquitous presence of $P c G$ and $\operatorname{tr} x G$ mRNAs during development, global alterations of Hox gene transcription have not been observed in the $P c G$ or $\operatorname{tr} x G$ mutant mice (Schumacher and Magnuson, 1997). The shiftes in Hox gene expression boundaries and skeletal transformations involve only one to two segments, and are neither fully penetrant nor observed in all tissues. This restricted boundary shifts within normal target tissues implies several possibilities. First, the distribution of and the interplay between repressors and activators vary regionally. Second, only Hox expression boundaries are sensitive to the presence of absence of these upstream regulators. Third, functional redundancy among trans-acting proteins masks the loss of a single component outside of expression boundaries, which is substantiated by the exacerbated phenotypes of homozygous mutant for two Polycomb members. These three possibilities can serve as the explanations of the limited shift of Hoxb 9 anterior transcription boundary in my study and mild homeotic transformations in mutant mice, alone of synergically.

Three findings on Geminin could help to define the functional phase of the Polycomb complex during the cell cycle. Firstly, Geminin is only available from the early $\mathrm{S}$ phase to the end of the mitosis. Secondly, this transient association with Geminin is crucial for Polycomb to inhibit Hox gene transcription, since a loss of Geminin function in the embryo by either dominant-negative Scmh1 or siRNA leads 
to a de-repression of Hox gene transcription (Luo et al., 2004) Thirdly, the mitotic phase is not the functional phase, since the complete Polycomb complex does not remain at its target site all the way through mitosis, although individual members could remain associated with the mitotic chromosome (Buchenau et al., 1998). Therefore, the repression of Hox genes by the Polycomb complex plausibly takes place at the S and G2 phase of the cell cycle (Luo and Kessel, 2004a). This is exactly coincident with a previously reported result, demonstrating that Hoxc10 gene expression is initiated at the late G1 phase of the cell cycle (Gabellini et al., 2003).

Geminin seems not to contribute to the transcriptional memory, the "memory body", epigenetically maintained by Polycomb complexes (Francis and Kingston, 2001), since it is absent from the nucleus in some phases of cell cycle. However, Geminin definitively contributes to the "functional body" of the complex, since its removal from the complex, either by dominant-negative titration or by siRNAmediated knock-down, de-represses Hox gene transcription. The componential difference between the "memory body" and the "functional body", and thus the mechanism underlying the maintenance of Polycomb repression throughout replication or mitosis still remains unclear. But, apparently, to perform its transcriptional repression function through each cell division, the "memory body" will recruit many transient components, including Geminin, to form the functional Polycomb complex (Luo and Kessel, 2004a).

\subsection{The Direct Interaction between Geminin and Hox Proteins}

Geminin not only inhibits Hox gene transcription through Polycomb-mediated interaction, but also binds to the homeodomains of Hox proteins directly. This direct interaction blocks the Hox homeodomain, inhibits its binding to DNA, and thus prohibits a regulatory function in downstream transcription, as was demonstrated in biochemical assays. Surprisingly little is known about downstream targets of vertebrate Hox genes, be it in an embryonic context or in tissue culture cells. However, as depicted above, a relatively well characterized example is the relationship between Hoxb7 as an activator, and $F G F 2$ in a melanoma cell line. In this experimental system it was shown that a modulation of the Geminin level led to reciprocal changes in the level of FGF2. Thus, the sequestration of a Hox protein and the consequent transcriptional inhibition of its downstream target FGF2 by Geminin correlated with the deceleration of cell cycle and cell proliferation, adding a second 
mechanism of action, besides the well-defined Cdt1 binding pathway (Luo and Kessel, 2004a).

The involvement of Geminin in the function of Hox genes accentuates its role as a regulator of embryonic processes. A different evidence for such a role was previously pointed out, when a function in the neuralization of ectodermal cells was shown in the frog Xenopus (Kroll et al., 1998). During eye development of the Medaka fish, Geminin directly interacts and antagonizes the role of another homeobox protein, Six3. Different over-doses of Geminin in the embryo result in smaller eyes, cyclopia, or loss of the entire forebrain, phenotypes resembling those after a loss of Six 3 function (Del Bene et al., 2004; Carl et al., 2002). Mechanistically, this shows that by means of direct binding and inhibiting Six3, Geminin can induce cellular proliferation inhibition accompanied by premature neural induction and apoptosis. Since Hox genes and Six3 all belong to the homeobox family, the question arises, if and how other homeodomain proteins might interact with Geminin.

\subsection{The Coordination of Cell Cycle and Developmental Control by Geminin}

The Hox interaction regions of Geminin partly overlap with its coiled-coil domain that has been demonstrated to be the Cdt1 binding and re-replication inhibition domain. Hence, there is a competition between the Hox-Geminin, and the Cdt1-Hox interaction (Fig. 4-1). If Cdt1 binds to Geminin, Hox proteins can be expected to be released from the Geminin inhibition. They would then be free to recognize and bind to enhancer sequences of their downstream target genes, and to activate their transcription. In the meantime, Cdt1 would be available to bind to Geminin, and not for the initiation of replication. This sequestration of Cdt1 during embryonic development would impede proliferation and, in effect, promote differentiation. Vice versa, if the Geminin-Hox association is dominant and Cdt1 is available for DNA replication, the transcriptional activation of Hox downstream target genes and the subsequent cell differentiation will be hampered, while proliferation will be favoured. These Geminin-mediated, competitive interactions establish an equilibratory system in the cells between Cdt1 and Hox proteins, or, more generally, between proliferation and differentiation (Fig. 4-1). It is most likely, that further factors are involved in the establishment of this equilibrium, and Polycomb complex members appear to be likely candidates. Post-translational polyubiquitination of Geminin can influence its interaction with Cdt1 (Li and Blow, 2004), and other modifications like 
phosphorylation of Geminin have also been demonstrated (Kulartz et al., 2003). However, the role of protein modifications for the affinity of Geminin to Hox proteins, and thus for the Hox-Geminin-Cdt1 equilibrium, are still not known. The qualitative and quantitative differences of the components in this system will finally decide, whether a cell will continue its proliferation, or start to undergo differentiation.

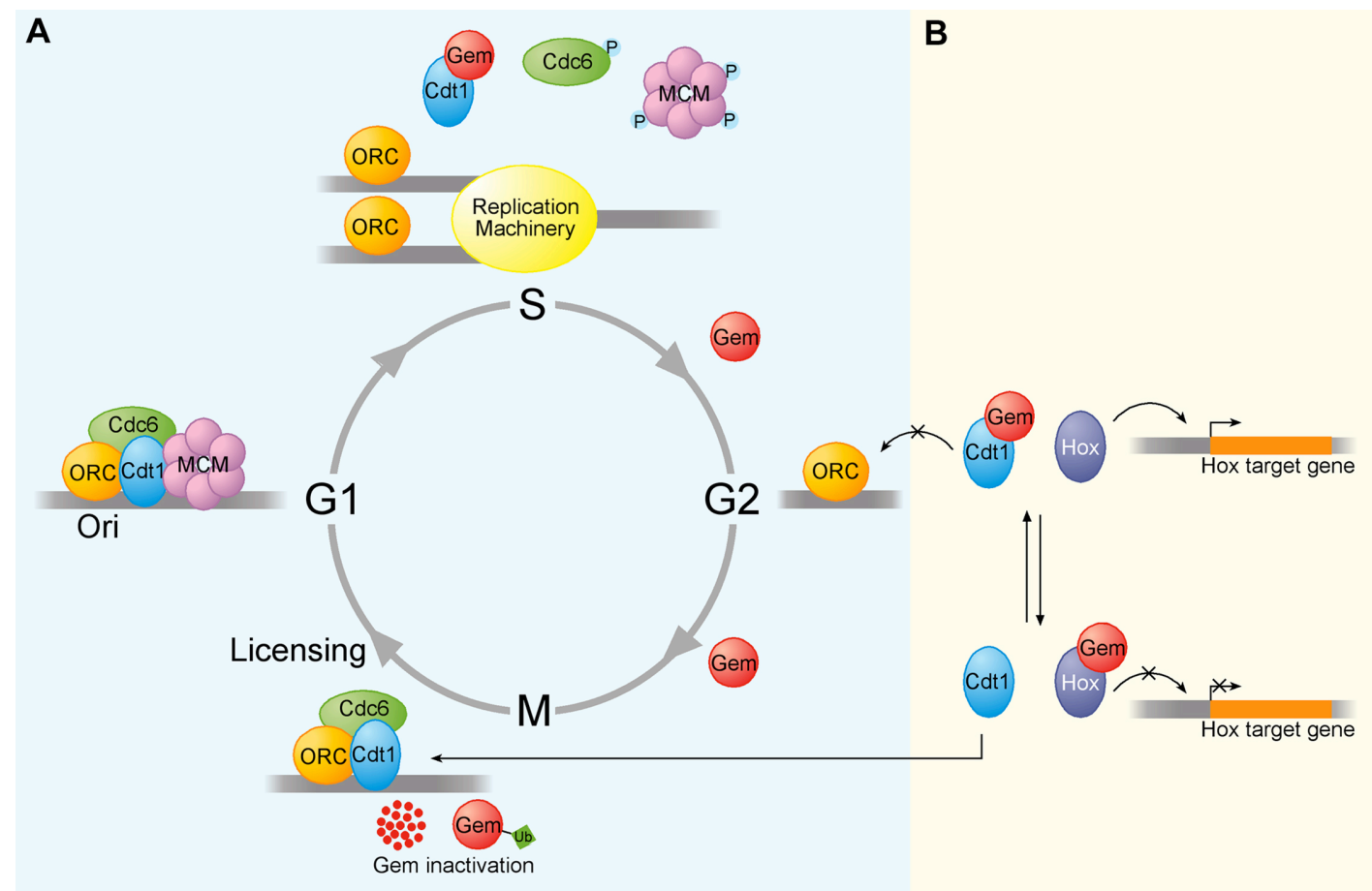

Figure 4-1: (A) The role of Geminin in cell cycle regulation through Cdt1 sequestration. (B) The competition of Hox and Cdt1 for Geminin binding. These competitive interactions establish an equilibratory system to decide on cellular proliferation or differentiation. P: phosphorylation. Ub: ubiquitination (Lygerou and Nurse, 2000; Luo and Kessel, 2004a).

A coordination between proliferative and differential controls is essential for embryonic development. This is particularly evident in the patterning of the anteroposterior axis controlled by the colinear activation of Hox genes. Positive or negative controls of proliferation must feed back on Hox gene activation or repression in order to guarantee proper formations of anatomical structures. If proliferation and Hox gene activation run out of register, a proper structure will be generated at a wrong place. Such a modification would perfectly fit a type of natural variation defined as "homeosis". In vertebrates, homeotic transformations are especially apparent along 
the vertebral column, when for example the base of the skull develops as a vertebra, or ribs develop in the cervical or lumbar regions of the vertebral column (Kessel and Gruss, 1991). Geminin is involved both in the regulation of proliferation by arresting Cdt1 and inhibiting rereplication during cell cycle, and in the regulation of Hox- and Polycomb-dependent embryonic patterning. Through its participation in both multiprotein machineries, Geminin could be a key element in the coordination of cell cycle and developmental control. 


\section{Summary and Conclusions}

In the work, I have shown that murine Geminin associates transiently with members of the Hox-repressing Polycomb complex dependent on the cell cycle, with the chromatin of Hox regulatory DNA elements, and with Hox proteins. Gain- and loss-of-function experiments in the chick neural tube demonstrate that Geminin modulates the anterior boundary of Hoxb9 transcription, indicating a Polycomb-like activity. The interaction between Geminin and Hox homeodomains blocks the binding of Hox proteins to DNA, inhibits the Hox dependent transcriptional activation of reporter and endogenous downstream target genes, and displaces Cdt1 from its complex with Geminin. Thus, the work suggests that Geminin is involved in two processes controlled by multiprotein complexes. One is the specification of cellular identity during embryogenesis, which is controlled by Hox proteins and the Polycomb complex, including Scmh1 (Fig. 5-1A,B). The other is the replication initiation of DNA during the cell cycle, which is controlled by ORC, Cdc6, Cdt1, and MCM complex (Fig. 5-1C). The participations of Geminin in these two processes are competitive with each other (Fig. 5-1C). Therefore, by establishing this competitive regulation, Geminin functions as a coordinator between developmental and proliferative control (Luo et al., 2004).
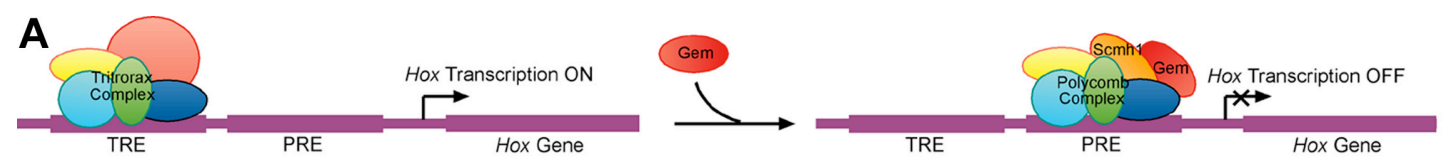

B
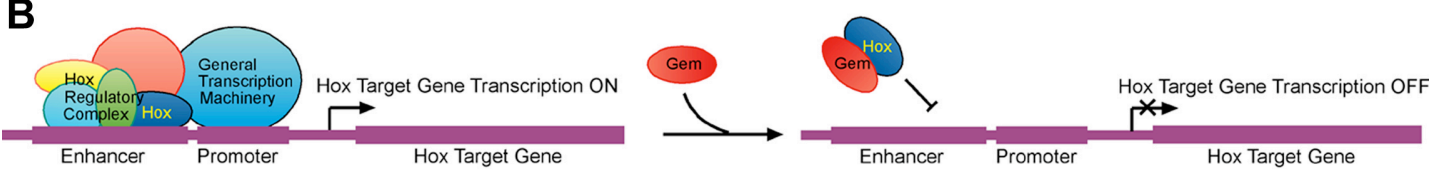

C
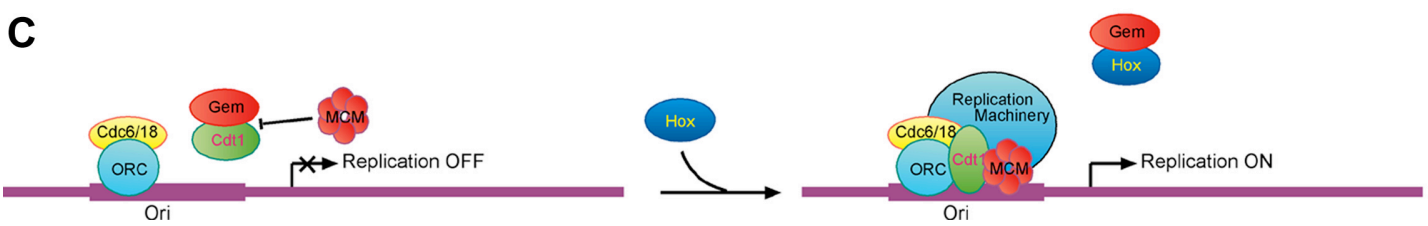

Figure 5-1: Geminin is involved in two processes controlled by multi-protein complexes and establishes their competitive regulation. (A, B) Geminin is involved in the specification of cellular identity during embryogenesis, which is controlled by Hox proteins and the Polycomb complex. (C) Geminin plays an important role in the replication initiation of DNA and preventing rereplication 
during the cell cycle. The participations of Geminin in these two processes are competitive with each other (Luo and Kessel, 2004b). 


\section{References:}

Akam M. The molecular basis for metameric pattern in the Drosophila embryo. Development, 101: 1-22 (1987).

Akasaka T, Kanno M, Balling R, Mieza MA, Taniguchi M and Koseki H. A role for mel-18, a Polycomb group-related vertebrate gene, during the anteroposterior specification of the axial skeleton. Development, 122: 1513-22 (1996).

Barna M, Merghoub T, Costoya JA, Ruggero D, Branford M, Bergia A, Samori B and Pandolfi PP. Plzf mediates transcriptional repression of HoxD gene expression through chromatin remodeling. Dev. Cell, 3: 499-510 (2002).

Bateson W. Materials for the study of variation treated with special regard to discontinuity in the origin of species. London: Macmillan (1894).

Bell SP and Dutta A. DNA replication in eukaryotic cell. Annu. Rev. Biochem., 71: 333-74 (2002).

Bell SP and Stillman B. ATP-dependent recognition of eukaryotic origins of DNA replication by a multiprotein complex. Nature, 357: 128-34 (1992).

Blow JJ and Laskey RA. A role for the nuclear envelope in controlling DNA replication within the cell cycle. Nature, 332: 546-8 (1988).

Bornemann D, Miller E and Simon J. The Drosophila Polycomb group gene Sex comb on midleg $(\mathrm{Scm})$ encodes a zinc finger protein with similarity to polyhomeotic protein. Development, 122: 1621-30 (1996).

Buchenau P, Hodgson J, Strutt H and Arndt-Jovin DJ. The distribution of polycombgroup proteins during cell division and development in Drosophila embryos: impact on models for silencing. J. Cell Biol., 141: 469-81 (1998). 
Burke AC, Nelson CE, Morgan BA and Tabin C. Hox genes and the evolution of vertebrate axial morphology. Development, 121: 333-46 (1995).

Calzada A, Sanchez M, Sanchez E and Bueno A. The stability of the Cdc6 protein is regulated by cyclin-dependent kinase/cyclin B complexes in Saccharomyces cerevisiae. J. Biol. Chem., 275: 9734-41 (2000).

Care A, Silvani A, Meccia E, Mattia G, Stoppacciaro A, Parmiani G, Peschle C and Colombo MP. HOXB7 constitutively activates basic fibroblast growth factor in melanomas. Mol. Cell Biol., 16: $4842-51$ (1996).

Carl M, Loosli F and Wittbrodt J. Six3 inactivation reveals its essential role for the formation and patterning of the vertebrate eye. Development, 129: 4057-63 (2002).

Carpenter PB, Mueller PR and Dunphy WG. Role for a Xenopus Orc2-related protein in controlling DNA replication. Nature, 379: 357-60 (1996).

Casanova J, Sanchez-Herrero E, Busturia A and Morata G. Double and triple mutant combinations of bithorax complex of Drosophila. EMBO J., 6: 3103-9 (1987).

Chesnokov I, Remus D and Botchan M. Functional analysis of mutant and wild-type Drosophila origin recognition complex. Proc. Natl. Acad. Sci. USA, 98: 11997-2002 (2001).

Chong JP, Mahbubani HM, Khoo CY and Blow JJ. Purification of an MCMcontaining complex as a component of the DNA replication licensing system. Nature, 375: 418-21 (1995).

Coleman TR, Carpenter PB and Dunphy WG. The Xenopus Cdc6 protein is essential for the initiation of a single round of DNA replication in cell-free extracts. Cell, 87: 53-63 (1996). 
Cook JG, Chasse DA and Nevins JR. The regulated association of Cdt1 with minichromosome maintenance proteins and Cdc6 in mammalian cells. J. Biol. Chem., 279: 9625-33 (2004).

Coré N, Bel S, Gaunt SJ, Aurrand-Lions M, Pearce J, Fisher A and Djabali M. Altered cellular proliferation and mesoderm patterning in Polycomb-M33-deficient mice. Development, 124: 721-9 (1997).

Dahmann C, Diffley JF and Nasmyth KA. S-phase-promoting cyclin-dependent kinases prevent re-replication by inhibiting the transition of replication origins to a pre-replicative state. Curr. Biol., 5: 1257-69 (1995).

Dekker EJ, Pannese M, Houtzager E, Boncinelli E and Durston A. Colinearity in the Xenopus laevis Hox-2 complex. Mech. Dev., 40: 3-12 (1993).

Del Bene F, Tessmar-Raible K and Wittbrodt J. Direct interaction of geminin and Six3 in eye development. Nature, 427: 745-9 (2004).

Detweiler CS and Li JJ. Ectopic induction of Clb2 in early G1 phase is sufficient to block prereplicative complex formation in Saccharomyces cerevisiae. Proc. Natl. Acad. Sci. USA, 95: 2384-9 (1998).

Drury LS, Perkins G and Diffley JF. The Cdc4/34/53 pathway targets Cdc6p for proteolysis in budding yeast. EMBO J., 16: 5966-76 (1997).

Duboule D. Patterning in the vertebrate limb. Curr. Opin. Genet. Dev., 1: 211-6 (1991).

Duboule, D. Vertebrate Hox genes and proliferation: an alternative pathway to homeosis? Curr. Opin. Genet. Dev., 5: 525-528 (1995).

Duboule D. Vertebrate hox gene regulation: clustering and/or colinearity? Curr. Opin. Genet. Dev., 8: 514-8 (1998). 
Duboule D and Dollé P. The structural and functional organization of the murine HOX gene family resembles that of Drosophila homeotic genes. EMBO J., 8: $1497-$ 505 (1989).

Dubrulle J, McGrew MJ and Pourquié O. FGF signaling controls somite boundary position and regulates segmentation clock control of spatiotemporal Hox gene activation. Cell, 106: 219-32 (2001).

Dutta A and Bell SP. Initiation of DNA replication in eukaryotic cells. Annu. Rev. Cell Dev. Biol., 13: 293-332 (1997).

Elbashir SM, Harborth J, Lendeckel W, Yalcin A, Weber K and Tuschl T. Duplexes of 21-nucleotide RNAs mediate RNA interference in cultured mammalian cells. Nature, 411: 494-8 (2001).

Elsasser S, Chi Y, Yang P and Campbell JL. Phosphorylation controls timing of Cdc6p destruction: A biochemical analysis. Mol. Biol. Cell, 10: 3263-77 (1999).

Findeisen M, El-Denary M, Kapitza T, Graf R and Strausfeld U. Cyclin A-dependent kinase activity affects chromatin binding of ORC, Cdc6, and MCM in egg extracts of Xenopus laevis. Eur. J. Biochem., 264: 415-26 (1999).

Francis NJ and Kingston RE. Mechanisms of transcriptional memory. Nature Rev. Mol. Cell Biol., 2: 409-21 (2001).

Francis NJ, Saurin AJ, Shao Z and Kingston RE. Reconstitution of a functional core polycomb repressive complex. Mol. Cell, 8: 545-56 (2001).

Fujita M, Yamada C, Tsurumi T, Hanaoka F, Matsuzawa K and Inagaki M. Cell cycle- and chromatin binding state-dependent phosphorylation of human MCM heterohexameric complexes. A role for cdc2 kinase. J. Biol. Chem. 273: 17095-101 (1998). 
Gabellini D, Colaluca IN, Vodermaier HC, Biamonti G, Giacca M, Falaschi A, Riva S and Peverali FA. Early mitotic degradation of the homeoprotein HOXC10 is potentially linked to cell cycle progression. EMBO J., 22: 3715-24 (2003).

Gould A. Functions of mammalian Polycomb group and trithorax group related genes. Curr. Opin. Genet. Dev., 7: 488-94 (1997).

Graham A, Papalopulu N and Krumlauf R. The murine and Drosophila homeobox gene complexes have common features of organization and expression. Cell, 57: 36778 (1989).

Greer JM, Puetz J, Thomas KR and Capecchi MR. Maintenance of functional equivalence during paralogous Hox gene evolution. Nature, 403: 661-5 (2000).

Hamburger V and Hamilton HL. A series of normal stages in the development of the chick embryo. J. Morphol., 88: 49-92 (1951).

Harding K, Wedeen C, McGinnis W and Levine M. Spatially regulated expression of homeotic genes in Drosophila. Science, 229: 1236-42 (1985).

Hartwell LH. Three additional genes required for deoxyribonucleic acid synthesis in Saccharomyces cerevisiae. J. Bacteriol.,115: 966-74 (1973).

Hendrickson M, Madine M, Dalton S and Gautier J. Phosphorylation of MCM4 by cdc2 protein kinase inhibits the activity of the minichromosome maintenance complex. Proc. Natl. Acad. Sci. USA, 93: 12223-8 (1996).

Hodgson B, Li A, Tada S and Blow JJ. Geminin becomes activated as an inhibitor of Cdt1/RLF-B following nuclear import. Curr. Biol., 12: 678-83 (2002).

Hofmann JF and Beach D. Cdt1 is an essential target of the Cdc10/Sct1 transcription factor: requirement for DNA replication and inhibition of mitosis. EMBO J., 13: 42534 (1994). 
Horan GS, Ramirez-Solis R, Featherstone MS, Wolgemuth DJ, Bradley A and Behringer RR. Compound mutants for the paralogous hoxa-4, hoxb-4, and hoxd-4 genes show more complete homeotic transformations and a dose-dependent increase in the number of vertebrae transformed. Genes Dev., 9: 1667-77 (1995).

Hua XH and Newport J. Identification of a preinitiation step in DNA replication that is independent of origin recognition complex and cdc6, but dependent on cdk2. J. Cell Biol. 140: 271-81 (1998).

Hua XH, Yan $\mathrm{H}$ and Newport J. A role for Cdk2 kinase in negatively regulating DNA replication during S phase of the cell cycle. J. Cell Biol., 137: 183-92 (1997).

Hunt P and Krumlauf R. Deciphering the Hox code: clues to patterning branchial regions of the head. Cell, 66: 1075-8 (1991).

Ishimi Y. A DNA helicase activity is associated with an MCM4, -6, and -7 protein complex. J. Biol. Chem., 272: 24508-13 (1997).

Ishimi Y and Komamura-Kohno Y. Phosphorylation of Mcm4 at specific sites by cyclin-dependent kinase leads to loss of Mcm4,6,7 helicase activity. J. Biol. Chem., 276: $34428-33$ (2001).

Ishimi Y, Komamura-Kohno Y, You Z, Omori A and Kitagawa M. Inhibition of Mcm4,6,7 helicase activity by phosphorylation with cyclin A/Cdk2. J. Biol. Chem., 275: 16235-41 (2000).

Izpisua-Belmonte JC, Falkenstein H, Dollé P, Renucci A and Duboule D. Murine genes related to the Drosophila AbdB homeotic genes are sequentially expressed during development of the posterior part of the body. EMBO J., 10: 2279-89 (1991).

Jiang W, Wells NJ and Hunter T. Multistep regulation of DNA replication by Cdk phosphorylation of HsCdc6. Proc. Natl. Acad. Sci. USA, 96: 6193-8 (1999). 
Kal AJ, Mahmoudi T, Zak NB and Verrijzer CP. The Drosophila brahma complex is an essential coactivator for the trithorax group protein zeste. Genes Dev., 14: 1058-71 (2000).

Kaufman TC, Seeger MA and Olsen G. Molecular and genetic organization of the antennapedia gene complex of Drosophila melanogaster. Adv. Genet., 27: 309-362 (1990).

Kelly TJ and Brown GW. Regulation of chromosome replication. Annu. Rev. Biochem., 69: 829-80 (2000).

Kessel M. Respecification of vertebral identities by retinoic acid. Development, 115: 487-501 (1992).

Kessel M. Reversal of axonal pathways from rhombomere 3 correlates with extra Hox expression domains. Neuron, 10: 379-93 (1993).

Kessel $\mathrm{M}$ and Gruss P. Homeotic transformations of murine vertebrae and concomitant alteration of Hox codes induced by retinoic acid. Cell, 67: 89-104 (1991).

Klemm RD, Austin RJ and Bell SP. Coordinate binding of ATP and origin DNA regulates the ATPase activity of the origin recognition complex. Cell, 88: 493-502 (1997).

Klemm RD and Bell SP. ATP bound to the origin recognition complex is important for preRC formation. Proc. Natl. Acad. Sci. USA, 98: 8361-7 (2001).

Kmita M, Fraudeau N, Herault Y and Duboule D. Serial deletions and duplications suggest a mechanism for the collinearity of Hoxd genes in limbs. Nature, 420: 145-50 (2002). 
Kmita M, van der Hoeven F, Zákány J, Krumlauf R and Duboule D. Mechanisms of Hox gene colinearity: transposition of the anterior Hoxbl gene into the posterior HoxD complex. Genes Dev., 14: 198-211 (2000).

Kondo T and Duboule D. Breaking colinearity in the mouse HoxD complex. Cell, 97: 407-17 (1999).

Kreitz S, Ritzi M, Baack M and Knippers R. The human origin recognition complex protein 1 dissociates from chromatin during S phase in HeLa cells. J. Biol. Chem., 276: 6337-42 (2001).

Kroll KL, Salic AN, Evans LM and Kirschner MW. Geminin, a neuralizing molecule that demarcates the future neural plate at the onset of gastrulation. Development, 125: 3247-58 (1998).

Kroon E, Krosl J, Thorsteinsdottir U, Baban S, Buchberg AM and Sauvageau G. Hoxa9 transforms primary bone marrow cells through specific collaboration with Meis1a but not Pbx1b. EMBO J., 17: 3714-25 (1998).

Krosl J, Baban S, Krosl G, Rozenfeld S, Largman C and Sauvageau G. Cellular proliferation and transformation induced by HOXB4 and HOXB3 proteins involves cooperation with PBX1. Oncogene, 16: 3403-12 (1998).

Krosl J and Sauvageau G. AP-1 complex is effector of Hox-induced cellular proliferation and transformation. Oncogene, 19: 5134-41 (2000).

Krumlauf R. Hox genes in vertebrate development. Cell, 78: 191-201 (1994).

Kubota Y, Mimura S, Nishimoto S, Masuda T, Nojima H and Takisawa H. Licensing of DNA replication by a multi-protein complex of MCM/P1 proteins in Xenopus eggs. EMBO J. 16: 3320-31 (1997). 
Kulartz M, Kreitz S, Hiller E, Damoc EC, Przybylski M and Knippers R. Expression and phosphorylation of the replication regulator protein geminin. Biochem. Biophys. Res. Commun., 305: 412-20 (2003).

Labib K and Diffley JF. Is the MCM2-7 complex the eukaryotic DNA replication fork helicase? Curr. Opin. Genet. Dev., 11: 64-70 (2001).

Labib K, Diffley JF and Kearsey SE. G1-phase and B-type cyclins exclude the DNAreplication factor Mcm4 from the nucleus. Nature Cell Biol., 1: 415-22 (1999).

Labib K, Tercero JA and Diffley JF. Uninterrupted MCM2-7 function required for DNA replication fork progression. Science, 288: 1643-7 (2000).

Lagos-Quintana M, Rauhut R, Meyer J, Borkhardt A and Tuschl T. New microRNAs from mouse and human. $R N A$, 9: 175-9 (2003).

Lawrence PA and Morata G. Homeobox genes: their function in Drosophila segmentation and pattern formation. Cell, 78: 181-189 (1994).

Lessard J and Sauvageau G. Bmi-1 determines the proliferative capacity of normal and leukaemic stem cells. Nature, 423: 255-60 (2003).

Lewis EB. A gene complex controlling segmentation in Drosophila. Nature, 276: 565-70 (1978).

Li A and Blow JJ. Non-proteolytic inactivation of geminin requires CDK-dependent ubiquitination. Nature Cell Biol., 6: 260-7 (2004).

Li X, Zhao Q, Liao R, Sun P and Wu X. The SCF (Skp2) ubiquitin ligase complex interacts with the human replication licensing factor Cdt1 and regulates Cdt1 degradation. J. Biol. Chem., 278: 30854-8 (2003).

Liu E, Li X, Yan F, Zhao Q and Wu X. Cyclin-dependent kinases phosphorylate human Cdt1 and induce its degradation. J. Biol. Chem., 279: 17283-8 (2004). 
Luo L and Kessel M. Geminin coordinates cell cycle and developmental control. Cell Cycle, 3: 711-4 (2004a).

Luo L and Kessel M. Coordination between patterning and cell cycle control by Geminin. MPIbpc News, 10(5): 1-4 (2004b).

Luo L, Yang X, Takihara Y, Knoetgen H and Kessel M. The cell-cycle regulator geminin inhibits Hox function through direct and polycomb-mediated interactions. Nature, 427: 749-53 (2004).

Lygerou $Z$ and Nurse P. Cell cycle. License withheld--geminin blocks DNA replication. Science, 290: 2271-3 (2000).

Madine MA, Khoo CY, Mills AD and Laskey RA. MCM3 complex required for cell cycle regulation of DNA replication in vertebrate cells. Nature, 375: 421-4 (1995).

Maiorano D, Moreau J and Mechali M. XCDT1 is required for the assembly of prereplicative complexes in Xenopus laevis. Nature, 404: 622-5 (2000).

McGarry TJ. Geminin deficiency causes a Chk1-dependent G2 arrest in Xenopus. Mol. Biol. Cell, 13: 3662-71 (2002).

McGarry TJ and Kirschner MW. Geminin, an inhibitor of DNA replication, is degraded during mitosis. Cell, 93: 1043-53 (1998).

McGinnis W, Levine MS, Hafen E, Kuroiwa A and Gehring WJ. A conserved DNA sequence in homoeotic genes of the Drosophila Antennapedia and bithorax complexes. Nature, 308: 428-33 (1984a).

McGinnis W, Garber RL, Wirz J, Kuroiwa A and Gehring WJ. A homologous protein-coding sequence in Drosophila homeotic genes and its conservation in other metazoans. Cell, 37: 403-08 (1984b). 
Mihaylov IS, Kondo T, Jones L, Ryzhikov S, Tanaka J, Zheng J, Higa LA, Minamino $\mathrm{N}$, Cooley L and Zhang H. Control of DNA replication and chromosome ploidy by geminin and cyclin A. Mol. Cell Biol., 22: 1868-80 (2002).

Mizushima T, Takahashi N and Stillman B. Cdc6p modulates the structure and DNA binding activity of the origin recognition complex in vitro. Genes Dev., 14: 1631-41 (2000).

Nguyen VQ, Co C, Irie K and Li JJ. Clb/Cdc28 kinases promote nuclear export of the replication initiator proteins Mcm2-7. Curr. Biol., 10: 195-205 (2000).

Nguyen VQ, Co C and Li JJ. Cyclin-dependent kinases prevent DNA re-replication through multiple mechanisms. Nature, 411: 1068-73 (2001).

Nishitani H, Lygerou Z, Nishimoto T and Nurse P. The Cdt1 protein is required to license DNA for replication in fission yeast. Nature, 404: 625-8 (2000).

Nishitani H, Taraviras S, Lygerou Z and Nishimoto T. The human licensing factor for DNA replication Cdt1 accumulates in $\mathrm{G} 1$ and is destabilized after initiation of Sphase. J. Biol. Chem., 276: 44905-11 (2001).

Ogawa Y, Takahashi T and Masukata H. Association of fission yeast Orp1 and Mcm6 proteins with chromosomal replication origins. Mol. Cell Biol., 19: 7228-36 (1999).

Pak DT, Pflumm M, Chesnokov I, Huang DW, Kellum R, Marr J, Romanowski P and Botchan MR. Association of the origin recognition complex with heterochromatin and HP1 in higher eukaryotes. Cell, 91: 311-23 (1997).

Pereverzeva I, Whitmire E, Khan B and Coue M. Distinct phosphoisoforms of the Xenopus Mcm4 protein regulate the function of the Mcm complex. Mol. Cell Biol., 20: $3667-76$ (2000). 
Perkins G and Diffley JF. Nucleotide-dependent prereplicative complex assembly by Cdc6p, a homolog of eukaryotic and prokaryotic clamp-loaders. Mol. Cell, 2: 23-32 (1998).

Petersen BO, Wagener C, Marinoni F, Kramer ER, Melixetian M, Denchi EL, Gieffers C, Matteucci C, Peters JM and Helin K. Cell cycle- and cell growthregulated proteolysis of mammalian CDC6 is dependent on APC-CDH1. Genes Dev., 14: $2330-43$ (2000).

Petruk S, Sedkov Y, Smith S, Tillib S, Kraevski V, Nakamura T, Canaani E, Croce $\mathrm{CM}$ and Mazo A. Trithorax and dCBP acting in a complex to maintain expression of a homeotic gene. Science, 294: 1331-4 (2001).

Pflumm MF and Botchan MR. Orc mutants arrest in metaphase with abnormally condensed chromosomes. Development, 128: 1697-707 (2001).

Quinn LM, Herr A, McGarry TJ and Richardson H. The Drosophila Geminin homolog: roles for Geminin in limiting DNA replication, in anaphase and in neurogenesis. Genes Dev., 15: 2741-54 (2001).

Ramirez-Solis R, Zheng H, Whiting J, Krumlauf R and Bradley A. Hoxb-4 (Hox-2.6) mutant mice show homeotic transformation of a cervical vertebra and defects in the closure of the sternal rudiments. Cell, 73: 279-94 (1993).

Riddihough G. Homing in on the homeobox. Nature, 357: 643-4 (1992).

Romanowski P, Madine MA, Rowles A, Blow JJ and Laskey RA. The Xenopus origin recognition complex is essential for DNA replication and MCM binding to chromatin. Curr. Biol., 6: 1416-25 (1996).

Rowles A, Chong JP, Brown L, Howell M, Evan GI and Blow JJ. Interaction between the origin recognition complex and the replication licensing system in Xenopus. Cell, 87: 287-96 (1996). 
Rowles A, Tada S and Blow JJ. Changes in association of the Xenopus origin recognition complex with chromatin on licensing of replication origins. J. Cell Sci., 112: $2011-8$ (1999).

Saha P, Chen J, Thome KC, Lawlis SJ, Hou ZH, Hendricks M, Parvin JD and Dutta A. Human CDC6/Cdc18 associates with Orc1 and cyclin-cdk and is selectively eliminated from the nucleus at the onset of S phase. Mol. Cell Biol., 18: 2758-67 (1998).

Sakai Y, Meno C, Fujii H, Nishino J, Shiratori H, Saijoh Y, Rossant J and Hamada H. The retinoic acid-inactivating enzyme CYP26 is essential for establishing an uneven distribution of retinoic acid along the anterio-posterior axis within the mouse embryo. Genes Dev., 15: 213-25 (2001).

Sánchez-Herrero E, Vernos I, Marco R and Morata G. Genetic organization of Drosophila bithorax complex. Nature, 313: 108-13 (1985).

Schock F, Reischl J, Wimmer E, Taubert H, Purnell BA and Jäckle H. Phenotypic suppression of empty spiracles is prevented by buttonhead. Nature, 405: 351-4 (2000).

Schumacher A and Magnuson T. Murine Polycomb- and trithorax-group genes regulate homeotic pathways and beyond. Trends Genet., 13: 167-70 (1997).

Scott MP and Weiner AJ. Structural relationships among genes that control development: sequence homology between the Antennapedia, Ultrabithorax, and fushi tarazu loci of Drosophila. Proc. Natl. Acad. Sci., 81: 4115-9 (1984).

Seki T and Diffley JF. Stepwise assembly of initiation proteins at budding yeast replication origins in vitro. Proc. Natl. Acad. Sci. USA, 97: 14115-20 (2000).

Sharpe J, Nonchev S, Gould A, Whiting J and Krumlauf R. Selectivity, sharing and competitive interactions in the regulation of Hoxb genes. EMBO J., 17: 1788-1798 (1998). 
Shreeram S, Sparks A, Lane DP and Blow JJ. Cell type-specific responses of human cells to inhibition of replication licensing. Oncogene, 21: 6624-32 (2002).

Simeone A, Acampora D, Arcioni L, Andrews PW, Boncinelli E and Mavilio F. Sequential activation of HOX2 homeobox genes by retinoic acid in human embryonal carcinoma cells. Nature, 346: 763-6 (1990).

Simon JA and Tamkun JW. Programming off and on states in chromatin: mechanisms of Polycomb and trithorax group complexes. Curr. Opin. Genet. Dev., 12: 210-8 (2002).

Spitz F, Gonzalez F and Duboule D. A global control region defines a chromosomal regulatory landscape containing the HoxD cluster. Cell, 113: 405-17 (2003).

Sugimoto N, Tatsumi Y, Tsurumi T, Matsukage A, Kiyono T, Nishitani H and Fujita M. Cdt1 phosphorylation by cyclin A-dependent kinases negatively regulates its function without affecting geminin binding. J. Biol. Chem., 279: 19691-7 (2004).

Suzuki M, Mizutani-Koseki Y, Fujimura Y, Miyagishima H, Kaneko T, Takada Y, Akasaka T, Tanzawa H, Takihara Y, Nakano M, Masumoto H, Vidal M, Isono K and Koseki H. Involvement of the Polycomb-group gene Ring1B in the specification of the anterior-posterior axis in mice. Development, 129: 4171-83 (2002).

Tada S, Li A, Maiorano D, Mechali M and Blow JJ. Repression of origin assembly in metaphase depends on inhibition of RLF-B/Cdt1 by geminin. Nature Cell Biol., 3 : 107-13 (2001).

Takihara Y, Tomotsune D, Shirai M, Katoh-Fukui Y, Nishii K, Motaleb MA, Nomura M, Tsuchiya R, Fujita Y, Shibata Y, Higashinakagawa T and Shimada K. Targeted disruption of the mouse homologue of the Drosophila polyhomeotic gene leads to altered anteroposterior patterning and neural crest defects. Development, 124: 367382 (1997). 
Tanaka T, Knapp D and Nasmyth K. Loading of an Mcm protein onto DNA replication origins is regulated by Cdc6p and CDKs. Cell, 90: 649-60 (1997).

Tomotsune D, Takihara Y, Berger J, Duhl D, Joo S, Kyba M, Shirai M, Ohta H, Matsuda Y, Honda BM, Simon J, Shimada K, Brock HW and Randazzo F. A novel member of murine Polycomb-group proteins, Sex comb on midleg homolog protein, is highly conserved, and interacts with Rae28/Mph1 in vitro. Differentiation, 65: 22939 (1999).

van der Vlag J and Otte AP. Transcriptional repression mediated by the human polycomb-group protein EED involves histone deacetylation. Nature Genet., 23: 4748 (1999).

van den Akker E, Fromental-Ramain C, de Graaff W, Le Mouellic H, Brulet P, Chambon P and Deschamps J. Axial skeletal patterning in mice lacking all paralogous group 8 Hox genes. Development, 128: 1911-21 (2001).

Vas A, Mok W and Leatherwood J. Control of DNA rereplication via Cdc2 phosphorylation sites in the origin recognition complex. Mol. Cell Biol., 21: 5767-77 (2001).

Voncken JW, Roelen BA, Roefs M, de Vries S, Verhoeven E, Marino S, Deschamps J and van Lohuizen M. Rnf2 (Ring1b) deficiency causes gastrulation arrest and cell cycle inhibition. Proc. Natl. Acad. Sci. USA, 100: 2468-73 (2003).

Wakimoto BT, Turner FR and Kaufman TC. Defects in embryogenesis in mutants associated with the antennapedia gene complex of Drosophila melanogaster. Dev. Biol., 102: 147-72 (1984).

Weinreich M, Liang C and Stillman B. The Cdc6p nucleotide-binding motif is required for loading mcm proteins onto chromatin. Proc. Natl. Acad. Sci. USA, 96: 441-6 (1999). 
Wellik DM and Capecchi MR. Hox10 and Hox11 genes are required to globally pattern the mammalian skeleton. Science, 301: 363-7 (2003).

Whittaker AJ, Royzman I and Orr-Weaver TL. Drosophila double parked: a conserved, essential replication protein that colocalizes with the origin recognition complex and links DNA replication with mitosis and the down-regulation of S phase transcripts. Genes Dev., 14: 1765-76 (2000).

Wohlschlegel JA, Dwyer BT, Dhar SK, Cvetic C, Walter JC and Dutta A. Inhibition of eukaryotic DNA replication by geminin binding to Cdt1. Science, 290: 2309-12 (2000).

Wohlschlegel JA, Kutok JL, Weng AP and Dutta A. Expression of geminin as a marker of cell proliferation in normal tissues and malignancies. Am. J. Pathol., 161: 267-73 (2002).

Yamaguchi R and Newport J. A role for Ran-GTP and Crm1 in blocking rereplication. Cell, 113: 115-25 (2003).

Yanagi K, Mizuno T, You Z and Hanaoka F. Mouse geminin inhibits not only Cdt1MCM6 interactions but also a novel intrinsic Cdt1 DNA binding activity. J. Biol. Chem., 277: 40871-80 (2002).

Yekta S, Shih IH and Bartel DP. MicroRNA-directed cleavage of HOXB8 mRNA. Science, 304: 594-6 (2004).

Yoshida K, Oyaizu N, Dutta A and Inoue I. The destruction box of human Geminin is critical for proliferation and tumor growth in human colon cancer cells. Oncogene, 23: 58-70 (2004).

You Z, Komamura Y and Ishimi Y. Biochemical analysis of the intrinsic Mcm4Mcm6-mcm7 DNA helicase activity. Mol. Cell Biol., 19: 8003-15 (1999). 
Zàkàny J, Kmita M, Alarcon P, de la Pompa JL and Duboule D. Localized and transient transcription of Hox genes suggests a link between patterning and the segmentation clock. Cell, 106: 207-17 (2001).

Zhong W, Feng H, Santiago FE and Kipreos ET. CUL-4 ubiquitin ligase maintains genome stability by restraining DNA-replication licensing. Nature, 423: 885-9 (2003). 


\section{Abbreviations:}

APS: ammonium persulphate

3AT: 3-amino-1,2,4-triazole

BMP: bone morphogenetic protein

bp: base pair

BSA: bovine serum albumin

CDK: cyclin dependent kinase

ChIP: chromatin immunoprecipitation

cpm: counts per minute

DAPI: 4,6-diamidino-2-phenylindol

DEPC: diethyl pyrocarbonate

DIG: digoxigenin

DMEM: Dulbecco's modified Eagle's medium

DMFA: dimethylformamide

DMSO: dimethylsulfoxide

dnScmh1: dominant negative sex comb on midleg homolog 1

d.p.c.: days post coitum

EDTA: ethylenediaminetetraacetic acid

EGFP: enhanced green fluorescence protein

EMSA: electrophoretic mobility shift assays

FCS: fetal calf serum

FGF: fibroblast growth factor

GFP: green fluorescence protein

GST: glutathione sulfur transferase

HOM-C: homeotic complex

HRP: horseradish peroxidase

IPTG: isopropylthio- $\beta$-D-galactoside

kDa: kilo Dalton

MCM: minichromosome maintenance

MEF: mouse embryonic fibroblast

O.D.: optical density

ORC: origin recognition complex

PBS: phosphate buffered saline 
PCR: polymerase chain reaction

PFA: paraformaldehyde

Plzf: promyelocytic leukemia zinc finger

PMSF: phenylmethylsulfonyl fluoride

PRC1: polycomb repressive complex 1

PRE: polycomb response element

pre-RC: pre-replicative complex

rpm: round per minute

RT-PCR: reverse transcription-polymerase chain reaction

Scmh1: sex comb on midleg homolog 1

SDS: sodium dodecyl sulfate

siRNA: small interference RNA

TAC: trithorax acetyltransferase complex

TBE: Tris-borate-EDTA

TCA: trichloride acetate

TEMED: N,N,N',N'-tetramethyl-ethylenediamine

Tm: melting temperature

TRE: trithorax response element

$\mathrm{U}$ : units

$\mathrm{V}$ : volts

UTR: untranslated region

YY1: yin yang 1 


\section{Curriculum Vitae}

\section{Personal Data:}

Surname:

Forename:

Nationality:

Birth:

Age:

Marital Status:

Private Address:

Telephone:

Work Address:

Telephone:

Fax:

E-mail:

Position at Work:

\section{Scientific Education:}

Oct. 2001-Present

Sep. 1999-Jul. 2000
Luo

Lingfei

P. R. China

November $4^{\text {th }}$, 1977; Chongqing, China

26

Married

Room 520

Robert-Koch-Str. 38

37075 Göttingen

Germany

0049-551-3791655

Department of Molecular Cell Biology

Max-Planck-Institute for Biophysical Chemistry

Am Fassberg 11

37077 Göttingen

Germany

0049-551-2011752

0049-551-2011504

1luo@gwdg.de, 1uolingfei@hotmail.com

Ph.D.

Department of Molecular Cell Biology

Max-Planck-Institute for Biophysical Chemistry

Doctor of Philosophy (Ph.D.)

Oct. 2000-Aug. 2001 International M.Sc./Ph.D. Program "Molecular Biology" Georg August University Göttingen and Max-Planck Research School Master of Science (M.Sc.)

Shanghai Institute of Biochemistry, Chinese Academy of Sciences 
Sep. 1995-Jun. 1999

Department of Biochemistry, Nanjing University

Bachelor of Science (B.Sc.)

\section{Publications:}

Lingfei Luo, Xiaoping Yang, Yoshihiro Takihara, Hendrik Knoetgen and Michael Kessel. The cell-cycle regulator geminin inhibits Hox function through direct and polycomb-mediated interactions. Nature, 427(6976): 749-753 (2004).

$\underline{\text { Lingfei Luo and Michael Kessel. Geminin coordinates cell cycle and developmental }}$ control. Cell Cycle, 3(6): 711-714 (2004).

Lingfei Luo and Michael Kessel. Coordination between patterning and cell cycle control by Geminin. MPIbpc News, 10(5): 1-4 (2004).

Erzsebet Mernyak, Janos Wolfling, Gabor Bunkoczi, Lingfei Luo, Thomas R. Schneider and Gyula Schneider. Stereoselective Synthesis of the Two trans-(16Hydroxymethyl)-3-methoxy-13a-estra-1,3,5(10)-trien-17-ol Isomers. Collect. Czech. Chem. Commun., 68(6): 1141-1148 (2003).

\section{Honor:}

Gruss-Jäckle-Prize 2003: Awarded by the Gruss-Jäckle foundation on May $6^{\text {th }}, 2004$ at the Max-Planck-Institute for Biophysical Chemistry in Göttingen. 